Linköping Studies in Science and Technology,

Dissertation No. 1738

\title{
Facilitating electron transfer in bioelectrocatalytic systems
}

\author{
Alina Sekretaryova
}

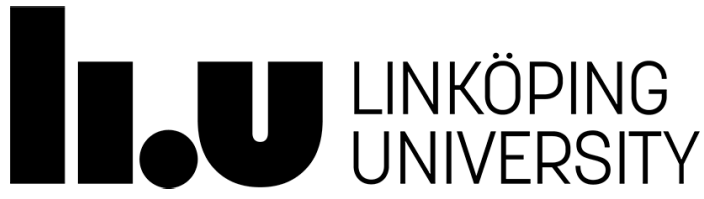

Division of Chemical and Optical Sensor Systems

Biosensors and Bioelectronics Centre

Department of Physics, Chemistry, and Biology (IFM)

Linköping University, SE-581 83 Linköping, Sweden 


\title{
Facilitating electron transfer in bioelectrocatalytic systems
}

\author{
Alina Sekretaryova
}

During the course of the research underlying this thesis, Alina Sekretaryova was enrolled in Forum Scientium, a multidisciplinary doctoral programme at Linköping University, Sweden

(C) Alina Sekretaryova, 2016, unless otherwise noted.

Cover design by Alina Sekretaryova

ISBN: 978-91-7685-841-7

ISSN: 0345-7524

Linköping studies in science and technology

Dissertation No. 1738

Printed in Sweden by LiU-Tryck, Linköping, Sweden, 2016 


\section{ABSTRACT}

Bioelectrocatalytic systems are based on biological entities, such as enzymes, whole cells, parts of cells or tissues, which catalyse electrochemical processes that involve the interaction between chemical change and electrical energy. In all cases, enzymes, isolated or residing inside cells or part of cells, implement biocatalysis. Electron transfer phenomena, within the protein molecules and between biological redox systems and electronics, enable the development of various bioelectrocatalytic systems, which can be used both for fundamental investigations of enzymatic biological processes by electrochemical methods and for applied purposes, such as power generation, bioremediation, chemical synthesis and biosensing.

Electrical communication between the biocatalysts redox centre and an electrode is essential for the functioning of the system. This can be established using two main mechanisms: indirect electron transfer and direct electron transfer. The efficiency of the electron transfer influences important parameters such as the turnover rate of the biocatalyst, the generated current density and partially the stability of the system. These in turn determine the response time, sensitivity, detection limit and operational stability of biosensors or the power densities and current output of biofuel cells, and hence they should be carefully considered when designing bioelectrocatalytic systems.

This thesis focuses on approaches that facilitate electron transfer in bioelectrocatalytic systems based on mediated and direct electron transfer mechanisms. Both fundamental aspects of electron transfer in bioelectrocatalytic systems and applications of such systems for biosensing and power generation are considered. First, a new hydrophobic mediator for oxidases, unsubstituted phenothiazine, and its improved electron transfer properties in comparison with commonly used mediators are discussed. Application of the mediator in electrochemical biosensors is demonstrated by glucose, lactate and cholesterol sensing. Utilisation of mediated biocatalytic cholesterol oxidation as the anodic reaction for the construction of a biofuel cell, acting as a power supply and an analytical device at the same time, is investigated as a "self-powered" biosensor. In addition, the enhancement of mediated bioelectrocatalysis by the employment of microelectrodes as a transducer is examined. The effect of surface roughness on the current response of the microelectrodes under conditions of convergent diffusion is considered. The applicability of the laccase-based system for total phenol analysis of weakly supported water is demonstrated. Finally, a new electrochemical approach derived from collision-based electrochemistry applicable for the examination of the electron transfer process of a single enzyme molecule is described. 
Overall, the results presented in this thesis contribute to the solution of the "electronic coupling problem", arising when interfacing biomolecules with electronics and limiting the performance of bioelectrocatalytic systems in practical applications. The developed methods to facilitate electron transfer will hopefully promote future biosensing devices and biofuel cells. I believe that the new approach for investigation of electron transfer processes at a single enzyme molecule will complement existing single molecule techniques, giving further insights into enzymatic electron transfer mechanisms at the molecular level and filling the gap between fundamental understanding of biocatalytic processes and their potential for bioenergy production. 


\section{POPULÄRVETENSKAPLIG SAMMANFATTNING}

Bioelektrokatalytiska system bygger på biologiska enheter, såsom enzymer, hela celler, delar av celler eller vävnader, som katalyserar elektrokemiska processer. Biokatalysen utförs av enzymer, isolerade eller inuti celler eller delar av celler. Elektronöverföringsfenomen, inom proteinmolekyler och mellan biologiska system och elektronik, möjliggör utvecklingen av olika bioelektrokatalytiska system, som kan användas både för grundläggande undersökningar av enzymatiska biologiska processer genom elektrokemiska metoder och för tillämpade ändamål, såsom elproduktion, bioremediering, kemisk syntes och biosensing.

Elektrisk kommunikation mellan redoxcentrum hos en biokatalysatorer och en elektrod är avgörande för systemets funktion. Denna kan etableras med hjälp av två huvudmekanismer: indirekt respektive direkt elektronöverföring. Elektronöverföringens effektivitet påverkar viktiga parametrar som biokatalysatorns omsättningstakt, den genererade strömtätheten och stabiliteten i systemet, vilket i sin tur bestämmer svarstid, känslighet, detektionsgräns och driftstabilitet hos en biosensor eller effekttäthet och levererbar ström hos biobränsleceller, och elektronöverföringen bör därför övervägas noga när man utformar bioelektrokatalytiska system.

Denna avhandling fokuserar på strategier som underlättar elektronöverföring i bioelektrokatalytiska system som är baserade på medierade (förmedlade) och direkta elektronöverföringsmekanismer. Både grundläggande aspekter av elektronöverföring i bioelektrokatalytiska system och tillämpningar av sådana system för biosensing och strömgenerering beaktas. Först undersöks osubstituerad fentiazin, en ny hydrofob mediator ("elektronförmedlare") för oxidaser, och dess förbättrade elektronmedieringsegenskaper i jämförelse med vanligt förekommande mediatorer. Tillämpning av mediatorn för biosensing exemplifieras med detektion av glukos, laktat och kolesterol. En självdriven biosensor för detektion av kolesterol är en annan tillämpning som undersöks. Användandet av mikroelektroder för att förbättra biosensorer undersöks med glukosoxidas- och lackasbaserade system som exempel. Möjligheten att använda ett lackasbaserat system för att detektera fenoler i lågkonduktivt vatten demonstreras. Slutligen beskrivs en ny elektrokemisk metod för undersökning av elektronöverföringsprocessen hos enstaka enzymmolekyler.

Sammantaget presenteras i denna avhandling resultat som bidrar till lösningen av det "elektroniska kopplingsproblem" som uppstår när biomolekyler ska kopplas till elektronik och som begränsar prestandan hos bioelektrokatalytiska system. De utvecklade metoderna kommer förhoppningsvis främja framtida biosensorenheter och biobränsleceller. Den nya metoden för undersökning av 
elektronmedieringsprocesser hos enstaka enzymmolekyler kommer förhoppningsvis att komplettera befintliga molekylära tekniker, vilket ger ytterligare inblickar i enzymatiska elektronöverföringsmekanismer på molekylär nivå och kan hjälpa till att fylla gapet mellan grundläggande förståelse av biokatalytiska processer och deras potential för bioenergiproduktion. 


\section{ACKNOWLEDGMENTS}

First of all, I would like to thank my supervisor Mats Eriksson for his excellent supervision and guidance. I would also like to thank my co-supervisors Mikhail Vagin and Prof. Anthony Turner for scientific discussions and support.

Thanks to Anna Maria Uhlin and Anette Andersson for taking care of all administrative issues.

I feel thankful to Stefan Klinström, director of Forum Scientium, for great opportunity to develop scientific and social contacts and to enjoy time during my $\mathrm{PhD}$ period.

I am also thankful to all present and former colleagues in the Chemical and Optical Sensor Systems group and Biosensors and Bioelectronics Center for making my working days pleasant. My special thanks go to Valerio Beni.

I would like to thank my office-mates, lab-mates and friends, Camilla Sandén, Michal Wagner, Nadia Ajjan, Mike Zhybak and many others that I did not mention for making my stay in Sweden really joyful.

And finally, Onur Parlak, thank you for always taking care of me, for your love and your patience. You always encourage me to be a better person. 



\section{LIST OF THE INCLUDED PAPERS}

The $\mathrm{PhD}$ thesis is based on the following papers:

Review paper:

Bioelectrocatalytic systems for health applications

Alina N. Sekretaryova, Mats Eriksson, Anthony P.F. Turner

Biotechnology Advances, (in press), doi:10.1016/j.biotechadv.2015.12.005

Contribution: Wrote a large part of the first draft and contributed to the revision and final editing of the manuscript.

Research papers:

I. Reagentless biosensor based on glucose oxidase wired by the mediator freely diffusing in enzyme containing membrane

Alina N. Sekretaryova, Darya V. Vokhmyanina, Tatyana O. Chulanova, Elena E. Karyakina, Arkady A. Karyakin Analytical Chemistry 2012, 84, 1120-1223

Contribution: Performed most of the experimental work, data evaluation and interpretation, wrote the experimental section and part of the results and discussion.

II. Unsubstituted phenothiazine as a superior water-insoluble mediator for oxidases

Alina N. Sekretaryova, Mikhail Yu. Vagin, Valerio Beni, Anthony P.F. Turner, Arkady A. Karyakin

Biosensors and Bioelectronics 2014, 53, 275-282

Contribution: Performed most of the experimental work, data evaluation and interpretation, wrote the first draft of the manuscript.

\section{Cholesterol self-powered biosensor}

Alina N. Sekretaryova, Valerio Beni, Mats Eriksson, Arkady A. Karyakin, Anthony P.F. Turner and Mikhail Yu. Vagin

Analytical Chemistry 2014, 86, 9540-9547

Contribution: Performed all experimental work, data evaluation and interpretation, wrote the first draft of the manuscript. 
IV. Arrays of screen-printed graphite microband electrodes as a versatile electroanalysis platform

Mikhail Yu. Vagin, Alina N. Sekretaryova, Rafael Sanchez Reategui, Ingemar Lundstrom, Fredrik Winquist, Mats Eriksson

ChemElectroChem 2014, 1, 755-762

Contribution: Performed part of the experimental work, data evaluation and interpretation (detection of ascorbic acid and glucose biosensor, optical microscopy).

V. The influence of capacitive and Faradaic processes on microelectrodes real surface area

Alina N. Sekretaryova, Mats Eriksson and Mikhail Yu. Vagin (manuscript)

Contribution: Performed a large part of the experimental work, data evaluation and interpretation, wrote a large part of the first draft.

VI. Total phenol analysis of weakly supported water using a laccase-based microband biosensor

Alina N. Sekretaryova, Anton V. Volkov, Igor V. Zozoulenko, Anthony P.F. Turner, Mikhail Yu. Vagin, Mats Eriksson Analytica Chimica Acta 2016, 907, 45-53

Contribution: Performed part of the experimental work (all electrochemical measurements), data evaluation and interpretation, wrote the first draft.

\section{Electrocatalytic currents from single enzyme molecules}

Alina N. Sekretaryova, Mikhail Yu. Vagin, Anthony P.F. Turner and Mats Eriksson

Journal of the American Chemical Society (accepted)

Contribution: Performed all experimental work, data evaluation and interpretation, wrote the first draft. 


\section{PAPERS NOT INCLUDED}

\section{Monitoring of epitaxial graphene anodization}

Mikhail Yu. Vagin, Alina N. Sekretaryova, Ivan G. Ivanov,

Anna Håkansson, Tihomir Iakimov, Mikael Syväjärvi, Rositsa Yakimova, Ingemar Lundström, Mats Eriksson

(submitted)

Probing carbon interfaces by bioelectrocatalysis

Alina N. Sekretaryova, Mikhail Yu. Vagin, Anna Håkansson, Tihomir Iakimov, Mikael Syväjärvi, Rositsa Yakimova, Mats Eriksson (manuscript)

\section{Semiconducting properties of graphene on silicon carbide}

Alina N. Sekretaryova, Mikhail Yu. Vagin, Battistel Alberto, Lesch Andreas, Tihomir Iakimov, Mikael Syväjärvi, Rositsa Yakimova, Hubert Girault and Mats Eriksson

(in preparation) 


\section{CONFERENCE PAPERS}

\section{Oral presentations}

Alina N. Sekretaryova, Anton V. Volkov, Igor V. Zozoulenko, Anthony P.F. Turner, Mikhail Yu. Vagin, Mats Eriksson XXIII International Symposium on Bioelectrochemistry and Bioenergetics, 14-18 June 2015, Malmö, Sweden.

Alina N. Sekretaryova, Mikhail Yu. Vagin, Anna Håkansson, Tihomir Iakimov, Mikael Syväjärvi, Rositsa Yakimova, Mats Eriksson $2^{\text {nd }}$ International Congress on Biosensors, 10-12 June 2015, Izmir, Turkey.

Alina N. Sekretaryova, Valerio Beni, Mats Eriksson, Mikhail Yu. Vagin, Anthony P.F. Turner $24^{\text {th }}$ Anniversary World Congress on Biosensors, 27-30 May 2014, Melbourne, Australia.

Alina N. Sekretaryova, Mikhail Yu. Vagin, Valerio Beni, Mats Eriksson, Anthony P.F. Turner

EC COST Thematic Workshop "Nano-scaled arrangements of proteins, aptamers, and other nucleic acid structures - and their potential applications", 8-9 October 2013, Leipzig, Germany.

Alina N. Sekretaryova, Mikhail Yu. Vagin, Mats Eriksson, Arkady A. Karyakin, Anthony P.F. Turner Advanced materials world congress, September 16-19 2013, Izmir, Turkey.

\section{Poster presentations}

Alina N. Sekretaryova, Mikhail Yu. Vagin, Anthony P.F. Turner Mats Eriksson $26^{\text {th }}$ Anniversary World Congress on Biosensors, 25-27 May 2016, Gothenburg, Sweden.

Mikhail Yu. Vagin, Anton V. Volkov, Igor V. Zozoulenko Alina N. Sekretaryova, Ingemar Lundstrom, Valerio Beni, Anthony P.F. Turner, Fredrik Winquist, Mats Eriksson $15^{\text {th }}$ International Conference on Electroanalysis, 11-15 June 2014, Malmö, Sweden. 


\section{CONTENTS}

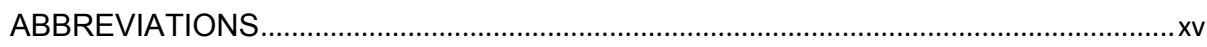

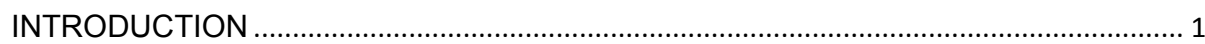

1.1 Electron transfer in bioelectrocatalytic systems ..................................................... 1

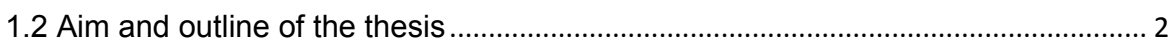

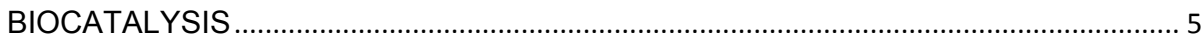

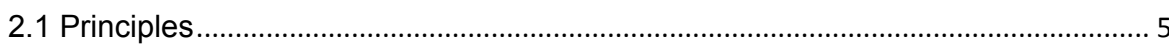

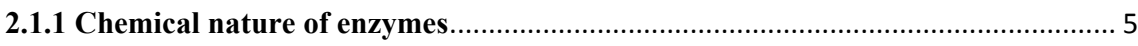

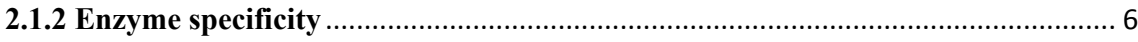

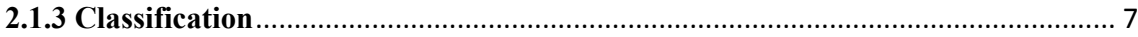

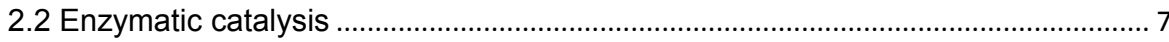

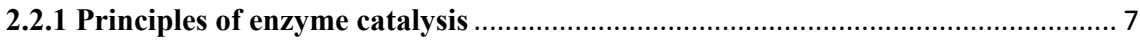

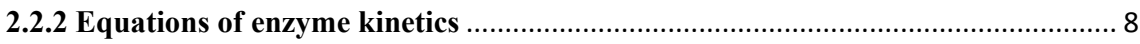

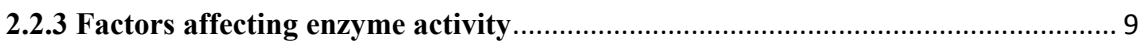

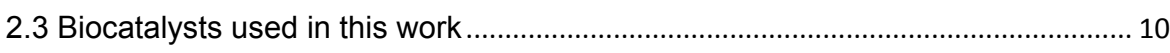

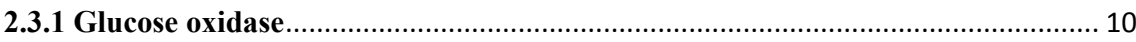

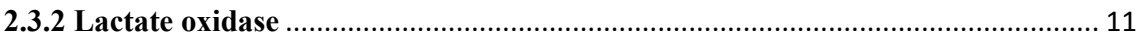

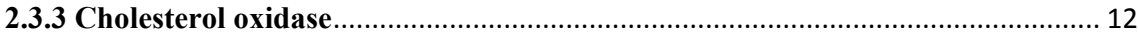

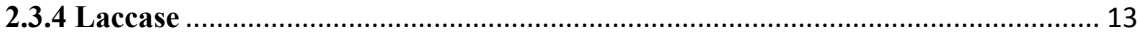

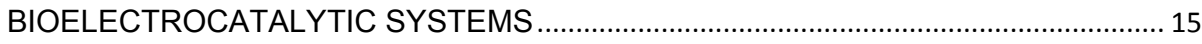

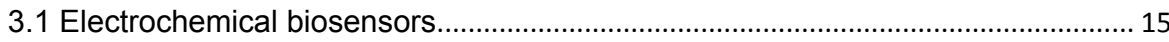

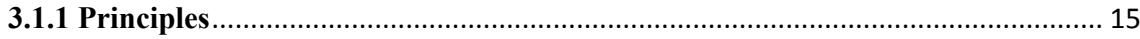

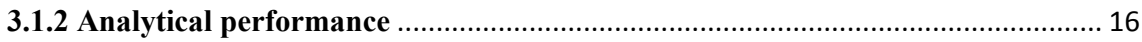

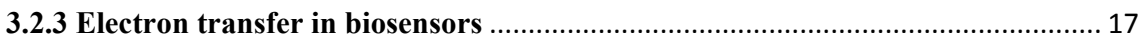

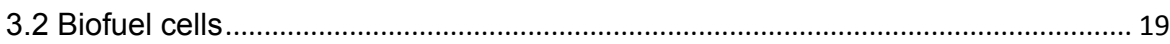

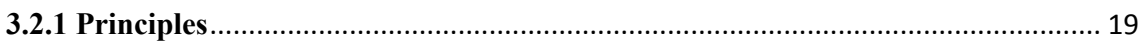

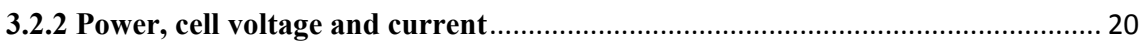

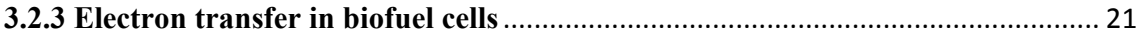

MEDIATED ELECTRON TRANSFER

4.1 Flavoenzyme-based mediated systems ................................................................. 23

4.1.1. General electron transfer mechanism ............................................................... 23

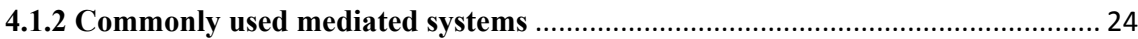

4.1.3 Bioelectrocatalysis with a hydrophobic mediator ............................................ 26 
4.2 Bioelectrocatalytic substrate recycling systems ................................................... 31

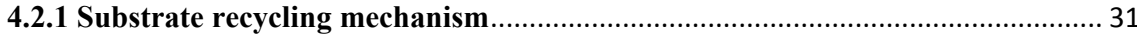

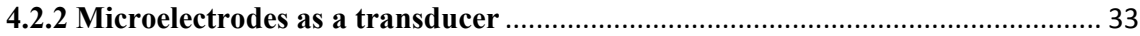

4.2.3 Diffusion-controlled $v s$ kinetic controlled currents .......................................... 35

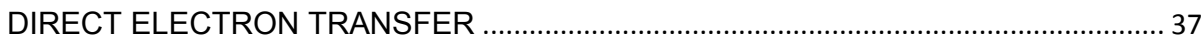

5.1 Surface functionalisation and new electrode materials......................................... 37

5.2 Investigation of direct electron transfer mechanisms in proteins............................. 39

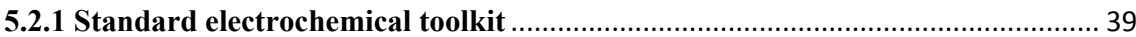

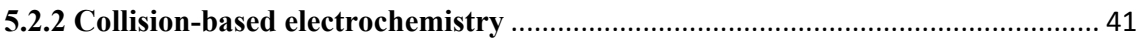

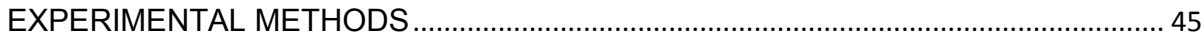

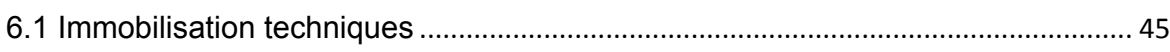

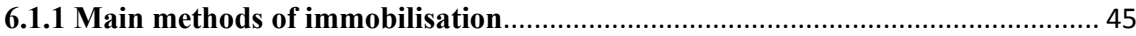

6.1.2 Immobilisation methods used in the work …...................................................... 47

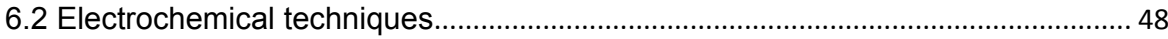

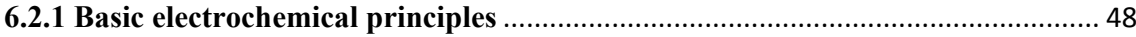

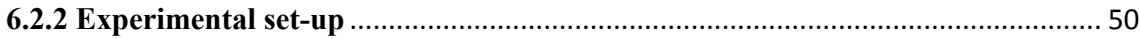

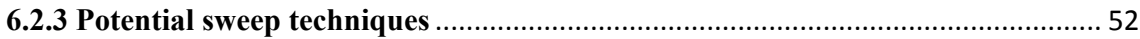

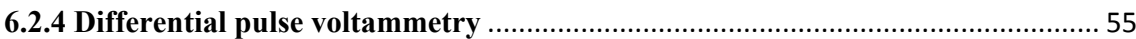

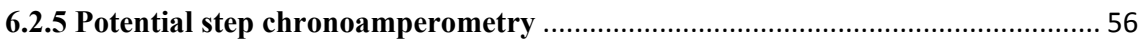

6.2.6 Measurements on hydrodynamic electrodes.................................................. 57

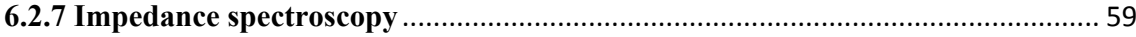

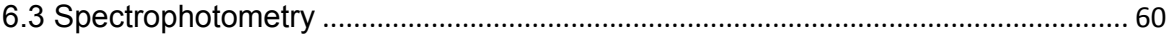

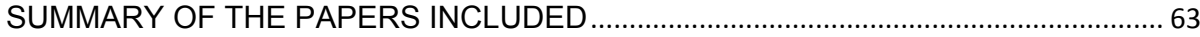

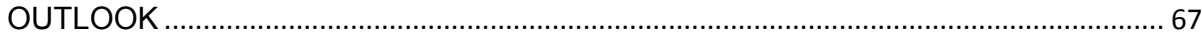

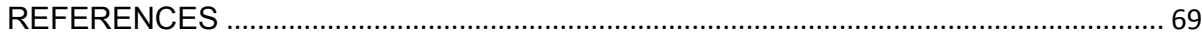




\section{ABBREVIATIONS}

$\begin{array}{ll}\text { APTEOS } & \text { 3-aminopropyl-triethoxysilane } \\ \text { BFC } & \text { biofuel cell } \\ \text { CCE } & \text { carbon cloth electrode } \\ \text { ChOx } & \text { cholesterol oxidase } \\ \text { CV } & \text { cyclic voltammetry } \\ \text { DET } & \text { direct electron transfer } \\ \text { DPV } & \text { differential pulse voltammetry } \\ \text { EASA } & \text { electrochemically active surface area } \\ \text { EC } & \text { enzyme comission } \\ \text { EDC/NHS } & \text { N-ethyl-N'-(3-dimethylaminopropyl)carbodiimide/ } \\ \text { ET } & \text { N-hydroxysulfosuccinimide } \\ \text { FAD } & \text { electron transfer } \\ \text { FMN } & \text { flavin adenine dinucleotide } \\ \text { GCE } & \text { flavin mononucleotide } \\ \text { GOx } & \text { glassy carbon electrode } \\ \text { IET } & \text { glucose oxidase } \\ \text { LOx } & \text { indirect electron transfer } \\ \text { LSV } & \text { lactate oxidase } \\ \text { MA } & \text { linear sweep voltammetry } \\ \text { MET } & \text { microband array } \\ \text { NP } & \text { mediated electron transfer } \\ \text { OCP } & \text { nanoparticle } \\ \text { PFV } & \text { open circuit potential } \\ \text { PTZ } & \text { protein film voltammetry } \\ \text { RDE } & \text { unsubstituted phenothiazine } \\ \text { SAM } & \text { selating disk electrode } \\ \text { SPE } & \text { screen-printed electrode } \\ \text { TEOS } & \text { tetraethoxysilane } \\ \text { TMOS } & \text { tetramethoxysilane } \\ & \end{array}$





\section{1 \\ INTRODUCTION}

\subsection{Electron transfer in bioelectrocatalytic systems}

Bioelectrocatalytic systems are based on biological entities, such as enzymes, whole cells, parts of cells or tissues interfaced with electronics. In all cases, enzymes, isolated or residing inside of cells, implement biocatalysis. Electron transfer phenomena within the protein molecules and between biological redox systems and electronics enable the development of various bioelectrocatalytic systems, which can be used both for fundamental investigations of enzymatic biological processes by electrochemical methods and for applied purposes, such as power generation, bioremediation, chemical synthesis and biosensors. Electrical contact between the biocatalyst's redox centre and the electronics is essential for the functioning of bioelectrocatalytic systems. Therefore, the question is "How can we establish effective electron communication in a bioelectrocatalytic system?"

In general, electron transfer in bioelectrocatalytic systems can be established by two main mechanisms (Fig. 1.1): indirect electron transfer (IET) and direct electron transfer (DET). ${ }^{1,2}$ Ostensibly, DET represents the easiest way of electron communication. However, redox proteins usually lack direct contact with the electrode due to an inactive shell covering their catalytically active centre, that can be explained by the Marcus theory. ${ }^{3}$ The active centre and the electrode can be considered as a donor-acceptor pair and the electron transfer rate constant $\left(k_{e t}\right)$ between them depends on the distance between them, and can be written in simplified form as: ${ }^{3}$

$k_{e t}=k_{0} \exp \left\{-\frac{\Delta G^{\ddagger}}{R T}\right\}$, where $k^{0}=10^{13} \exp \left\{-\beta\left(r-r_{0}\right)\right\}$

where: $\Delta G^{\neq}$is the activation energy for electron transfer, $R$ is the gas constant, $T$ is the absolute temperature, $\beta$ is the electron-coupling constant, $r$ is the distance between the donor and the acceptor and $r_{0}$ is the van der Waals distance.

The equation predicts exponential decay of the electron transfer rate with the distance between the electrode and enzyme's active centre, thus, making DET possible only for a limited number of enzymes having their active centres close (up to $15 \AA)^{4}$ to the molecule's surface. ${ }^{5}$ 
Since the redox centre is embedded in a substantial number of bioelectrocatalytic redox enzymes, additional electron carriers are needed in order to establish electrochemical communication (Fig. 1.1a). In some systems the natural cosubstrates of the enzyme, the second substrate of the enzymatic reaction, operate as a natural electron shuttle, which could transfer electrons between the active centre of the enzyme and an electrode. ${ }^{6}$ Alternatively, artificial electron shuttles, commonly referred to as "mediators", can be introduced into the system and replace the natural co-substrate in the reaction..$^{7-9}$ The process of indirect electron transfer utilising artificial electron shuttles is termed mediated electron transfer (MET).

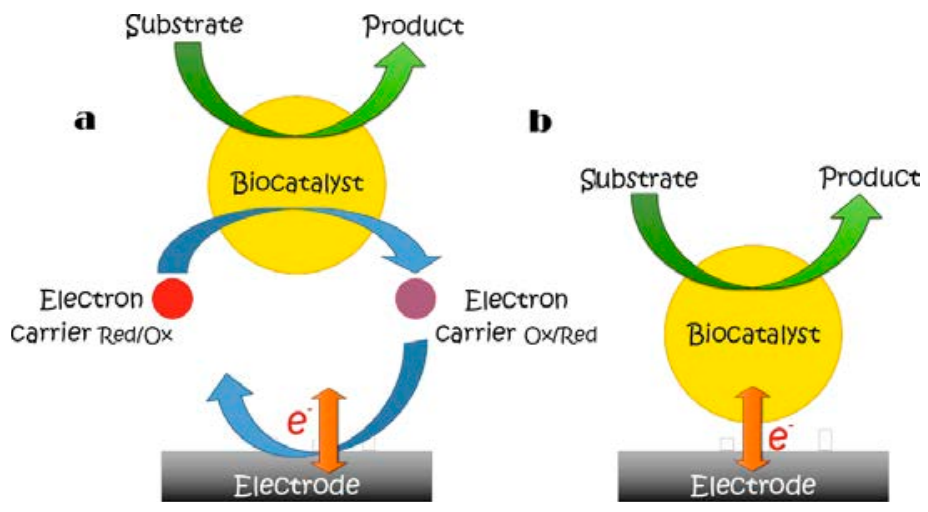

Figure 11. Schematic illustrations of electron transfer mechanisms in bioelectrocatalytic systems: a. Indirect and Mediated electron transfer; b. Direct electron transfer. The substrate is a molecule that the biocatalyst acts upon to form the product. Reprinted with permission from ${ }^{10}$. Copyright (C) 2015 Elsevier B.V.

\subsection{Aim and outline of the thesis}

The efficiency of the electron transfer (ET) influences important parameters of the bioelectrocatalytic system, such as the turnover rate of the biocatalyst, the generated current density and partially the stability of the system. These in turn determine the response time, sensitivity, detection limit and operational stability of biosensing devices or the power densities and current output of biofuel cells, and hence should be carefully considered when designing bioelectrocatalytic systems. Therefore, the aim of this thesis is to contribute to the solution of the "electronic coupling problem", i.e. the problem associated with the electrical connection between the electrode and the enzyme's active site, arising when interfacing biomolecules with electronics, and thus limiting the performance of bioelectrocatalytic systems in applications.

In order to reach this aim, several new approaches to control the ET in bioelectrocatalytic systems based on mediated and direct electron transfer mechanisms are suggested in the thesis. The thesis starts with some introductory 
information about biocatalysis, the biocatalysts used in the work and possible applications of bioelectrocatalytic systems for biosensing and power generation in Chapters 2 and 3. Chapter 4 gives an overview of mediated bioelectrocatalytic systems and describes suggested approaches to facilitate ET. First, by using a new hydrophobic mediator and a new protocol for the enzyme and mediator coimmobilisation into a sol-gel matrix from water-organic mixtures with a high content of organic solvent, which increases the stability of the system and at the same time, establishes effective electron communication. Secondly, Chapter 4 details the use of microband arrays as signal transducers in a substrate recycling system that supports effective ET due to convergent diffusion of a substrate acting as a mediator in the system. Chapter 5 overviews ways to enhance direct ET in bioelectrocatalytic systems. It also depicts electrochemical methods for the investigation of direct ET, such as protein-film voltammetry and a new approach based on single enzyme collisions with a microelectrode. Chapter 6 includes information about the experimental methods used in the thesis. Finally, a summary of the work and future perspectives are given in Chapters 7 and 8. 



\section{2 \\ BIOCATALYSIS}

The enzyme is an essential part of any bioelectrocatalytic system and determines its catalytic activity. To investigate ET in bioelectrocatalytic systems and parameters influencing its efficiency, knowledge of the enzyme's working principles and kinetics are necessary. This chapter contains basic information about enzymes, principles of enzymatic catalysis and details about catalytic specificity, activity and ET mechanisms of enzymes used in the work presented in this thesis.

\subsection{Principles}

Enzymes are (typically) proteins, which have the ability to significantly increase reaction rates (in the order of $10^{6}$ to $10^{18}$ ) of their substrates. The word 'enzyme' (en=in, zyme=yeast) was invented by the German physiologist Wilhem Kuhne in 1877. ${ }^{11}$

\subsubsection{Chemical nature of enzymes}

Since 1926, when the American biochemist James Sumner crystalised urease, ${ }^{12}$ it has been known that most of the enzymes are proteins. Enzymes are mainly globular proteins i.e. protein molecules where the tertiary structure has given the molecule a generally rounded shape (enzyme globule).

Enzyme molecules usually consist of an apoenzyme (a protein part) and a cofactor (non-protein part required for enzyme catalytic activity). The entire active complex is called the holoenzyme. Enzyme cofactors can be divided in two groups:

1. Organic cofactors:

a) Coenzymes - organic substances loosely attached to the protein part;

b) Prosthetic groups - organic substances strongly attached to the protein part;

2. Inorganic cofactors - metal ions.

The enzyme molecule contains one or more active sites, where the substrate molecule binds and the reaction occurs. The active site occupies a small portion of the enzyme molecule and has a well-defined 3D structure. The active site has two tasks: catalytic action and specificity. ${ }^{11}$ 


\subsubsection{Enzyme specificity}

One of the properties of enzymes, that make them widely used in various applications, is their specificity for the catalysed reaction. Enzyme specificities for their substrates vary from biomolecule to biomolecule. ${ }^{11}$ There are enzymes with rather wide specificity catalysing reactions of some group of compounds, as for example laccase catalysing oxidation of phenols, diamines and also some inorganic ions. ${ }^{13}$ Many enzymes are very specific showing even stereochemical specificity, as for instance lactate oxidase.

There are two main theories that describe enzyme specificity: the lock-and-key model and the induced fit model (Fig. 2.1). The lock-and-key theory was proposed in the 1890 s by Fisher. ${ }^{14}$ According to this theory, the active site has a rigid structure similar to a lock. A substrate has a complementary structure as a key. According to another theory proposed in 1958 by Koshland, structures of the active site and the substrate are not complementary. ${ }^{15}$ The binding of the substrate to the active site induces changes in the 3-D structure of the active site to make it fit to the substrate structure. After release of the products of the reaction, the active site returns to its initial configuration. The specificity of enzymes with single substrates can be explained using the lock-and-key model. However, not all experimental facts for more complicated enzymes can be explained using this theory. In such cases, the induced fit model is more appropriate.

\section{Lock-and-key theory}

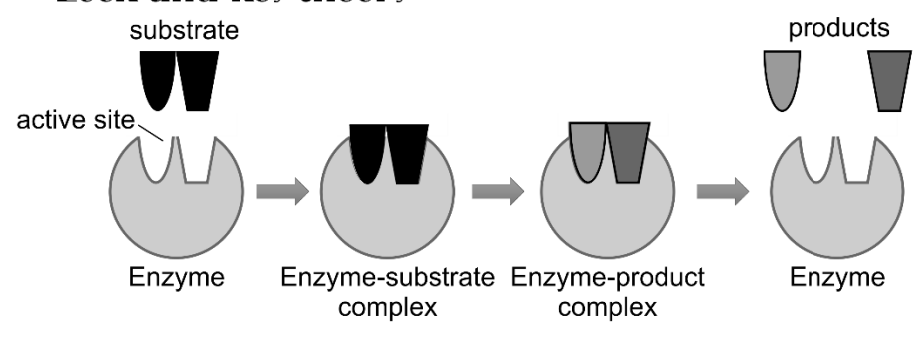

\section{Induced fit theory}

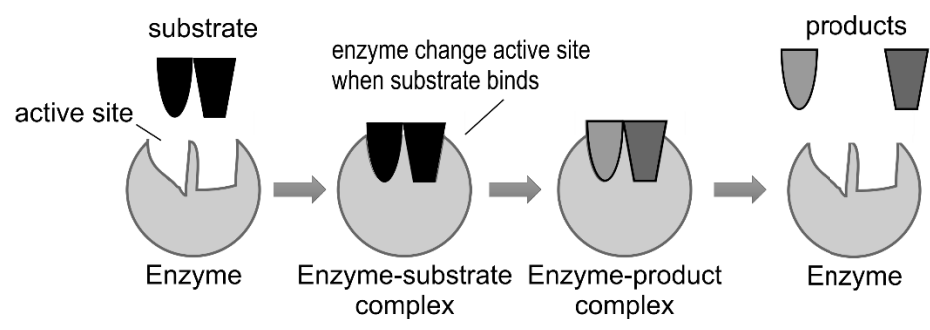

Figure 21. Illustration of the two theories of enzyme binding. 


\subsubsection{Classification}

There are six main classes of enzymes distinguished according to the reaction they catalyse: ${ }^{16}$

- Oxidoreductases - catalyse redox reactions;

- Transferases - catalyse transfer of functional groups;

- Hydrolases - catalyse hydrolysis of substrates;

- Lyases - catalyse removal of groups other than hydroxyl;

- Isomerases - catalyse inter-molecular rearrangements;

- Ligases - catalyse the union of two molecules.

Each enzyme is represented by 4 numbers in the Enzyme Commission (EC) database. The first number indicates the class, the second number the subclass, the third number the sub-subclass and the fourth number the serial number in the subsubclass.

The oxidases used in Papers I-IV and VI, VII are oxidoreductases that catalyse redox reactions involving molecular oxygen, $\mathrm{O}_{2}$.

\subsection{Engn atic a talg $\mathrm{s}$}

\subsubsection{Principles of enzyme catalysis}

The enzymatic reaction can be described as proposed by Arrhenius in 1888:

$$
\mathrm{E}+\mathrm{S} \underset{k_{-1}}{\stackrel{k_{1}}{\rightleftharpoons}} \mathrm{ES} \stackrel{k_{2}}{\longrightarrow} \mathrm{E}+\mathrm{P}
$$

where $\mathrm{E}$ is the enzyme, $\mathrm{S}$ is the substrate, $\mathrm{P}$ is the product and ES is the enzymesubstrate complex. The enzyme, being a catalyst, speeds up the reaction without being consumed by the process. It lowers the Gibbs energy of activation (Fig. 2.2) by changing the reaction mechanism. ${ }^{11}$

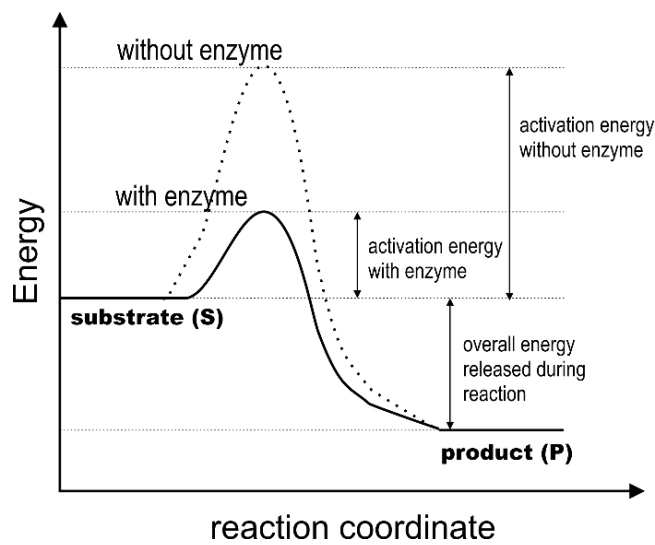

Figure 2.2. Gibbs energy change for a catalysed reaction. 


\subsubsection{Equations of enzyme kinetics}

In enzyme kinetics, the initial rate $\left(V_{0}\right)$ of the enzymatic reaction is the most important parameter, which corresponds to a known fixed substrate concentration (Fig. 2.3). In 1913, Michaelis and Menten proposed a mechanism to explain the dependence of the initial rate of enzyme-catalysed reactions on concentration, giving rise to what is now known as the Michaelis-Menten equation: ${ }^{17}$

$$
V_{0}=V_{\max } \frac{[S]}{K_{M}+[S]}
$$

where $V_{\max }$ is the maximum rate of the reaction at saturating substrate concentrations, $[S]$ is the concentration of the substrate and $K_{M}$ is the Michaelis constant, defined as: ${ }^{17}$

$$
K_{M}=\frac{k_{-1}+k_{2}}{k_{1}}
$$

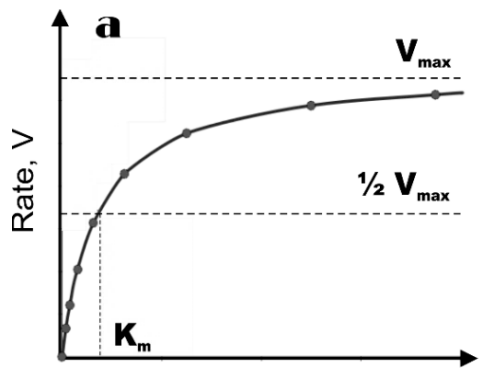

Concentration, [S]

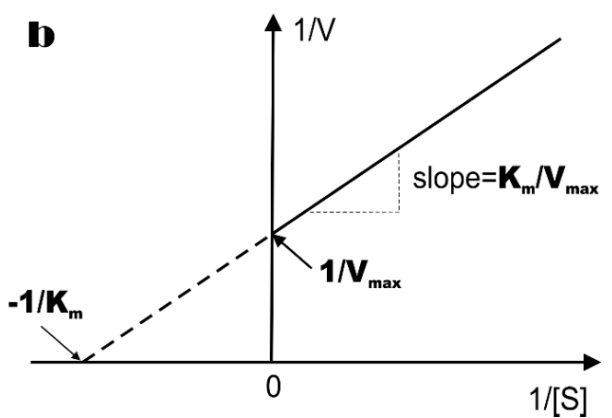

Figure 23 Enzymatic kinetics. a. Plot of the initial rate of the enzyme catalysed reaction vs concentration. b. Lineweaver-Burk plot.

Equation (2.2) is a fundamental equation of enzyme kinetics. When

$$
V_{0}=1 / 2 V_{\text {max }} \Rightarrow K_{M}=[S]
$$

Both parameters, $V_{\max }$ and $K_{M}$ can be determined from Fig. 2.3a. However, there is an easier way to determine these parameters from the equation suggested by Lineweaver and Burk: ${ }^{18}$

$\frac{1}{V_{0}}=\frac{K_{M}}{V_{\max }[S]}+\frac{1}{V_{\max }}$

As Fig. 2.3b shows, $V_{\max }$ and $K_{M}$ can be obtained from the intercepts and the slope of the straight line. 
$K_{M}$ varies from one enzyme to another and from substrate to substrate for the same enzyme. It depends on the enzyme source, temperature, $\mathrm{pH}$, ionic strengths and other reaction conditions. $K_{M}$ is a measure of the affinity between the enzyme and substrate. High $K_{M}$ values mean weak affinity and low $K_{M}$ values equate to strong affinity. In bioelectrocatalytic systems, $K_{M}$ values signify the efficiency of an immobilisation technique. Comparison between $K_{M}$ values of enzymes in solution and immobilised enzyme, or between different immobilisation techniques, allows conclusions about the suitability of a chosen means of immobilisation.

$V_{\max }$ is the maximum rate of an enzymatic reaction, corresponding to a situation where all enzyme molecules have formed the enzyme-substrate complex:

$$
V_{\text {max }}=k_{2}\left[E_{0}\right]
$$

If the initial concentration of the enzyme $\left[E_{0}\right]$ is known, then from values of $V_{\max }$ we can obtain values of $k_{2}$ (eq. 2.2, 2.3 and 2.6). $k_{2}$ is the turnover number also known as $k_{c a t}$ - the catalytic constant. It is the maximum number of molecules of the substrate that can be converted to the product per catalytic site in unit time. Another way to characterise the activity of the enzyme, especially in the case where the purity of the enzyme or the number of active sites per molecule is unknown, is to calculate the activity as units per milligram of protein (specific activity). One unit is defined as the amount of enzyme that produces one micromole of product per minute. ${ }^{19}$

\subsubsection{Factors affecting enzyme activity}

Several factors affect the rate of a biocatalytic reaction: temperature, $\mathrm{pH}$, enzyme concentration and presence of inhibitors or activators.

The rate of an enzyme catalysed reaction, like the rate of most chemical reactions, increases with increasing temperature. Since most enzymes are proteins, they denature at temperatures of $40-60{ }^{\circ} \mathrm{C}$. Therefore the dependence of the enzyme activity on temperature has a maximum, the optimum temperature (Fig. 2.4a). ${ }^{16}$ In order to optimise the performance of a bioelectrocatalytic system, it is necessary to know the temperature dependence of the enzyme activity and to work at temperatures close to the optimum.

The $\mathrm{pH}$ dependence curve of the enzyme activity has a similar shape (Fig. 2.4b). The $\mathrm{pH}$ at the maximum height of the curve is the $\mathrm{pH}$ optimum. Most enzymes have an effective $\mathrm{pH}$ range from 4.0 to $9.0 .{ }^{16}$ To obtain the best performance it is important to work in buffered solutions at the $\mathrm{pH}$ optimum for the enzymatic catalytic activity. 

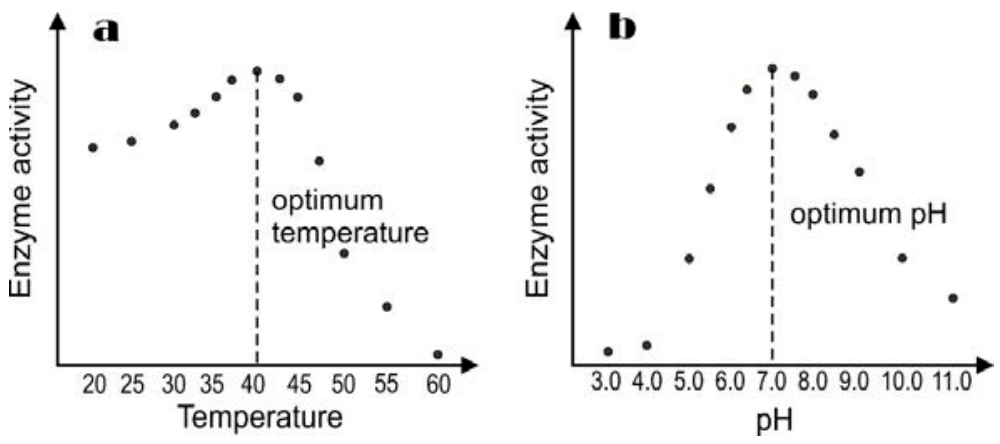

Figure 24. Illustration of the dependence of enzyme activity on: a. temperature; b. pH.

Inhibitors are compounds that decrease the rate of enzymatic catalytic reactions. Inhibitors can be reversible or irreversible. Michaelis-Menten kinetics is applicable only to reversible inhibition and this type of inhibition is the more common in bioelectrocatalytic systems.

\subsection{Biocatalysts used in this work}

For detailed information about enzyme inhibitors, temperature and $\mathrm{pH}$ maxima, the online database http://www.brenda-enzymes.org/ was used. For each enzyme described in the thesis a link to the corresponding page of the database is inserted.

\subsubsection{Glucose oxidase}

Glucose oxidase (GOx, EC 1.1.3.4) is an oxidoreductase with high specificity. It catalyses the oxidation of $\beta$-D-glucose to hydrogen peroxide and D-glucono- $\delta$ lactone which afterwards hydrolyses spontaneously to gluconic acid: ${ }^{20}$

$$
\text { glucose }+\mathrm{O}_{2} \stackrel{\mathrm{GOx}}{\longrightarrow} \text { gluconic acid }+\mathrm{H}_{2} \mathrm{O}_{2}
$$

GOx is a rigid glycoprotein composed of two subunits; each subunit has one molecule of a non-covalently bound coenzyme, flavin adenine dinucleotide (FAD), which are facing each other. ${ }^{21}$ (Fig. 2.5a). FAD transfers electrons and protons at the active site of the enzyme. It exists in two redox forms due to the presence of flavin in the structure: ${ }^{22}$ Enzymes having FAD in the active centre are referred to as flavoenzymes.<smiles>[R]N1C2=NC(=O)NC(=O)C2=Nc2cc(C)c(C)cc2N1[R]</smiles>

Since the active site of the GOx is buried inside of the enzyme globule $\sim 20 \AA$ from the surface, direct ET between FAD in the active centre of the enzyme and an 
electrode surface should be impossible due to the rapid decay of ET rates with the distance according to Marcus theory. ${ }^{3}$ In bioelectrocatalytic systems, communication between the enzyme and the electrode can be established via IET mechanisms.

GOx extracted from Aspergillus niger is the most commonly used enzyme in bioelectrocatalysis as it is easy to obtain, cheap and can retain its activity at more extreme $\mathrm{pHs}$, ionic strengths and temperatures than many other enzymes, thus allowing it to be used as a standard enzyme for studies of the principle of bioelectrocatalytic systems. ${ }^{21} K_{M}$ values reported for the enzyme in solution are $33-110 \mathrm{mM} \cdot{ }^{23}$ Facilitation of mediated bioelectrocatalysis of GOx from A. niger, was studied in Papers I, II and IV.

\subsubsection{Lactate oxidase}

Lactate 2-monooxygenase (EC 1.13.13.4) or the synonym: lactate oxidase- LOx (EC 1.1.3.2) is an enzyme that catalyses the chemical reaction: ${ }^{24}$

$$
\mathrm{L} \text {-lactate }+\mathrm{O}_{2} \stackrel{\text { LOx }}{\longrightarrow} \text { pyruvate }+\mathrm{H}_{2} \mathrm{O}_{2} \rightarrow \text { acetate }+\mathrm{CO}_{2}+\mathrm{H}_{2} \mathrm{O}
$$

The structure of the active site of lactate oxidase is not yet well known, as it always has different number of cofactors and water molecules in the structure and it is difficult to stabilise the holoenzyme biomolecule. It is known that the active site contains flavin mononucleotide (FMN). ${ }^{25}$ The redox activity of the active site is provided by flavin, as in the case of GOx (eq. 2.8). FAD in the active centre of LOx is located deep inside of the protein globule resulting in inability of the enzyme to communicate directly with an electrode. IET pathways are used to interface LOx and electronics.

Lactate, the LOx substrate, is the major metabolite of the anaerobic glycolytic pathway. It can exist in two enantiomeric forms: L-(+) and D-(-). L-(+) enantiomer is the normal intermediate in mammalian metabolism, whereas the D-(-) form is usually produced by microorganisms and algae. ${ }^{26} \mathrm{~L}$-lactate concentration in blood is related to various serious symptoms such as shock, metabolic disorders, respiratory insufficiency and heart failure. ${ }^{26}$ Lactate monitoring in blood or sweat is used in sports medicine for control of training programs and athlete efficiency. ${ }^{27}$ In the food industry, L-lactate determination is used for control of fermentation and for quality control of several products such as tomato sauces, fruits, juices, milk and wine. ${ }^{28,29}$

In order to achieve low detection times at low costs, L-lactate oxidase from Pediococcus species has been used by many laboratories in the construction of lactate oxidase-based bioelectrocatalytic systems. ${ }^{30}$ The enzyme has the advantage of high specificity over other enzymes used for lactate determination. Facilitation 
of mediated bioelectrocatalysis by L-lactate oxidase from Pediococcus $s p$. by the application of a new mediator was investigated in Paper II.

\subsubsection{Cholesterol oxidase}

Cholesterol oxidase (ChOx, EC 1.1.3.6) is a FAD-containing enzyme with absolute specificity. In the presence of oxygen, ChOx catalyses two reactions: oxidation of cholesterol to cholest-5-en-3-one and, subsequently, isomerisation to cholest-4-en-3-one: ${ }^{31}$

$$
\text { cholesterol }+\mathrm{O}_{2} \stackrel{\mathrm{ChOx}}{\longrightarrow} \text { cholest }-4-\mathrm{en}-3-\text { one }+\mathrm{H}_{2} \mathrm{O}_{2}
$$

The most commonly used ChOx's are isolated from Streptomyces hydroscopicus or Brevibacterium sterolicum. The ChOx from Streptomyces sp. contains noncovalently bound FAD (coenzyme), whereas ChOx from Brevibacterium $s p$. has covalently linked FAD (prosthetic group) ${ }^{32}$ However, enzymes from both sources have similar structure, consisting of two domains: a FAD-binding domain and a substrate-binding domain. The active site lies at the interface of these domains and is unavailable for the direct communication with an electrode, ${ }^{33}$ similar to GOx and LOx. (Fig. 2.5b). The distinctive feature of ChOx compared to the discussed flavoenzymes, is the hydrophobic surrounding of the enzyme active centre, which favours ChOx specificity to a hydrophobic substrate - cholesterol.
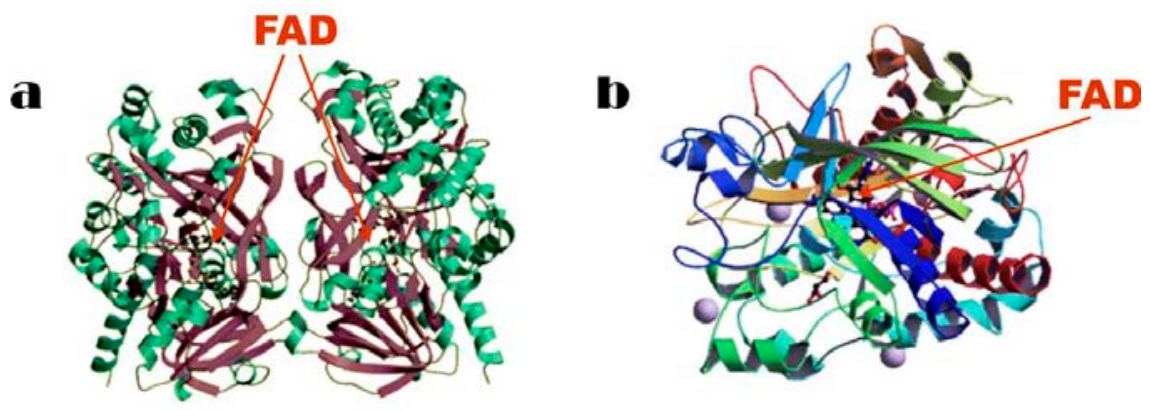

Figure 25 Structure of flavoenzymes used in the work: a Glucose ox dase from A. niger; b. Cholesterol ox dase from Brevibacterium $s p$.

The cholesterol level in blood is related to patient health status and is therefore very important in clinical diagnosis. A high cholesterol level in the blood increases the risk of clinical disorders such as hypertension, stroke, myocardial infarction, cerebral thrombosis, coronary and peripheral vascular diseases. ${ }^{34}$

Despite the higher stability of ChOx with covalently linked FAD, ChOx from Streptomyces sp. was used in Paper II and III as it has much higher activity compared to ChOx from Brevibacterium sp. By manipulation of the enzyme environment, we facilitated ET from the enzyme molecule to the electrode via 
indirect and mediated ET pathways, which allowed the development of a new bioelectrocatalytic system - a single enzyme based self-powered biosensor, described in Paper III.

\subsubsection{Laccase}

Laccase (EC 1.10.3.2) is a multinuclear copper-containing oxidase with a broad specificity towards various phenolic compounds, such as o-, $\mathrm{p}$ - and some $\mathrm{m}$ diphenols, aminophenols, polyphenols, as well as phenol. ${ }^{35}$ Laccase specifically catalyses the four-electron reduction of molecular oxygen to water concomitant with the one-electron oxidation of various substrates: $:^{36}$

$$
o, m, p \text {-benzendiols }+\frac{1}{2} \mathrm{O}_{2} \stackrel{\text { laccase }}{\longrightarrow} o, m, p \text {-quinones }+\mathrm{H}_{2} \mathrm{O}
$$

The active site of the enzyme molecule is formed by four copper ions. Substrates are oxidised near the solvent accessible mononuclear type $1 \mathrm{Cu}$ site (T1), which is located about $7 \AA$ below the enzyme surface. Then electrons are transferred through the protein in a process of the intramolecular ET over a distance of $\sim 13 \AA$ to a trinuclear $\mathrm{Cu}$ cluster, consisting of one $\mathrm{T} 2 \mathrm{Cu}$ and two $\mathrm{T} 3 \mathrm{Cu}$ sites, where the four-electron reduction of oxygen occurs. ${ }^{37}$ Such a structure (Fig. 2.6) promotes the establishment of an efficient direct ET between the enzyme's active centre and an electrode. ${ }^{38}$ In the case of direct communication, the electrode acts as a reducing substrate.

Laccase has an important application as an efficient biocatalyst for oxygen reduction in biofuel cells, due to the remarkably small overpotential required for the catalytic reaction. ${ }^{39}$ Laccases isolated from fungi demonstrate the highest potential, close to the equilibrium potential of oxygen reduction $(0.82 \mathrm{~V}){ }^{2}$ For biofuel cell construction, direct and mediated ET mechanisms are used to interface the enzyme with the electrodes. Another important application of laccases in bioelectrocatalytic systems originates from their specificity in the oxidation of phenols. Laccase-based biosensors are widely applied for the detection of phenolic compounds. ${ }^{40}$ Monitoring of phenolic compounds is of great importance for environmental and food quality control. ${ }^{41}$ In laccase-based biosensors, a phenolic compound is both the enzyme's substrate and acts at the same time as a mediator, which transfers electrons between the active site of the enzyme and the electrode, resulting in the formation of a so called substrate recycling system (see section 4.2).

Laccases can be obtained from different sources, including plants, fungi, some bacteria and insects. ${ }^{38}$ In this work we used fungal laccase from Trametes versicolor, since it is a cheap enzyme with a well-characterised structure ${ }^{42}$ (Fig. 2.6). In Paper VI we obtained a significant signal enhancement in the laccase-based substrate recycling system due to the utilisation of microelectrodes and demonstrated the application of the system for water analysis. In Paper VII, 
we investigated the DET mechanism at a single enzyme molecule using a new approach of collision-based electrochemistry (see section 5.2.2).

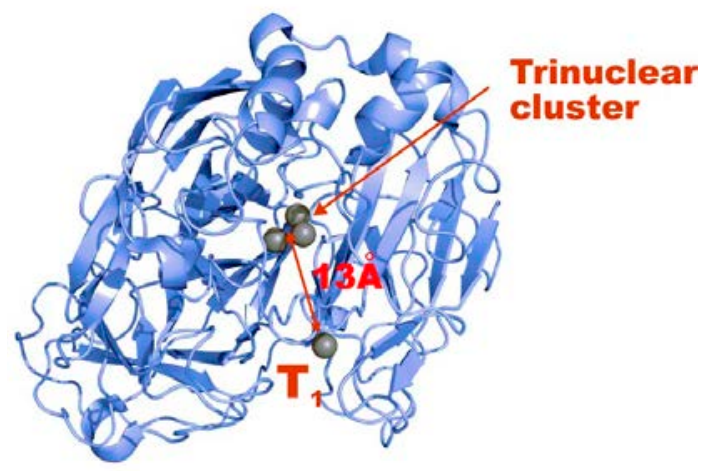

Figure 26. Structure of Trametes versicolor laccase. 


\section{3 \\ BIOELECTROCATALYTIC SYSTEMS}

Bioelectrocatalytic systems based on chemically-modified electrodes have important applications in biosensors and biofuel cells. In this chapter, a brief overview of these two possible applications is given.

\subsection{Electrochemical biosensors}

\subsubsection{Principles}

A biosensor is a device incorporating a biological sensing element and a transducer (Fig. 3.1) and providing real-time reliable information about the chemical composition of its surrounding environment. ${ }^{43}$ In case of electrochemical sensors the electrode is used as a transducer. Enzymes, antibodies, receptors or whole cells can be used as a bio-recognition element in biosensors. Enzymes were historically the first biorecognition elements used in biosensors. ${ }^{6}$ Enzyme electrodes were constructed by attaching an enzyme layer to the electrode surface. Such a device could monitor the electrochemical signal resulting from the biocatalytic reaction.

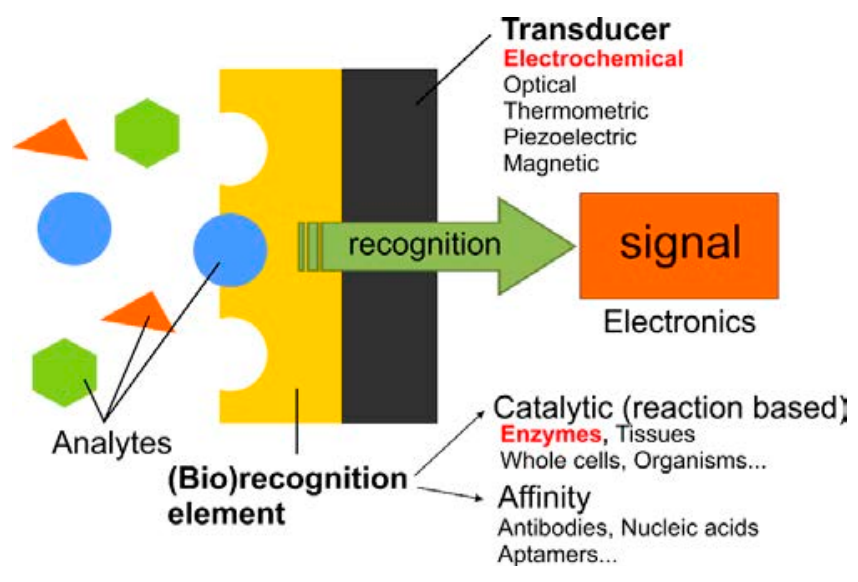

Figure 3.1. Scheme of a biosensor.

Electrochemical biosensors are based on potentiometric, voltammetric, or conductivity measurements. Voltammetric sensors depend on the recording of current-potential profiles. A special case of voltammetric sensors is amperometric sensors. Amperometric sensors, that this thesis deals with, are based on the 
monitoring of currents produced by electroactive species involved in the electrode process. The potential of the working electrode is maintained at a fixed value (relative to a reference electrode) and the current is monitored as a function of time. The resulting current is a direct measure of the rate of the ET reaction driven by the applied potential and it is proportional to the concentration of the target analyte. ${ }^{44}$ In potentiometric sensors, the analytical information is obtained from the monitoring of a potential difference at equilibrium related to the electrode process. The signal is proportional to the concentration of species generated or consumed in the recognition event. Usually potentiometric sensors are slower than amperometric. ${ }^{44}$ In conductometric sensors, changes in conductivity are monitored. A drawback of the conductometric transducer is the strong dependence of the response on buffer capacity and on the number of ions present in the solution. ${ }^{44}$

\subsubsection{Analytical performance}

Efficiency and applicability of the sensor in different areas is determined by its analytical performance, which strongly depends on the efficiency of the ET. There are many parameters to describe sensor's performance but I would like to discuss only those used for amperometic biosensor characterisation in this thesis, i.e. calibration graph (curve), sensitivity, detection limit, linear and dynamic range (Fig. 3.2).
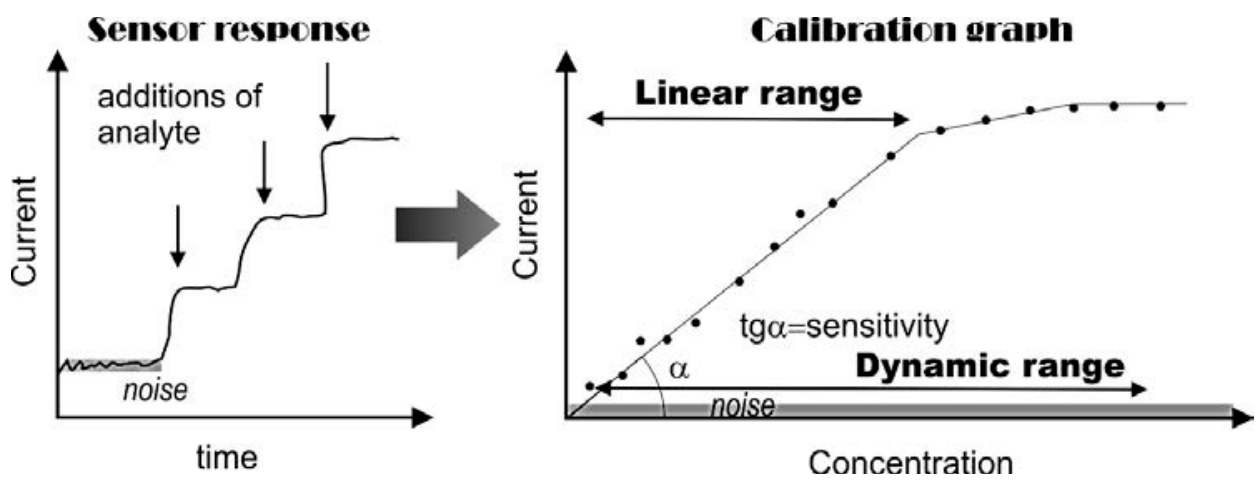

Figure 3.2. Illustration of determination of analytical performance from amperometric sensor response.

\section{Calibration graph}

To obtain quantitative information about the concentration of the analyte of interest one should know the dependence of the current signal on the concentration of the analyte in the same system that would be used for a test sample analysis. The results are used to plot a calibration graph (or calibration plot, or calibration curve) which is then used to determine the analyte concentrations in test samples by interpolation. ${ }^{45}$ 


\section{Sensitivity}

In analytical techniques, sensitivity is defined as the slope of the calibration graph. ${ }^{46}$ If the curve is not linear then sensitivity will be a function of analyte concentration (or amount). Sensitivity must depend only on the process of the measurement and not upon the scale factors in order to be a comparable and universal performance characteristic of a biosensor.

\section{Detection limit}

Detection limit (or limit of detection) is a theoretical term that may be described as the concentration of the analyte that gives an analytical signal significantly higher than the background noise. There is still not full agreement between researchers how to calculate the detection limit. In all my publications included in the thesis I have calculated detection limit as the standard deviation of the baseline current multiplied by three and divided by the sensitivity. ${ }^{47}$

\section{Linear and dynamic range}

The linear range is the range of concentrations of the analyte within the working range where the measured current is directly proportional to the concentration. The dynamic range is the range of analyte concentrations over which there is a measurable sensitivity to the analyte. ${ }^{48}$

\subsubsection{Electron transfer in biosensors}

Amperometric biosensors depending on the ET mechanism can be classified according to three so-called 'generations' ${ }^{49}$ (Fig. 3.3), which will be illustrated by oxidases.

\section{"First-generation" biosensors}

In first-generation biosensors electron communication is established by means of a natural enzyme's co-substrate, which shuttles electrons. In first generation biosensors either the increase of a product of an enzymatic reaction or the decrease of the enzyme substrate is detected as an analytical signal. Changes in concentration of a natural enzyme substrate participating in an enzymatic reaction can be also monitored. In all these cases, it is necessary that the measured compound is electrochemically active. The first invented biosensor, reported in 1962 by Clark and Lyons, was a first generation biosensor using GOx as a biorecognition element. ${ }^{6}$ In this biosensor GOx had been immobilised onto an oxygen-sensitive detector (known now as the Clark electrode) via a semipermeable membrane. As a result of enzymatic oxidation of glucose, catalysed by GOx, the concentration of oxygen in the solution decreases, which can then be monitored by the Clark electrode. Oxidase-based first generation biosensors 
measure the concentrations of oxygen as a natural oxidising substrate or hydrogen peroxide as a product: ${ }^{50}$

$$
\begin{aligned}
& \text { substrate }^{\text {enzyme }} \text { ox } \\
& \text { enzyme }_{\text {red }}+\mathrm{O}_{2} \rightarrow \text { enzyme }_{\text {red }}+\text { product } \\
& \text { ex }
\end{aligned}
$$

Here, the increasing concentration of $\mathrm{H}_{2} \mathrm{O}_{2}$ or the decrease in $\mathrm{O}_{2}$ concentrations can be detected electrochemically in order to monitor analyte concentration.

First-generation biosensors have several drawbacks. Firstly, the amperometric measurements of hydrogen peroxide and oxygen require application of relatively high potentials at which the impact of interferences present in biological or environmental samples is significant. Secondly, since this type of oxidase-based biosensor uses oxygen as a natural electron acceptor, their response depend on oxygen concentrations, which can fluctuate giving rise to errors. ${ }^{49}$

\section{"Second-generation" biosensors}

The mentioned drawbacks of the first-generation biosensors can be partially overcome by replacing oxygen with a synthetic electron acceptor - a mediator. The mediator transfers electrons, generated or consumed during the enzymatic reaction between the enzyme and the electrode in the process of MET. This type of biosensor, also called "mediated biosensors", is now the most commonly used configuration. This technological and commercial success started from the application of ferrocene as a mediator for amperometric glucose sensing in whole blood. ${ }^{9}$ Mediated biosensors will be discussed in detail in Chapter 4 of the thesis.

\section{"Third-generation" biosensors}

Third-generation biosensors are based on direct ET between the enzyme and the electrode surface. The absence of a mediator is the main advantage of such biosensors, thus providing high efficiency and simple design. However, only a limited number of enzymes are available that undergo direct ET and the efficiency of the DET depends not only on the distance between the active site of the enzyme and the electrode, but also on the properties of the electrode material and on the immobilisation technique. Even if the enzyme molecule is immobilised on the electrode surface, it can be oriented in such a way that direct ET is not possible due to a longer distance between the active site and the electrode compared to the ideal orientation. ${ }^{49}$ Thus, although third-generation biosensors are advantageous compared to the two other generations, they are still not widely used due to aforementioned problems. DET transfer in biocatalytic systems will be overviewed in Chapter 5 of the thesis. 


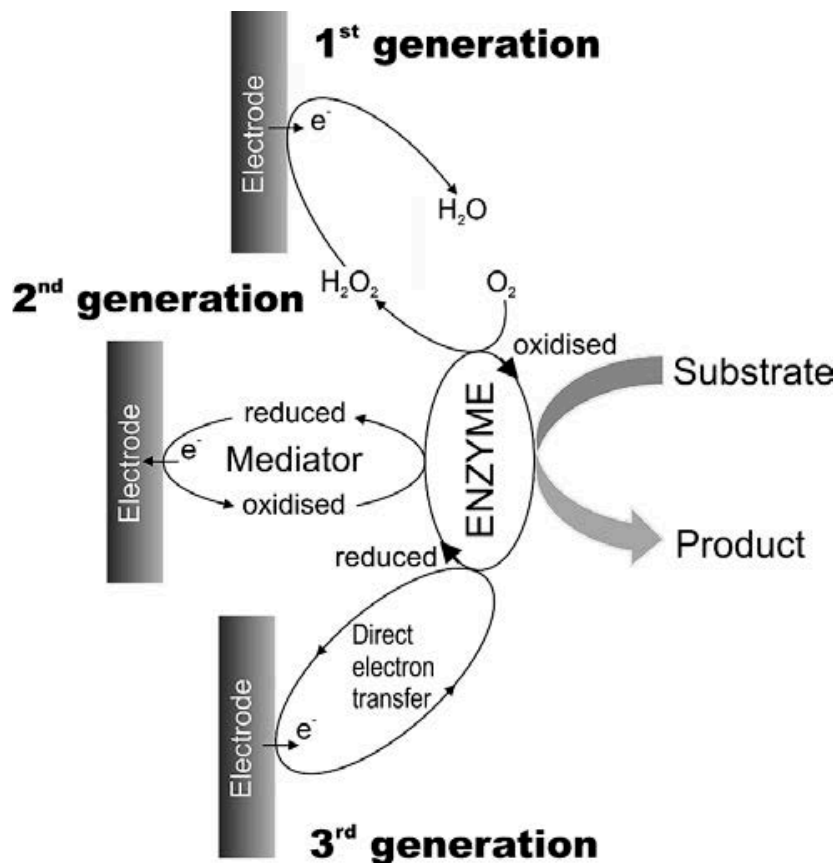

Figure 3 3. Representation of three amperometric biosensor generations.

\subsection{Biofuel cells}

\subsubsection{Principles}

Biofuel cells (BFCs) based on enzymes have been known since 1964. ${ }^{51}$ However, they have received revived attention during the last decade as a new energy conversion technology after Willner and co-workers published work on a membraneless enzymatic BFC. ${ }^{52}$

BFCs transform the energy of a biological catalytic reaction into electricity by oxidising a fuel at the anode and reducing an oxidant at the cathode. ${ }^{53}$ They are categorised according to the biological catalyst used for the fuel oxidation. Microbial BFCs use living cells or organelles as catalysts. ${ }^{54}$ In enzymatic BFCs enzymes are used as a catalyst for fuel oxidation. To understand the working principle of an enzymatic BFC one can consider it as a combination of two enzyme electrodes (Fig. 3.4). These two electrodes can be mediated biosensors as presented in Fig. 3.4 as well as any other possible combination of enzyme biosensors of different generations. Cells in which the reaction at only one electrode is catalysed by an enzyme and the other is a noble metal catalyst are also considered as enzymatic BFCs. ${ }^{55}$ 


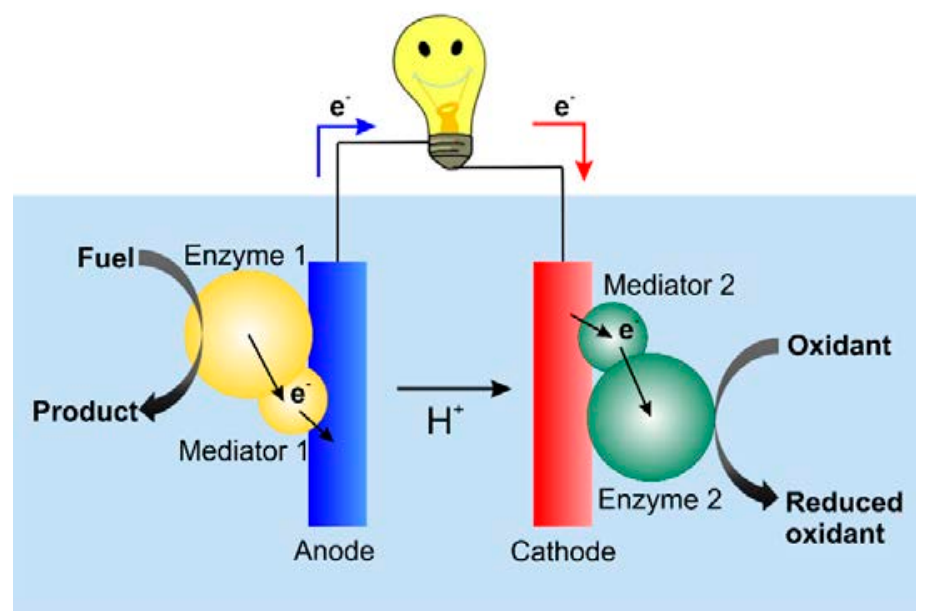

Figure 3.4. Schematic illustration of an enzymatic biofuel cell.

\subsubsection{Power, cell voltage and current}

The power output is one of the main characteristics of biofuel cell performance. It depends on the current detected at different cell voltages (Fig. 3.5) and is determined by the ET efficiency. One extreme of this dependence is the so called open circuit potential (OCP), which is a measure of the maximum voltage provided by a fuel cell. It is determined as the difference between the formal redox potentials of the fuel/product and oxidant/reduced oxidant couples. At the other extreme we have the short circuit current. This occurs when the anode and cathode are electrically connected (i.e. no voltage applied). Useful power appears at current and voltage values between OCP and short circuit potential. ${ }^{55}$

Cell voltages depend on the fuel and oxidant, the rate of ET, the current flowing, resistance within the cell and mass transport processes. ${ }^{53}$

The value of the current is determined by the slowest electrocatalytic reaction (anodic or cathodic). The maximum electrocatalytic current that can be achieved at the anode or cathode depends on the density of catalytically active sites and the rate of catalysis per active site. The rate in turn depends on the efficiency of the ET between the active centre and the electrode..$^{55}$ 


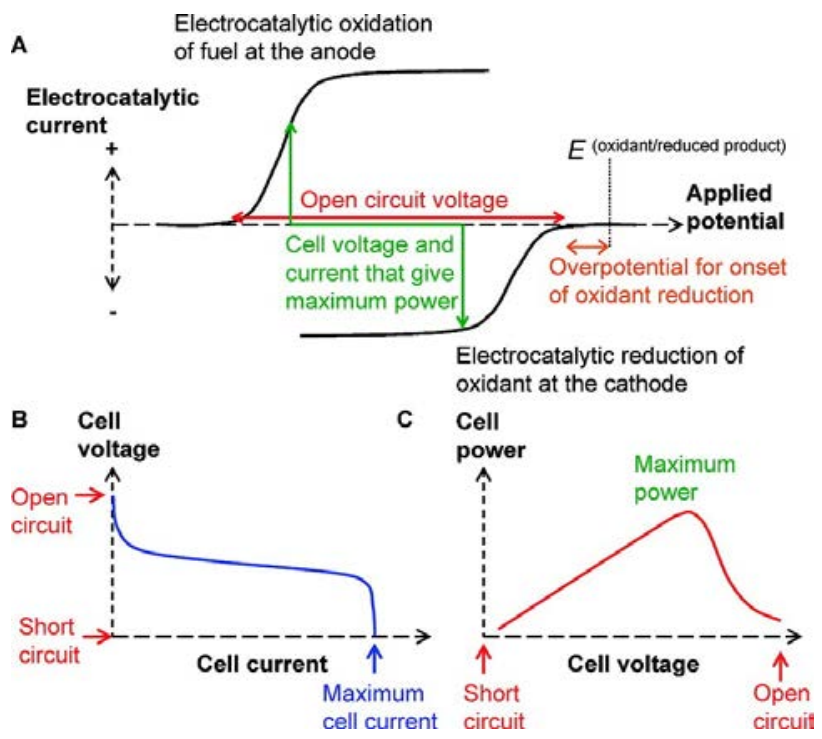

Figure 3.5. Illustration of factors that determine fuel cell performance. a. Open circuit potential. b. Maximum cell current. c. Maximum power. Reprinted with permission from ${ }^{55}$. Copyright (C) 2008 American Chemical Society.

\subsubsection{Electron transfer in biofuel cells}

ET in biofuel cells is usually implemented via DET and/or MET mechanisms on cathodic and anodic enzymatic electrodes. To achieve effective DET the enzyme should be immobilised on the electrode surface in such a way that the active centre lies close to the electrode surface (Fig. 3.6). ${ }^{4}$ The problem of such a design for the construction of biofuel cells is that only one layer of the enzyme will be located within the electron's tunnelling distance from the electrode, resulting in low current densities due to the low density of catalytic sites. One way to overcome this problem is by the use of $3 \mathrm{D}$ electrodes, which provide high enzyme loading. ${ }^{2}$ Another way utilised also for enzymes which lack ability of DET, is application of electron mediators.

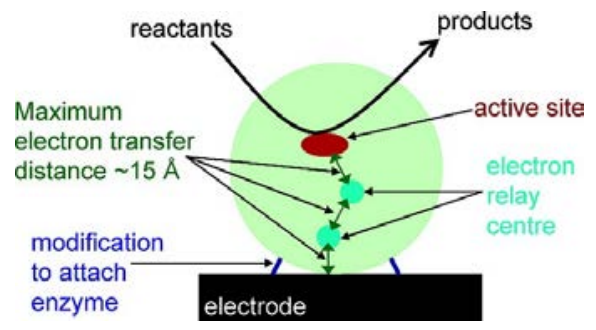

Figure 3.6. Cartoon diagram of an enzyme molecule immobilised on an electrode surface. Reprinted with permission from ${ }^{55}$. Copyright (C) 2008 American Chemical Society. 
However, the choice of possible redox mediators for biofuel cells is limited to those that have their redox potential close to the redox potential of the enzyme active centre. ${ }^{2}$ The reversible potential of a mediated bioelectrocatalytic electrode is mainly controlled by the mediator redox reaction. Thus, the open-circuit potential of a biofuel cell formed by two mediated enzyme electrodes as shown in Fig. 3.7 depends on the potential difference of the two mediator couples. At the same time, the potential difference between the enzyme's substrate and the mediator must be non-zero to drive ET. In Fig. 3.7, this statement is considered for the example of the glucose-oxygen biofuel cell.

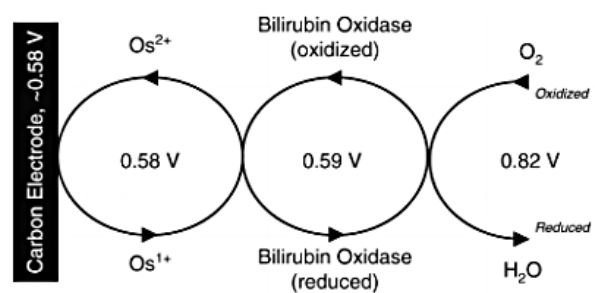

a.

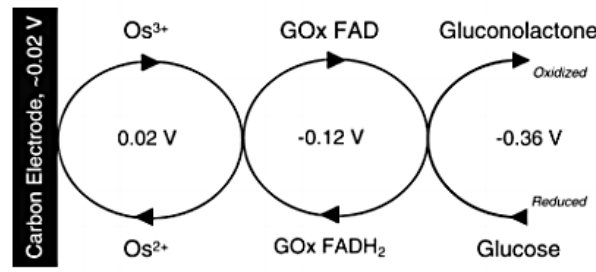

b.

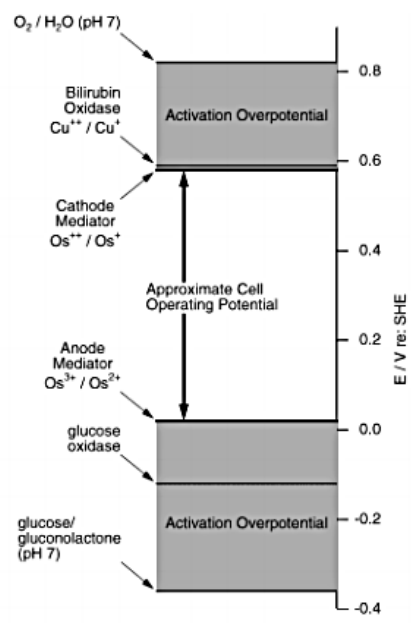

c.

Figure 3.7. Potential schematic for a mediated biofuel cell. Reprinted with permission from $^{2}$. Copyright (C) 2004 American Chemical Society.

The experimentally observed open-circuit potential is lower compared to a theoretical maximum, determined by the formal potential difference between the fuel and oxidant, due to the application of mediators. 


\section{4 \\ MEDIATED ELECTRON TRANSFER}

Bioelectrocatalytic systems based on MET implemented by artificial redox mediators nowadays find broad applications in biosensors, biosensing devices and biofuel cells. This chapter focuses on a discussion of ways to facilitate mediated ET between the biocatalyst and the electrode. An analysis of the enhanced mediated bioelectrocatalytic systems described in this thesis, in comparison with those reported in the literature, and their application in bioelectronics will be given. More detailed information on mediated ET together with an up-to-date overview of its application in bioelectrocatalytic systems can be found in the Review Paper.

\subsection{Flavoenzyme-based mediated systems}

\subsubsection{General electron transfer mechanism}

A mediator acts as an artificial enzyme substrate in an enzymatic redox reaction and shuttles electrons between the active site of the enzyme and the electrode. In a catalytic reaction, the mediator first reacts with the enzyme active site and then participates in rapid ET with the electrode.

Mediated catalytic reactions can, in the case of GOx, be described as follows: ${ }^{56}$

$$
\begin{aligned}
& \text { glucose }+\mathrm{FAD}+\mathrm{H}_{2} \mathrm{O} \rightarrow \text { gluconic acid }+\mathrm{FADH}_{2} \\
& \mathrm{FADH}_{2}+\mathrm{M}_{\text {ox }} \stackrel{k_{s}}{\longrightarrow} \mathrm{FAD}+\mathrm{M}_{\text {red }}+2 \mathrm{H}^{+}
\end{aligned}
$$

At electrode: $M_{\text {red }} \rightarrow M_{o x}$

where $\mathrm{M}$ is the mediator. In order to provide effective ET, the redox potential of the mediator should maintain a potential gradient between the active site of the enzyme and the electrode. Thus, the redox potential of the mediator should be more positive than the redox potential of the active centre of the enzyme in the case of oxidative bioelectrocatalysis and vice versa for reductive bioelectrocatalysis. ${ }^{57} \mathrm{At}$ the same time, the redox potential of the mediator should be small enough to avoid interfering with the electrochemical reactions and both the oxidised and reduced forms of the mediator should be sufficiently stable. In the catalytic reaction, the mediator competes with the enzyme's natural substrate (e.g. oxygen) for the electron flow. Thus, to promote ET in the system the mediator should possess a 
high ET rate constant between the mediator and the enzyme, $k_{s}$ (eq. 4.2). ${ }^{58}$ The overall efficiency of ET depends not only on the mediator properties, but also on the whole design of the system. ${ }^{57}$

Mediated bioelectrocatalysis includes both homogeneous and heterogeneous mediation. In the homogeneous reaction, both the enzyme and the mediator are located in the solution. In order to characterise the efficiency of homogeneous ET, cyclic voltammetry ${ }^{59,60}$ is often used (see section 6.2.3). In the heterogeneous system, the enzyme is immobilised on the electrode surface and the mediator can either be in the solution or also immobilised on the electrode surface. In the latter case, a so-called "reagentless architecture" of the bioelectrocatalytic system is realised. To estimate the efficiency of the ET in heterogeneous systems, rotating disk voltammetry, ${ }^{61,62}$, cyclic voltammetry ${ }^{63,64}$ or chronoamperometry ${ }^{65,66}$ can be used (sections 6.2.6, 6.2.3 and 6.2.5, respectively).

\subsubsection{Commonly used mediated systems}

Despite several attempts to use quiones, azines and metal complexes ${ }^{7,8}$ as mediators in the 1970s, the wider application of mediated systems did not begin until the discovery of the possibility to use the ferricinium ion (oxidised ferrocene) as a mediator for GOx in $1984 .{ }^{67}$

Ferrocene and its derivatives, ferri/ferrocyanide complexes of transition metals such as osmium and ruthenium as well as redox organic dyes (mainly azines) are widely used redox mediators for oxidases. Ferri/ferrocyanide is one of the most commonly used and most efficient soluble inorganic mediators. ${ }^{68-70}$ However due to its small size and high solubility, it easily diffuses away from the electrode surface into the bulk solution, which reduces the long-term operational stability and hampers its application in both continuous laboratory analysers and implantable probes. The less soluble ferrocene derivatives provide a partial solution to this problem and have achieved considerable success in commercial home-use devices, but the ferrocinium ion is still soluble. ${ }^{9}$ Tertrathiafulvalene has been proposed as one alternative to ferrocene derivatives as an insoluble mediator for amperometric biosensors. ${ }^{71-73}$ In spite of their high efficiency in mediating the ET of oxidases, osmium and ruthenium complexes ${ }^{74,75}$ have essential drawbacks due to their high toxicity.

The reagentless bioelectrocatalytic system is the most widely used architecture for a variety of applications. There are four main methods to immobilise the biocatalyst on the electrode surface: physical adsorption on the electrode surface, covalent bonding to the electrode, cross-linking of the biocatalyst and entrapment of the biocatalyst in membranes or polymeric matrixes ${ }^{76}$ (see section 6.1). An effective retention of the mediator on the electrode surface can be achieved by its covalent attachment to an electrode, a biocatalyst or the bonding between the mediator groups and the matrix-formed polymer or gel used for enzyme 
entrapment. The best known examples, which have also had a remarkable commercial success in home blood glucose tests, are biosensors with the membrane formed by poly(vinylpyridine $)^{77}$ and poly(vinylimidazole $)^{74,78}$ with Os complexes as the mediator. For more details about systems with covalently attached mediators, see the Review Paper. Systems with covalently attached mediators are usually more complicated and less efficient than systems with diffusional mediators due to problems with electron communication and a need to design ET pathways to achieve high ET rate constants. Two such ET pathways that are commonly used are illustrated in Fig. 4. The first approach is based on shortening of the ET distance by dividing the process in a series of electron hopping reactions between several mediator molecules attached covalently to a membrane (Fig. 4.1a). ${ }^{1}$ To provide effective electron communication, the process of the electron exchange between the mediator molecules should be faster than the ET between the active group of the enzyme and the mediator. The second approach is based on covalent attachment of a redox mediator either to the electrode surface or to the enzyme globule, so called "electroenzymes", via long and flexible space chains (Fig. 4.1b). ${ }^{1}$ The ET process in such systems is usually not efficient due to a small concentration of redox molecules available for the establishment of the electron communication.
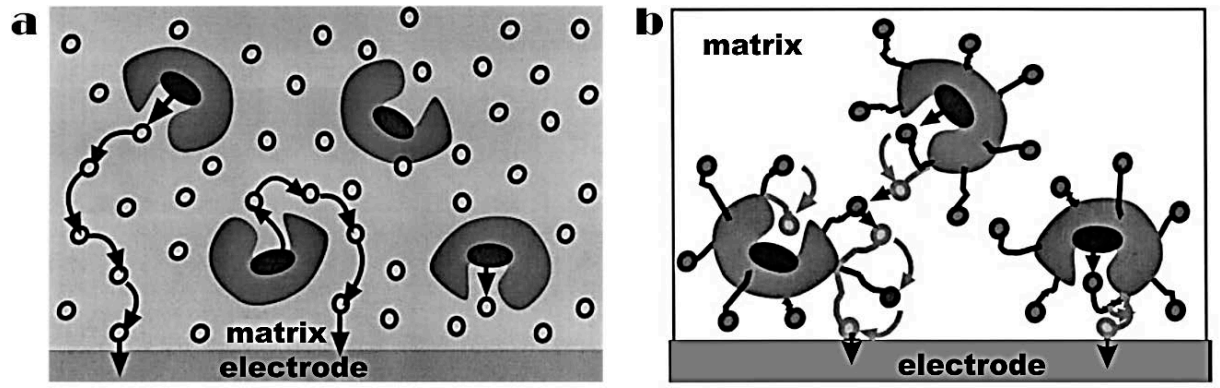

Figure 41. ET pathways in systems with a covalently attached mediator. a. Electronhopping pathway. b. Mediators bound to an enzyme via a flex ble chain. Reprinted with modifications from ${ }^{1}$. Copyright (C) Springer-Verlag Berlin Heidelberg.

Diffusional mobility of the redox mediator facilitates effective ET. The mediator can be retained on the surface by electrostatic interactions, for example in polyelectrolyte membranes ${ }^{79}$ or due to hydrophobic-hydrophilic interactions in polymer matrices ${ }^{80}$ For more information on mediated bioelectrocatalytic systems with diffusional mediators see the Review Paper. Despite the productivity of ET processes in bioelectrocatalytic systems utilising soluble diffusional electron mediators, they suffer from an inherent drawback: the mediating species can easily diffuse away from the electrode surface into the bulk solution and that causes sample contamination and low long-term operational stability of the system. 


\subsubsection{Bioelectrocatalysis with a hydrophobic mediator}

In order to facilitate MET, we suggested for the first time in Papers I-III to use water insoluble azines as diffusional mediators for oxidases. The hydrophobicity of the mediator allowed us to overcome the stability problem, since it prevents the mediator from diffusing away from the electrode surface. The use of a diffusional mediator enables ET and simplifies the system design compared to systems with a covalently attached mediator (Fig. 4.1).

Azines are one of the widely used mediators for oxidases. Azines are a class of organic compounds that can be considered as derivatives of phenazine. Some examples are shown in Fig. 4.2. Azines are aromatic structures with pronounced redox properties (Fig. 4.3). ${ }^{81}$ The main advantage of azines compared to ferrocene ${ }^{9}$ and tertrathiafulvalene ${ }^{71-73}$, commonly used hydrophobic mediators, is that at open circuit potential they occur in the oxidised form, i.e. in a form that is ready to react with the active site of an enzyme. Historically, methylene blue, one of the representatives of the azines, was the first artificial redox acceptor of GOx. ${ }^{82}$ Several azines such as methylene green, ${ }^{83}$ methylene blue, ${ }^{84}$ meldola blue, ${ }^{85}$ celestine blue, ${ }^{86}$ phenazine,${ }^{87,88}$ thionine, ${ }^{89}$ azure $\mathrm{B},{ }^{90}$ toluidine blue ${ }^{91}$ can be used as ET mediators for oxidases when immobilised on the electrode surface. However, all previously used azines were hydrophilic.<smiles>c1ccc2c(c1)Nc1ccccc1S2</smiles><smiles>c1ccc2c(c1)Nc1ccccc1O2</smiles><smiles>Cc1ccc2c(c1)Sc1cc(-c3ccc4c(c3)Sc3cc(C(F)(F)F)ccc3N4)ccc1N=c1ccc(=c3ccc4c(c3)Sc3cc(C(C)(C)C)ccc3N=4)cc1S2</smiles><smiles>Cc1ccc2c(c1)Oc1cc(-c3ccc4c(c3)Oc3cc(C)ccc3N4)ccc1N2</smiles>

Figure 42. Structures of investigated water insoluble azines. a. Phenothiazine (PTZ). b. Phenox zine. c. Polyphenothiazine. d. Polyphenox zine.

In Paper I we have evaluated the possibility to eliminate mediator leakage by using water-insoluble azines as mediators for oxidases. We tested unsubstituted phenothiazine (PTZ), phenoxazine and their oligomers as possible mediators for oxidases (Fig. 4.2). Among them, only the enzyme containing membrane with 
phenothiazine demonstrated catalytic response in the presence of the enzyme substrate. We note that since it is water-insoluble, phenothiazine was previously unknown as a mediator for oxidases.

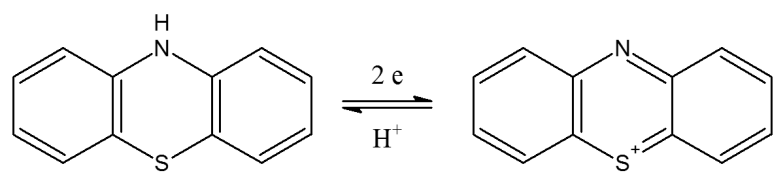

Figure 4.3. Suggested two-electron redox eaction of phenothiazine.

We suggested a two electron mechanism of the PTZ redox process based on a literature review and the dependence of the common peak potentials on solution $\mathrm{pH}$, which pointed to a two-electron, two-proton reaction (Fig. 4.3). In Paper II we have scrutinised the kinetics of this reaction using cyclic voltammetry, rotatingdisk electrode measurements and chronoamperometry (see section 6.2) and evaluated the ET efficiency of the mediator in comparison with commonly used systems. The observed characteristics place this new mediator among the best organic mediators for oxidases and opens up possibilities to construct novel reagentless biosensors and biological fuel cells, which was demonstrated in Papers II, III.

Hydrophobicity of the mediator improves stability of the system and provides high loading of the membrane with the mediator. However, the establishment of effective electron communication between the hydrophobic mediator and the hydrophilic enzyme is challenging. The use of polymeric membranes, having hydrophobic and hydrophilic domains in the structure ${ }^{92}$ suitable for the retention of the mediator and the enzyme molecules, respectively, enables effective ET. In Papers I-III we used a new protocol for enzyme-mediator co-immobilisation, which allowed us to increase the stability of the system and at the same time to establish effective ET. The proposed protocol is based on the well-known sol-gel process; however, the immobilisation was carried out from a medium with a high content of organic solvent.

\section{Sol-gel process}

The sol-gel process is a low temperature method for trapping enzymes in inorganic glasses. The application of the sol-gel process for enzymes was first demonstrated in 1990, by Braun and co-workers, and has developed apace since that time. ${ }^{93}$ During the sol-gel process, alkoxide monomers undergo hydrolysis to form silanols. Condensation of silanols with subsequent aging and drying processes under ambient atmosphere, leads to the formation of porous sol-gel matrices. The chemistry of such a process is: ${ }^{94}$ 
$\mathrm{R}-\mathrm{Si}(\mathrm{OEt})_{3}+3 \mathrm{H}_{2} \mathrm{O} \rightarrow \mathrm{RSi}(\mathrm{OH})_{3}+3 \mathrm{EtOH}$

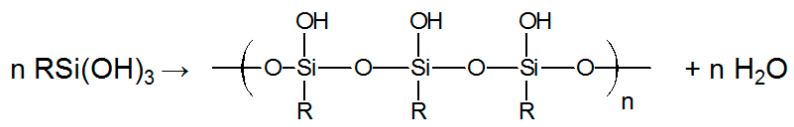

The most widely used monomers for the sol-gel process are tetramethoxysilane (TMOS) and tetraethoxysilane (TEOS). However, the introduction of various organic functional groups into the monomers leads to organically modified sol-gel glasses, or ormosils. Ormosils have several advantages compared to inorganic solgels including the: ${ }^{94}$

- possibility of specific binding of a biomolecule to the matrix;

- possibility to incorporate a mediator in the same matrix as the enzyme;

- possibility to tune the wettability of the matrix, by controlling the ratio of hydrophilic to hydrophobic monomers; ${ }^{95,96}$

- possibility to control thickness and porosity of the biocatalytic layer.97,98

There are four different approaches for enzyme immobilisation in a sol-gel matrix (Fig. 4.4): ${ }^{94}$

- enzyme entrapment in the matrix; ${ }^{99}$

- enzyme attachment on the surface of an ormosil; ${ }^{100}$

- enzyme immobilisation in a sandwich configuration; ${ }^{101}$

- enzyme immobilisation in a bilayer configuration. ${ }^{102}$
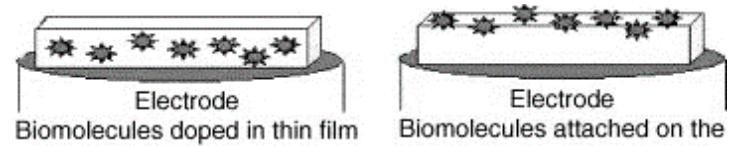

Biomolecules attached on the

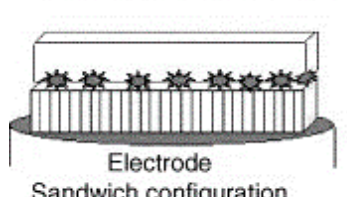

Sandwich configuration

Biomolecule

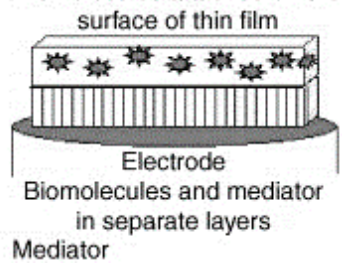

Figure 4.4. Schematic illustration of different approaches of enzyme immobilisation in a sol-gel: a. Entrapment; b. enzyme attachment on the surface of an ormosil; c. sandwich configuration; d. bilayer configuration. Reprinted with permission from ${ }^{94}$. Copyright (C) 2005 Elsevier B.V.

The choice of immobilisation approach depends on the convenience, stability and sensitivity required for the bioelectrocatalytic system. In Papers I, II and partially III, enzyme entrapment in the sol-gel matrix together with the mediator was applied. In Paper III the bilayer configuration was also used; $\mathrm{ChOx}$ in a sol-gel 
matrix was immobilised on top of the electrode covered by Prussian blue (ferric ferricyanide). In Papers I-III, we used 3-aminopropyl-triethoxysilane (APTEOS) as a monomer for formation of the gel matrix (Fig. 4.5). In Paper I, two additional siloxanes were tested as a matrix for enzyme immobilisation, vinyl- and phenyltriethoxysilanes, however biosensors based on APTEOS showed better operational stability. The organic structure in the APTEOS provides a strong cage for the enzyme molecules and solves the enzyme leaching problem. The presence of amino groups in the ormosil creates a hydrophilic microenvironment beneficial for biomolecules. ${ }^{103}$
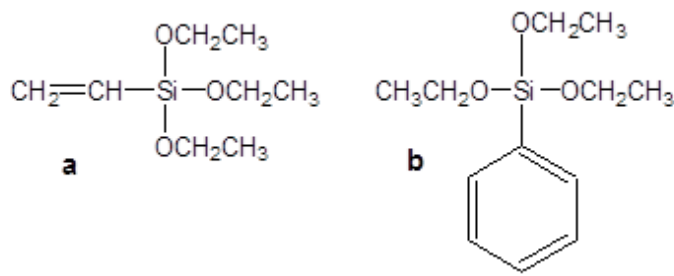<smiles>CO[Si](CCCN)(OC)OC</smiles>

Figure 4.5. Structural formulas of a. vinyl-, b. phenyl, c. 3-aminopropiyltriethoxs ilane.

\section{Immobilisation from organic solvent}

Preparation of gel membranes with uniformly distributed hydrophobic PTZ requires media with a high content of organic solvent. Such an immobilisation procedure allows a stable membrane to be obtained with a well-distributed mediator providing effective ET between the redox enzyme and the electrode. As a uniform membrane can be obtained only from a diluted solution of monomers (1-3\%) and for hydrolysis of one molecule of the monomer 3 to 4 molecules of water are needed, the concentration of water in the solution should not exceed $15 \%$. Higher concentrations of water lead to spontaneous hydrolysis and condensation and therefore to a heterogeneous membrane. ${ }^{104}$

In Papers I-III, we used the concept of enzyme immobilisation from waterorganic mixtures with a high content of organic solvent, based on the knowledge that enzymes can retain their activity after being exposed to such media. ${ }^{105,106}$ It has been shown previously that the dependence of the enzyme catalytic activity in a water-organic mixture on the organic solvent concentration has three regions. ${ }^{107}$ There is no significant decrease in enzyme activity at low content of organic solvent $(0-20 \%)$. At concentrations higher than a critical value ("threshold value"), ${ }^{108}$ the enzyme undergoes conformational changes and completely loses its activity. In concentrated organic solutions with a water content less than 10-15\% the enzyme activity reappears. The reasons for this phenomenon are still not clear. One suggestion is that the enzyme becomes insoluble in such media and that the presence of colloid particles prevents the biomolecules from inactivation by the 
organic solvent. ${ }^{105}$ Fig. 4.6 represents our investigation of the enzyme (GOx) activity in water-isopropanol mixtures that we used for sol-gel immobilisation of biomolecules in Papers I-III. As can be seen, the maximum of the remaining activity occurs at $15 \%$ of water. This mixture was used for immobilisation of biomolecules in our work.

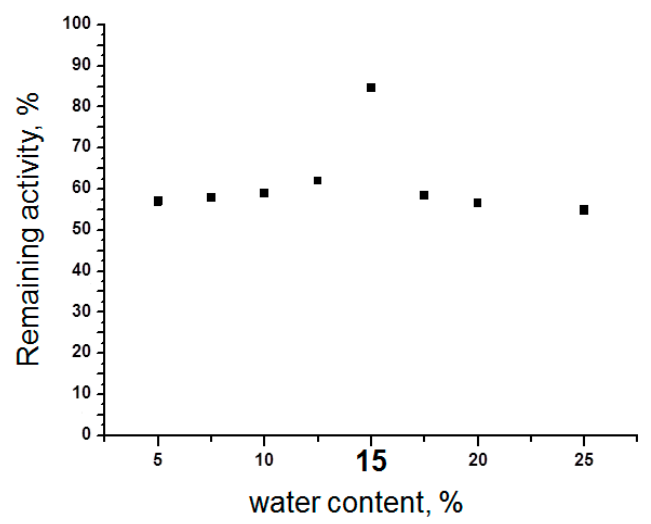

Figure 4.6. Remaining activity of glucose ox dase after $10 \mathrm{~min}$ of eos ure to waterisopropanol mix ures.

The finding of a novel water insoluble mediator with improved properties combined with a new protocol for its co-immobilisation with the biocatalyst resulted in the development of new mediated bioelectrocatalytic systems with improved ET properties. In Paper II we demonstrated the applicability of the developed strategy for construction of glucose, lactate and cholesterol biosensors, based on the mediated bioelectrocatalysis of GOx, LOx and ChOx, respectively. As a result of the development of the bioelectrocatalytic systems developed in Papers I and II, we presented two complementing platforms of bioelectrocatalysis that have been combined for the fabrication of a self-powered biosensor in Paper III.

A self-powered biosensor is a type of an enzymatic biofuel cell (BFC) where the power output is measured, either as an open circuit potential (OCP) or a current proportional to the fuel concentration. ${ }^{54}$ The main advantage of self-powered biosensing devices is that they can operate without any power input to the cells, producing power and thus making it attractive for the potential use in implantable devices ${ }^{109}$ and in inexpensive screening devices based on printed electronics. ${ }^{43}$ Self-powered biosensors, however, produce relatively low power densities and have low open circuit potentials that prevent them from real life applications where the generated power should be sufficient for measurements and an analytical signal transmission. In order to apply self-powered devices in real life, the power output of the BFCs should be improved. Facilitation of ET in BFCs using DET or effective mediators which minimise the biocatalyst overpotential is a promising 
approach to overcome the limitations of the self-powered biosensors in applications. Another possible approach is to retain the activity of the biocatalysts used in the BFC construction for a longer period. For BFC construction at least two enzymes are usually used. These enzymes might have different optimum conditions which complicates the design of the device and reduces the activity of the biocatalysts. In Paper III, we introduced the new concept of a single enzymebased self-powered biosensor. Anodic and cathodic counterparts of the selfpowered biosensor were based on ChOx immobilisation into a sol-gel matrix, as described below, on carbon cloth electrodes (Fig. 4.7). Mediated biocatalytic cholesterol oxidation provided the anodic reaction and electrocatalytic reduction of hydrogen peroxide on Prussian Blue (PB) was the cathodic reaction. Due to a synergetic effect, the characteristics of the self-powered cholesterol biosensor exceeded the combined analytical parameters of the single counterparts. The application of the biosensor for free cholesterol detection in plasma was demonstrated and results showed correlation with the standard method of colorimetric cholesterol quantification.

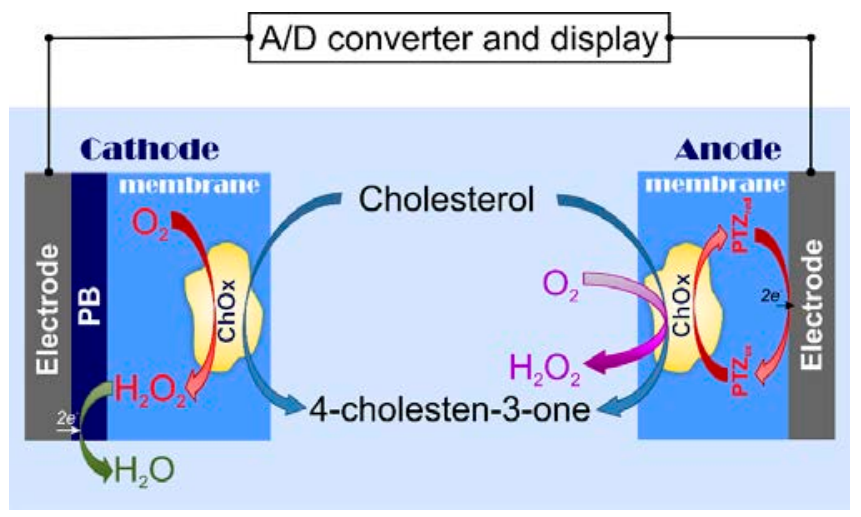

Figure 47 Scheme of a single enzyme based self-powered biosensor. Reprinted from ${ }^{110}$. Copyright (C) 2014 American Chemical Society.

\subsection{Bioelectrocatalytic substrate recycling systems}

\subsubsection{Substrate recycling mechanism}

Enzymatic substrate recycling systems are based on sequential consumption and regeneration of the substrate on the electrode surface. This process leads to a significant enhancement of the detected signal, which in case of biosensing devices means increase of sensitivity. The electrochemical recycling can be realised in various ways (Fig. 4.8). ${ }^{111}$ In the electrochemical and bioelectrocatalytic systems, the target analyte is recycled between the electrodes or an electrode and an enzyme active centre. In the biocatalytic approach, a substrate and a product are recycled between a couple of enzymes. Here we will consider bioelectrocatalytic substrate recycling systems. 
Flectrochemical

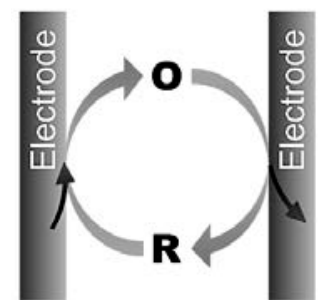

Bioelectrocatalytic

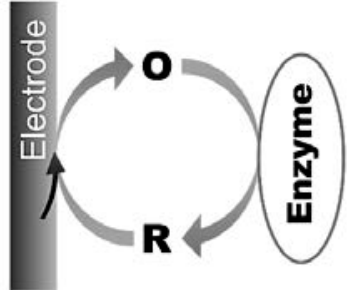

Biocatalytic

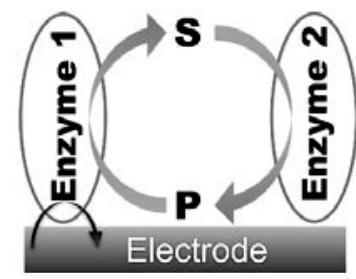

Figure 4.8. Illustration of the principles of substrate recycling electrodes. $\mathrm{O}-\mathrm{ox}$ dised species, $\mathrm{P}$ - reduced species, $\mathrm{S}$ - substrate, $\mathrm{P}$ - product.

The first bioelectrocatalytic substrate recycling system was demonstrated in 1984 by Wasa, and was based on laccase. ${ }^{12}$ Since then other enzymatic systems, utilising various copper containing oxidases ${ }^{113,114}$, flavoenzymes ${ }^{115,116}$ and dehydrogenases ${ }^{117,118}$ have been investigated. For the realisation of substrate recycling, the biosensor reaction should be reversible. Catechols (benzenediols) represent one of the most commonly used substrates in such systems ${ }^{119-121}$ due to reversibility of the redox reaction of the phenolic ring and due to the relevance of their determination with high sensitivity for medical, food safety and environmental applications. In Fig. 4.9, the mechanism of the bioelectrocatalytic recycling of catechol using the laccase-based enzymatic electrode is presented. For conversion of the analyte, which in this case acts also as the enzyme mediator, the electrode should be polarised to a reduction potential relative to the standard redox potential of the analyte, in order to regenerate the reduced form of catechol which is oxidised in the enzymatic reaction.

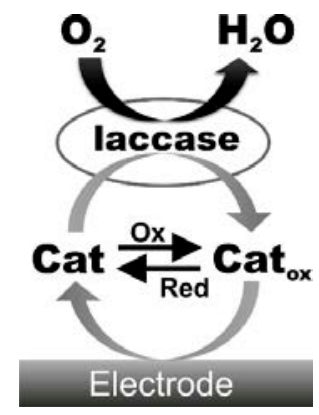

Figure 4.9. Scheme of the bioelectrocatalytic recycling system based on laccase.

Enzyme electrodes under optimised conditions can detect substrate concentrations of the order of $10^{-6} \mathrm{M}$. Application of substrate recycling allows analysis to be performed in the nanomolar range, which is especially relevant for the detection of pollutants in the environment and in food products. In Paper VI, we applied a laccase-based recycling system described previously ${ }^{122}$ for the detection of phenols in wastewaters and in tap water. However, in order to promote ET in the 
system by improving the diffusion of the analyte and to be able to perform analysis in a weakly supported media, we applied microelectrode arrays as transducers.

\subsubsection{Microelectrodes as a transducer}

Microelectrodes are electrodes that have at least one dimension smaller than $100 \mu \mathrm{m}$ and therefore have special characteristics, directly related to their size. Reduction of size leads to lower capacitive currents and to convergent diffusion (Fig. 4.10) instead of the planar diffusion observed at macroelectrodes. This allows steady-state currents to be attained within a shorter time for the microelectrode.
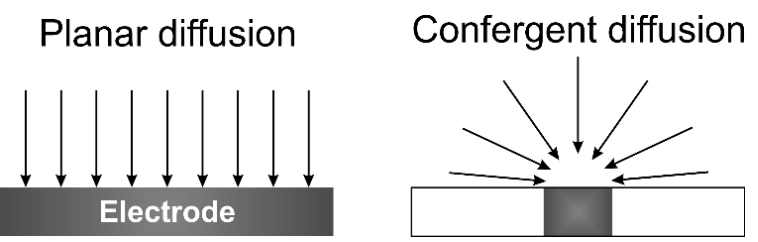

Figure 4.10. Illustration of planar diffusion on a macroelectrode $v s$ convergent diffusion on a microelectrode.

In recent years, microelectrodes have been widely applied in analytical and physiological studies due to their beneficial properties. These include their small size, allowing smaller sample volumes to be used, and making possible their application for in vivo measurements, low background currents due to the reduced surface area, and high current density resulting from enhanced mass transport to the electrode surface. ${ }^{123}$ However, single microelectrodes produce small currents, which are difficult to detect with conventional electrochemical equipment. This problem can be solved by using an assembly of microelectrodes, with each microelectrode independent of its neighbours. With appropriate design, such an assembly may show all the useful properties of a single microelectrode while generating higher currents. ${ }^{124}$ Application of micro- and nanoelectrode arrays for the construction of bioelectrocatalytic systems is discussed in detail in the Review Paper.

In Paper IV we fabricated arrays of graphite microelectrodes using screen printing technology. Screen-printing is a standard technology for cost-effective production of electrochemical devices. ${ }^{125}$ However, since the minimum feature size in screenprinting is about $50-100 \mu \mathrm{m}$, which is not small enough for efficient fabrication of microelectrodes in the lateral dimension, a strategy of cross-cutting has been adapted for the fabrication of microelectrodes with microband geometries. ${ }^{126} \mathrm{~A}$ microband design of the microelectrodes combines convergent mass transport due to the microscale width and high output currents due to the macroscopic length (Fig. 4.11). 


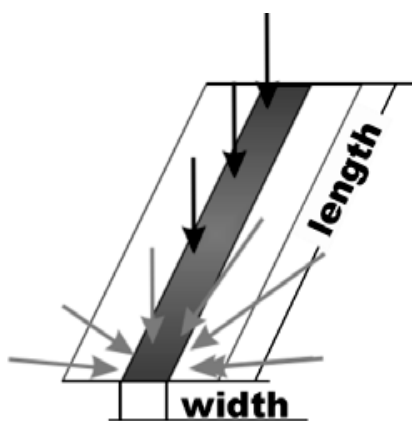

Figure 4.11. Schematic illustration of the microband geometry of a microband electrode.

We produced monolayer microband arrays with different band lengths and multilayer arrays by screen-printing followed by scissor crosscutting. One of the distinguishing features of microelectrodes is the small currents lying typically in the $\mathrm{pA}$ range, but with high current densities due to the small electrode size. ${ }^{127}$ Therefore, even small errors in the determination of the real surface area of the microelectrode have a huge impact on current density calculations. Since electrode reaction rates and most double layer parameters are dependent on the area of the interface, knowledge of the real surface area of an electrode is needed for correct calculations of various parameters of electrochemical processes in bioelectrocatalytic systems. ${ }^{128}$ The real surface area, referred to in electrochemistry as an electrochemically active surface area (EASA), is in many cases different from the geometrical surface area determined by microelectrode boundaries. The ratio of the EASA to the geometrical surface area is characterised by the "electrochemical roughness". ${ }^{129}$ In Paper V, we considered the effect of the surface roughness on the electrochemically active surface area of the microelectrodes under conditions of convergent diffusion. We have shown that the current response obtained under Faradaic conditions (current generated because of a redox reaction) is almost insensitive to the roughness of the microelectrodes, which is introduced in the process of crosscutting.

The microelectrode array developed and characterised in Papers IV and V, was utilised as a platform for the development of the substrate recycling bioelectrocatalytic system in Paper VI. To achieve rapid heterogeneous ET in the substrate recycling system, the enzyme and the electrode should be in close contact. ${ }^{111}$ To provide the contact we attached the enzyme covalently to the microelectrode array activated by anodisation (see section 6.1). Mediated laccase bioelectrocatalytic oxidation of phenols was studied on the fabricated microelectrode arrays in comparison with macroscale graphite electrodes. The reduction of the dimensions of the transducer led to a significant improvement of the performance of the bioelectrocatalytic system due to an increase in the signalto-noise ratio and the contribution of convergent diffusion of the analyte. 


\subsubsection{Diffusion-controlled $v s$ kinetic controlled currents}

Nonlinear diffusion of redox species on microelectrode disks results in a steadystate current according to: ${ }^{127}$

$i_{s S}=4 n F C D r_{0}$

where $i_{s s}$ is the steady-state current, $n$ is the number of transferred electrons per single redox reaction, $F$ is the Faraday constant, $D$ is the diffusion coefficient, $C$ is the bulk concentration of the redox species and $r_{0}$ is the microelectrode radius.

In bioelectrocatalytic systems a steady-state current is achieved when the mass transfer due to the substrate diffusion is in equilibrium with the rate of the enzymatic reaction. ${ }^{130}$ In case of bioelectrocatalytic systems based on microelectrodes these two mechanisms compete with each other. However, when the enzymatic reaction is fast, the steady-state current is controlled by the substrate diffusion and the current becomes independent of enzyme activity. ${ }^{131}$ The rate of the mediated reaction for the laccase-based substrate recycling system described in Paper VI, depends on the diffusion rate of the enzyme substrates - phenols.

Thus, we demonstrated that application of microelectrode arrays as a transducer in a bioelectrocatalytic system is useful for the construction of amperometric biosensors, since it leads to improved analytical performances of the biosensor due to nonlinear diffusion, which results in enhancement of the ET in the system. Moreover, the utilisation of microelectrodes allows analysis to be performed in weakly supported media without additions of an electrolyte, and this is especially advantageous for water analysis. The microbiosensor developed in Paper VI showed fast responses towards catechol additions to tap water, a weakly supported medium. This enhanced laccase-based microsensor was used for water quality monitoring and its performance for total phenol analysis of wastewater samples from different stages of the cleaning process was compared with the results of a reference method (gas chromatography tandem mass-spectrometry - GC$\mathrm{MS} / \mathrm{MS})$. 



\section{5 \\ DIRECT ELECTRON TRANSFER}

A limited number of enzymes are able to transfer electrons directly between the active site and an electrode surface. ${ }^{132}$ Among them are copper oxidases (laccases, tyrosinase, billirubin oxidase), heme-containing enzymes (cytochrome $\mathrm{C}$ peroxidase, fructose dehydrogenase, cellobiose dehydrogenase) and some ironsulphur cluster containing hydrogenases. ${ }^{133}$ However, even for these enzymes a proper orientation of the biomolecule on the suitable electrode surface is necessary for the establishment of effective ET. In this chapter, approaches to the design of suitable surfaces facilitating DET using new materials and various surface functionalisation techniques will be overviewed. More details on the strategies applied to provide effective direct electron communication in bioelectrocatalytic systems can be found in the Review Paper. Further research on ET mechanisms in enzymes are required to modulate ET for the design and development of effective biosensors and biofuel cells based on direct bioelectrocatalysis and for fundamental understanding of ET processes in biological systems. A new electrochemical approach derived from collision-based electrochemistry applicable for an examination of the ET process at a single enzyme molecule, together with standard electrochemical techniques used for investigation of ET mechanisms will be discussed.

\subsection{Surface functionalisation and new electrode materials}

Surface functionalisation with self-assembled monolayers (SAMs) is one approach for anisotropic and oriented immobilisation of enzymes. Use of SAMs for oriented immobilisation of enzymes was proposed by Hill and co-workers in 1980, and has since then become arguably the most commonly used technique to facilitate direct bioelectrocatalysis. ${ }^{134}$ SAMs with a proper composition according to the enzyme utilised, can promote orientation of protein molecules in such a way that the active site is directed towards the electrode surface to facilitate DET according to Marcus theory. ${ }^{3}$ In Fig. 5.1, this approach is demonstrated for the example of nitride reductase, a copper containing enzyme. Composition of the SAM influences the enzyme orientation on the gold electrode. When copper in the active site of the enzyme is oriented towards the electrode surface DET is observed. 


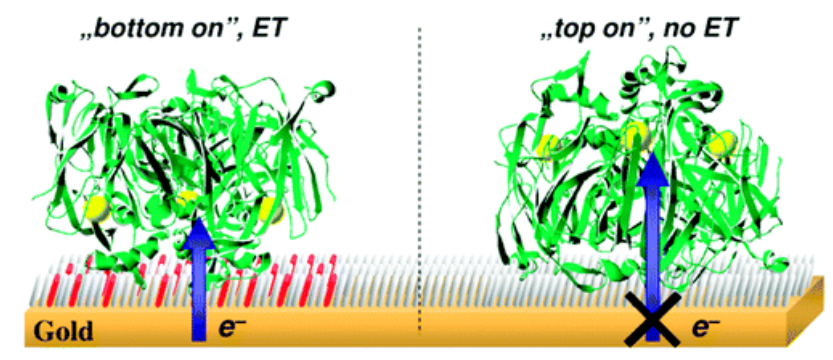

Figure 5. Illustration of the oriented immobilisation of the enzyme molecule on selfassembled monolayers. On the left the electroactive, bottom-on, enzyme orientation on the electrode, for which DET occurs from the modified gold to copper centres within the enzyme molecules, is shown. On the right the electroinactive, top-on, orientation of the enzyme on SAM electrodes, for which direct ET cannot occur because of a lack of electrical coupling between the gold and the redox centres, is presented. Red parts of the SAM on the left scheme demonstrate difference in the composition of the layer. Reprinted with the permission from ${ }^{135}$. Copyright $(C) 2011$ American Chemical Society.

Another popular approach for DET modulation is the entrapment of enzymes in a conducting material, such as sol-gel composites with graphitic nanomaterials ${ }^{136,137}$ or conducting polymers. ${ }^{138,139}$ The conducting matrix acts as a "virtual" electrode surface providing an electrical contact for the active centre of the enzyme. This is illustrated in Fig. 5.2 for the example of laccase immobilised into a well-designed conducting polymer poly(3,4-ethylenedioxythiophene) (PEDOT). ${ }^{139}$ The polymer chains are located close to the copper in the active site of the enzyme ensuring effective electron communication.

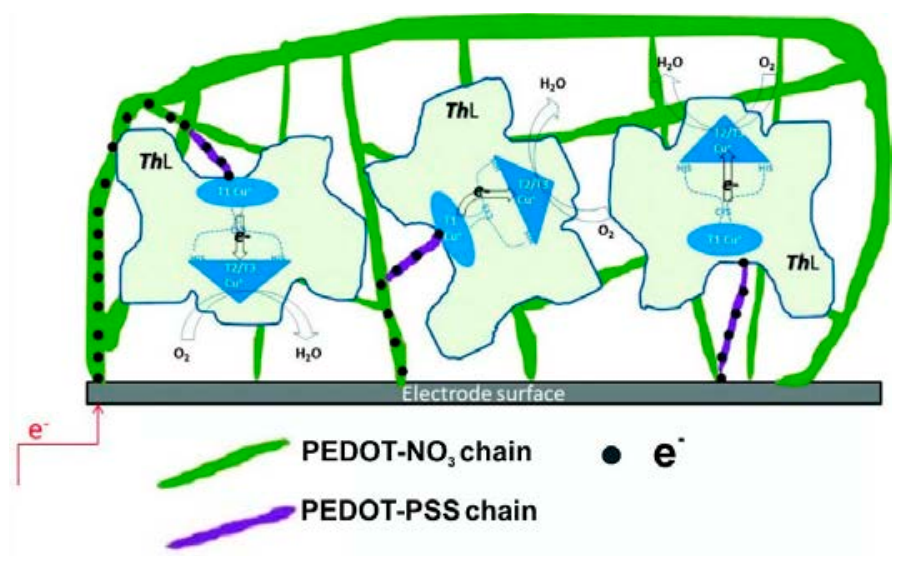

Figure 5.2. Illustration of the ET in the dual-layer-architecture of conducting PEDOT with encapsulated enzyme molecules. Reprinted with modifications from ${ }^{139}$. Copyright (C) 2011 American Chemical Society.

Application of nanomaterials such as nanoparticles, carbon nanotubes and graphene-related materials for electrode functionalisation has attracted the interest 
of researches over recent decades as a promising way to establish effective DET. ${ }^{140}$ The nanodimensions of these new materials permit them to approach the enzyme's active site and support fast and effective ET. One example of DET enhancement on a nanomaterial-functionalised electrode is illustrated in Fig. 5.3 with nitrite reductase. ${ }^{141}$ Nitrite reductase is an enzyme catalysing the reduction of nitrite to ammonia and having a catalytic centre placed close to a hydrophobic domain in the enzyme structure. The hydrophobic domain promotes enzyme adsorption on the hydrophobic carbon nanotubes in an orientation that supports effective electron communication.

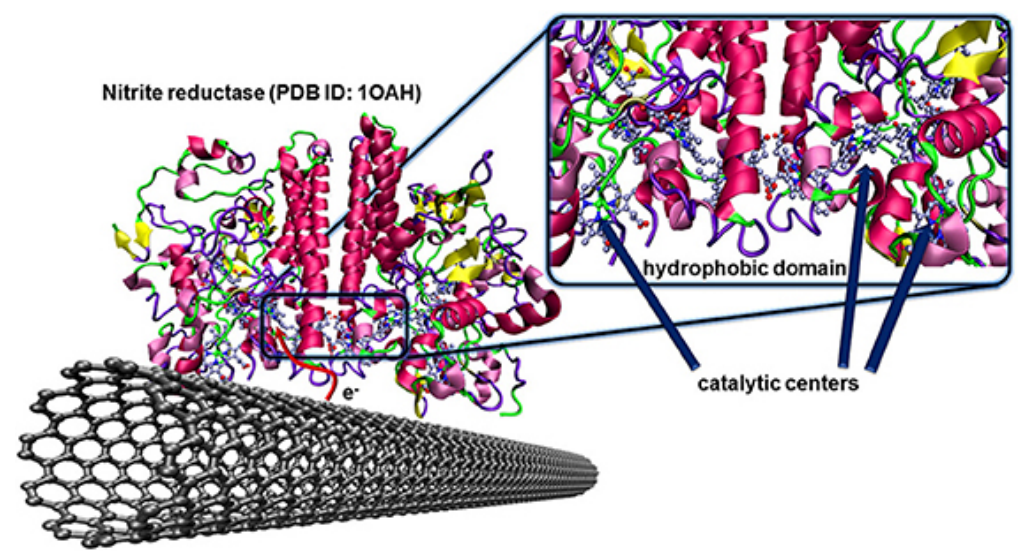

Figure 5.3. Illustration of DET facilitation due to the oriented immobilisation of nitrite reductase on carbon nanotubes via hydrophobic interactions between the enzyme and the carbon nanotube surface. Reprinted with the permission from ${ }^{140}$. Copyright (C) 2014 Holzinger, Le Goff and Cosnier.

The mentioned approaches to establish effective DET in bioelectrocatalytic systems as well as current trends in their applications are discussed in detail in the Review Paper.

\subsection{Investigation of direct electron transfer mechanisms in proteins}

\subsubsection{Standard electrochemical toolkit}

Understanding of the ET mechanisms in redox proteins and determination of parameters that promote DET can significantly contribute to the development of DET-based biosensors, biofuel cell and bioreactors, as well as providing fundamental insights into ET in biological systems. Electrochemical methods are of particular importance among the commonly used techniques for investigations of the ET mechanisms in redox proteins. 
The so called protein film voltammetry (PFV) technique is a powerful technique based on standard voltammetric measurements (see sections 6.2.3, 6.2.4), which makes investigations of interfacial ET kinetics and the organisation of catalytic ET in redox enzymes with multiple catalytic centres possible. ${ }^{142,143}$ In PFV the redox protein is immobilised on the surface of a modified electrode as a thin film, with a monolayer or less coverage (Fig. 5.4). The immobilisation should be performed in such a way that the native structural and reactivity characteristics of the protein are retained. By changing the electrode potential, the catalytic activity of the enzyme can be monitored as a catalytic current.

Substrates, inhibitors, ligands, metal ions etc. all at controlled flux

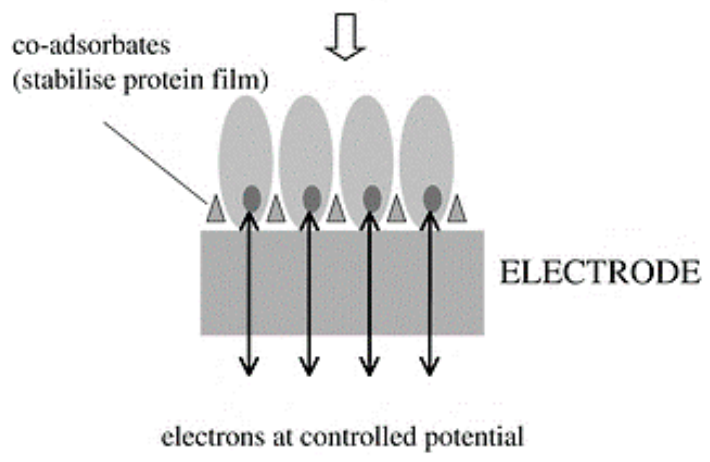

Figure . Illustration of enzyme molecule adsorption on an electrode used in protein film voltammetry measurements. Reproduced from ${ }^{143}$. Copyright $(0)$ The Royal Society of Chemistry 2002.

PFV has a number of advantages compared to spectroscopic methods, which are widely used for redox enzyme studies, including: ${ }^{143}$

- the direct control of the redox centre reactivity by the electrode potential;

- relative simplicity of determination of the number of redox centres, their redox potentials and ET rate constants;

- the possibility to investigate properties of enzymes in various environments ( $\mathrm{pH}$, alternative solvents) by simply changing the solution;

- sample economy, since only a monolayer of the enzyme is required;

- the possibility to investigate fast reactions.

Although PFV is widely used to study the DET mechanisms of redox enzymes, it deals with large ensembles of enzyme molecules. Studies at the single molecule level can give some new insights into the mechanism of DET and ways to facilitate it. PFV can be scaled down towards single enzyme molecule investigation by applying nanoelectrodes with sizes comparable to the size of the single enzyme molecule (Fig. 5.5). This approach, however, due to technical and instrumental limitations, currently only allows a resolution of $8-46$ biomolecules. ${ }^{144}$ 


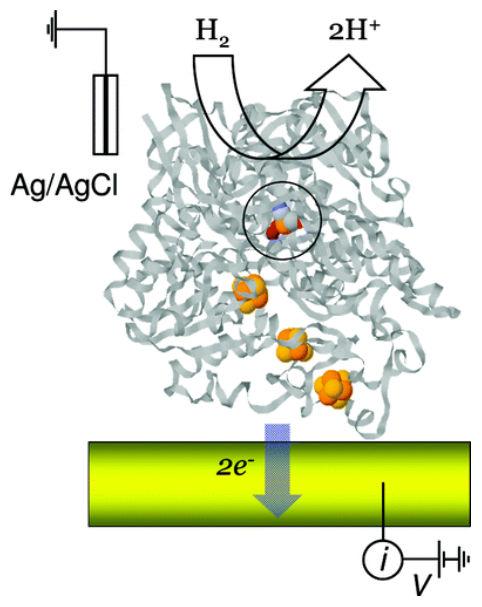

Figure 5.5. Schematic illustration showing a single redox-active enzyme molecule ([NiFe]-hydrogenase catalysing hydrogen oxidation) adhered to a nanosized electrode . Reprinted with permission from ${ }^{144}$. Copyright (C) 2008 American Chemical Society.

In Paper VII, we suggest the use of collision-based electrochemistry as an alternative, or rather complementary, approach to study the DET mechanism at single molecule level.

\subsubsection{Collision-based electrochemistry}

Collision-based electrochemistry measures particle impacts on electrodes. The first works in this field have involved impacts that are capacitive in nature. Scholz was the first who studied the collisions of liposomes with a mercury electrode by recording current transients observed when liposomes contacted the electrode, burst and spread on its surface. ${ }^{145}$ Heyrovsky in 2006, demonstrated detection of faradaic current transients during collisions of metal colloids particles for the first time. ${ }^{146}$ The methodology was further developed by Bard ${ }^{147}$ and Compton ${ }^{148}$ using two different approaches.

In the approach suggested by Bard, single nanoparticle (NP) collisions driven by diffusion at microelectrodes, were observed via electrocatalytic amplification. The key aspect in this approach is the right choice of an indicator reaction. The redox reaction should not occur at the selected microelectrode in the absence of NPs under the applied potential or at the NP when not in contact with the electrode. When the NP collides with the electrode, the catalytic reaction occurs that leads to characteristic current-time transients for a particle-catalysed reaction (Fig. 5.6). The current transients (Fig. 5.7) can be correlated to the particle size, the particle residence time and the nature of the particle interaction with the electrode surface. ${ }^{147}$ The mechanism of the electrocatalytic amplification provides an indirect method for the detection of the NPs. 


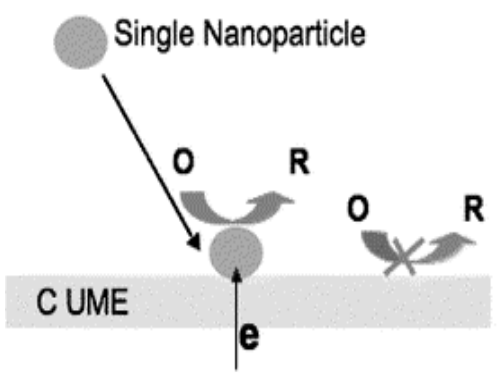

Figure 5.6. Indirect method for the detection of nanoparticle collisions. Schematic illustration of the electrocatalytic amplification mechanism. Reprinted with permission from ${ }^{147}$. Copyright (C) 2007 American Chemical Society.

The current response in the mechanism of the electrocatalytic amplification can have two different shapes, a current staircase and a current spike (or blip) response (Fig. 5.7). The staircase response occurs when the particle sticks to the electrode surface and remains on the surface during the time of the experiment, so the stepwise accumulation of individual catalytic particles on the electrode surface is observed (Fig. 5.7a). The spike response occurs when a particle collides with the electrode surface, but does not remain on the surface for a long time. Spikes can also be observed if there are some processes that deactivate the electrocatalytic reaction are taking place (Fig. 5.7b). ${ }^{149}$
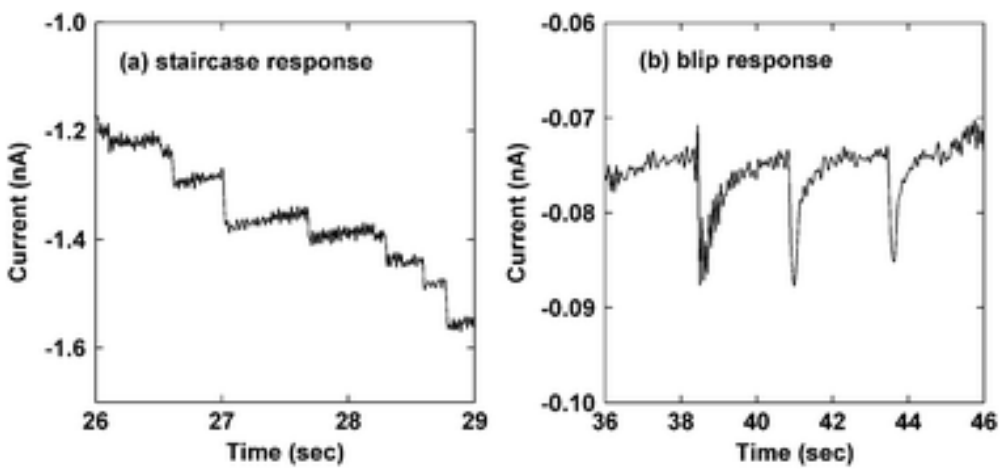

Figure 5.7. Typical responses of single particle collisions detected by the electrocatalytic amplification. a. Staircase response. b. Blip (spike) response. Reproduced from ${ }^{149}$ with permission from the PCCP Owner Societies. Copyright (C) 2011 Royal Society of Chemistry.

Another approach developed by Compton uses direct detection of a NP oxidation or reduction on the electrode surface during a collision (Fig. 5.8a). ${ }^{148}$ The charge passed during the spike response, calculated as the integral of the spike current by time, is quantitatively related to the size of the NP and therefore size distributions 
could be extracted from the amperometric measurements of particle collisions. This method can be also used to study NP aggregation in time (Fig. 5.8b).

a

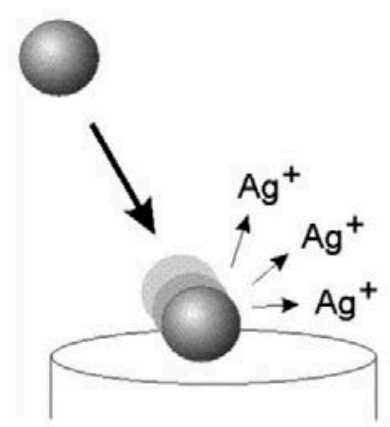

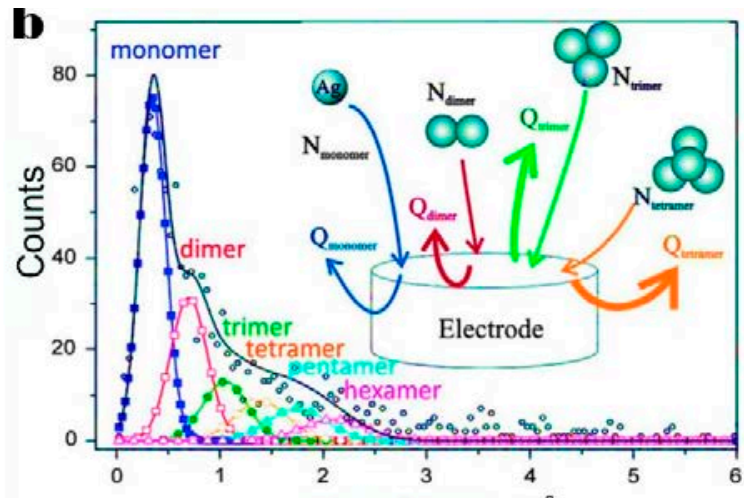

No. atoms $/ 10^{6}$

Figure 5.8. Direct method for the detection of nanoparticle collisions. a. Scheme of the process occurring during a nanoparticle $(\mathrm{Ag})$ collision. The nanoparticle is oxidised during the collision leading to the formation of silver ions. Reproduced with permission from ${ }^{150}$. Copyright (C) 2012 Royal Society of Chemistry. b. Determination of the agglomeration state of silver nanoparticles by calculation of the charge per impact spike. Reproduced from ${ }^{151}$ with permission from the PCCP Owner Societies. Copyright (C) 2013 Royal Society of Chemistry.

Collision-based electrochemistry is an important emerging field applied for the detection and characterisation of various single "hard" nanoparticles, ${ }^{152}$ detection of biomolecules labelled with nanoparticles ${ }^{153}$ and for investigation of "soft" particles, such as micelles, emulsion droplets ${ }^{154}$ and other nanodroplets. ${ }^{155}$ In Paper VII, we suggest for the first time to apply the electrocatalytic amplification approach of collision-based electrochemistry for DET observation of single enzyme molecules. (Fig 5.9).

a

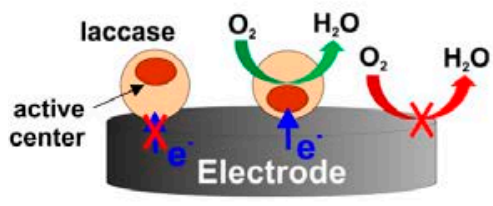

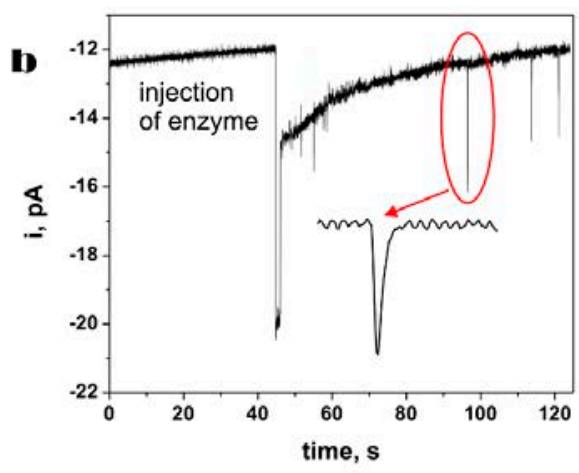

Figure 9 a. Scheme of collision-based electrochemistry applied for the detection of DET from a single enzyme molecule $b$. The observed current responses for individual laccase molecules. 
Laccase was used as a model enzyme in our work. The basic idea is that if a laccase globule hits a gold ultramicroelectrode in the correct orientation then the electrode will turn over the enzyme and allow catalysis of the substrate - oxygen (Fig. 5.9). The observed spikes are due to DET between the enzyme active site and the electrode. The experimental data provides information for the calculation of enzyme turnover rates for single enzyme molecules and investigation of the factors influencing the efficiency of DET. The suggested approach can give some insights into the direct ET mechanisms and determine parameters that will facilitate DET in bioelectrocatalytic systems. 


\section{6 \\ EXPERIMENTAL METHODS}

\subsection{Immobilisation techniques}

Immobilisation in bioelectrocatalytic systems refers to biocatalyst retention in close proximity to the electrode surface while maintaining its catalytic activity. Generally, there are 4 main methods for enzyme immobilisation (Fig. 6.1): adsorption, entrapment, covalent bonding and cross-linking. ${ }^{156}$ Enzyme immobilisation on the electrode surface leads in most cases to the enhancement of its stability and the electron coupling between the active site and the electrode. The main immobilisation techniques and methods used in the thesis are briefly described in the following text.

\subsubsection{Main methods of immobilisation}

Adsorption

Adsorption is the simplest and fastest way to construct a biocatalytic layer without significant structural changes of the enzyme globules. The enzyme globule can be held on the surface of the electrode via electrostatic interactions, Van der Waals forces or via the formation of covalent bonds. ${ }^{157}$ One of the main drawbacks of the adsorption method of immobilisation is the low operational stability of the immobilised layer due to enzyme release to the solution. To overcome this drawback layer-by-layer techniques are used. ${ }^{158}$ An additional protective layer that prevents the enzyme from leaching from the electrode surface then covers an enzymatic layer. However, such a layer usually decreases the biosensor sensitivity. Another disadvantage is the problem to establish effective electron communication. Direct adsorption of proteins on the electrode leads to electrode fouling due to a partial denaturation of the enzyme molecules and thus being adverse for DET. ${ }^{1}$ However, adsorption on a SAM modified electrode can improve direct electron communication (Fig. 5.1). In case of MET, adsorption is usually insufficient for the mediator immobilisation due to high mediator leakage. This method is used for mediated systems with the mediator in the solution or in a combination with other techniques for mediator immobilisation. 


\section{Entrapment}

Entrapment is a method of immobilisation that refers to the enclosure of enzyme molecules behind a membrane or in a gel or a polymer matrix. The main cons of this method are hindered diffusion of the substrate through the matrix leading to reaction delay and possible loss of bioactivity through pores in the matrix. The matrices commonly used include polyacrylamide, starch gels, nylon, silastic gels, conducting polymers, etc. The advantages of the method are the possibility to include enzyme mediators in the same biocatalytic membrane ${ }^{159}$ for the MET establishment and a tuneable ion selectivity of the membrane, which helps to avoid interferences. ${ }^{160}$ This immobilisation method is also used to support efficient DET. In this case, enzyme molecules are entrapped in conducting matrixes (Fig. 5.2)

\section{Covalent bonding}

In this method, the bond occurs between a functional group of the biomolecule and the support matrix or the electrode. During the immobilisation, the functional groups of the enzyme that provide catalytic activity should not be involved in the bonding. It requires mild conditions under which reactions are performed. Covalent immobilisation of biomolecules on the electrode surface provides high stability of the biocatalytic layer.$^{161}$ The main disadvantage of the method is a high possibility to harm the catalytic activity of the enzyme globule during immobilisation. ${ }^{162}$ Covalent bonding to SAMs is often used to establish effective DET (Fig. 5.1). Covalent attachment of a mediator usually leads to less efficient MET than in case of a diffusional mediator. However, a proper design of ET pathways can provide high electron transfer rates.
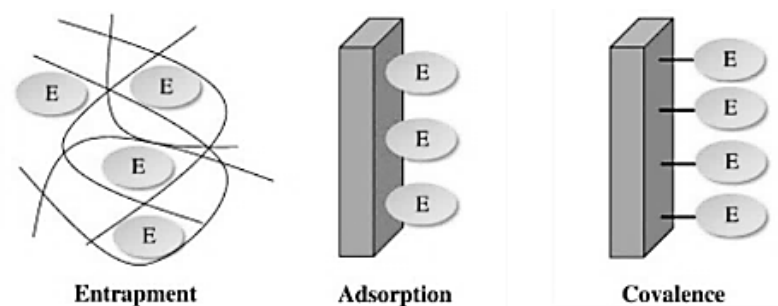

Adsorption

Covalence

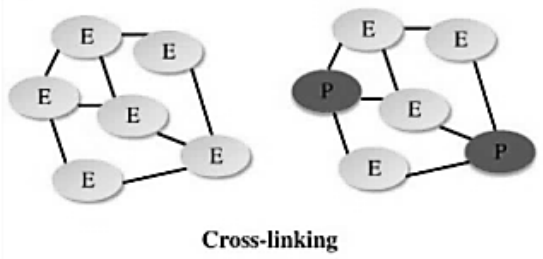

Figure 61. Schematic representation of the main different methods of enzyme immobilisation. E - enzyme, $\mathrm{P}$ - inert protein. Reproduced with modifications from ${ }^{76}$. Copyright (C) 2011 Elsevier Inc. 


\section{Cross-linking}

In this method, biomolecules are chemically bonded to each other or to a crosslinking agent. The method is attractive due to its simplicity and strong stabilisation of the adsorbed material. The main drawback is the possibility to lose enzymatic activity due to deformation of the enzyme at the active site. Glutaraldehyde is the mostly used agent for cross-linking. The compounds used for cross-linking could negatively affect the enzyme activity, especially at high concentrations. ${ }^{76}$ This method can be used only for the enzyme immobilisation, so it should be combined with other methods for the mediator immobilisation. The enzyme immobilisation by cross-linking is often combined with entrapment in carbon paste. ${ }^{76}$

\subsubsection{Immobilisation methods used in the work}

\section{Sol-gel process immobilisation from water-organic mixtures}

In Papers I-IV, enzyme entrapment in a sol-gel matrix containing the hydrophobic mediator from a water-organic mixture with a high content of organic phase ${ }^{104}$ was used (see section 4.1.3). Aqueous solution of the appropriate enzyme (GOx, or ChOx, or LOx) was suspended in an isopropanol solution of APTEOS containing PTZ. The resulting mixture was applied with a syringe onto the working electrode to cover its entire surface and dried at $4^{\circ} \mathrm{C}$ (Fig. 6.2).

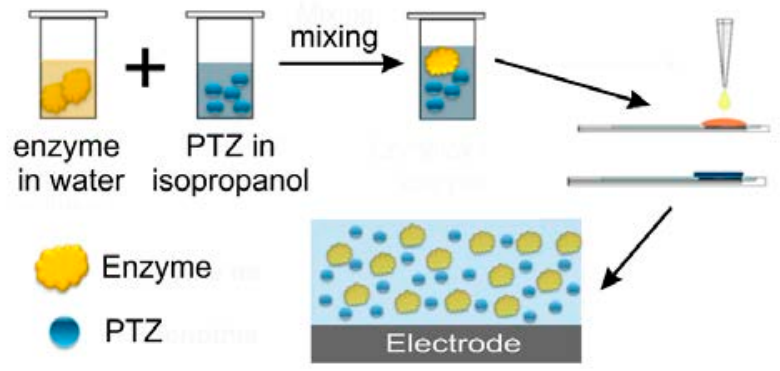

Figure 62. Scheme of the sol-gel immobilisation process.

\section{EDC/NHS immobilisation}

In Paper VI, the enzyme laccase was covalently attached to the surface of microelectrode arrays fabricated and characterised in Papers IV, $\mathbf{V}$ via N-ethylN'-(3-dimethylaminopropyl)carbodiimide/ N-hydroxysulfosuccinimide (EDC/NHS) chemistry. EDC reacts with NHS and forms an NHS-ester which allows conjugation with the amine groups on the surface of the enzyme globule through formation of the peptide bond. ${ }^{163}$ For EDC/NHS immobilisation of laccase, electrodes were first anodised to introduce oxygen containing groups that can be used for coupling with EDC (Fig. 6.3). 


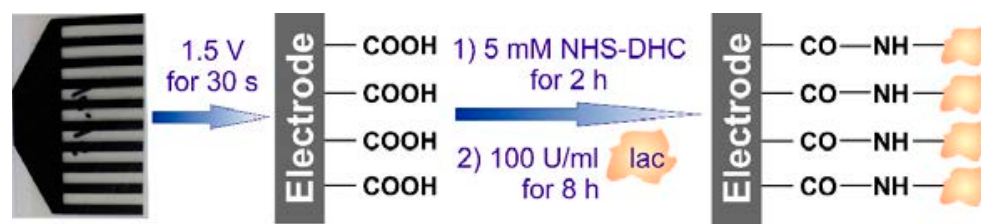

Figure 63 Scheme of the EDC/NHS immobilisation of laccase on the surface of the microelectrode array.

\subsection{Electrochemical techniques}

Electrochemical approaches represent the basis of the experimental techniques used in all papers and are therefore discussed here in detail.

\subsubsection{Basic electrochemical principles}

At the electrode surface two main processes can take place: capacitive and Faradaic. ${ }^{164}$

\section{Capacitive process}

The electrode has some charge density, which occurs due to an excess or deficiency of electrons at the electrode surface. In order to keep electrical neutrality of the interface the electrolyte ions and solvent dipoles have to redistribute in such a way that the solution near to the electrode surface possesses an equal but opposite charge. This layer near to the interface is called the electrical double layer. The charge separation in the double layer creates a capacitor associated with a potential difference across the interface and produces a capacitive current $\left(I_{c}\right)$ :

$$
I_{c}=C_{d l} \frac{d E}{d t}
$$

where $C_{d l}$ is the double layer capacitance. $I_{c}$ contributes to the total current measured in the experiment but it is not related to the charge transfer process. ${ }^{164}$

\section{Faradaic process}

The faradaic current is the result of the electrochemical reactions on the electrode surface and heterogeneous ET at the electrode/solution interface. The charge transfer process with transfer of electrons can be presented as follows:

$O+n e^{-} \leftrightarrow R$

where $\mathrm{O}$ is the oxidised species, $\mathrm{R}$ is the reduced species and $\mathrm{n}$ is the number of electrons transferred. 
The dependence of the electrode potential for the electrochemical reaction (6.2) on the activities (effective concentrations) of the oxidised $\left(a_{0}\right)$ and reduced $\left(a_{R}\right)$ species can be described by the Nernst equation: ${ }^{164}$

$E=E^{0}+\frac{R T}{n F} \ln \frac{a_{O}}{a_{R}}$

where $R$ is the gas constant $\left(8.3144621(75) \mathrm{J} \mathrm{mol}^{-1} \mathrm{~K}^{-1}\right), T$ is the thermodynamic temperature, $F$ is the Faraday constant $\left(9.64853399(24) \times 10^{4} \mathrm{C} \mathrm{mol}^{-1}\right)$. $E_{0}$ is the standard electrode potential of the electrochemical reaction which is defined as the electrode potential of reaction (6.1) when $a_{0}=a_{R}=1 .{ }^{164}$

In electroanalytical experiments, it is usually more convenient to deal with concentrations (C) of the electroactive species rather than their activities, as a generalised quantitative parameter developed for non-ideal chemical systems. The activity coefficient $\gamma$ relates the concentration of an ion to its activity according to following equation:

$a=\gamma C$

Thus, the Nernst equation is more often used with concentrations: ${ }^{165}$

$E=E^{0^{\prime}}+\frac{R T}{n F} \ln \frac{C_{O}}{C_{R}}$

where $E^{0^{\prime}}$ is called the formal potential.

$E^{0^{\prime}}=E^{0}+\frac{R T}{n F} \ln \frac{\gamma_{O}}{\gamma_{R}}$

\section{Electrode processes}

In the description of the electrode processes, it is necessary to consider the transport of species to the electrode surface as well as the electrode reaction itself. This transport can be provided by diffusion, convection or migration. In electroanalytical experiments, the conditions are chosen in such way that only transport by diffusion occurs. This leads to the scheme of electrode processes illustrated in Fig. 6.4.

It is usually possible to divide electrode processes in processes controlled by diffusion and processes controlled by kinetics of the electrode reaction. This means that in the first case, the rate of mass transport to the electrode surface is the slowest step of the electrode processes and it determines the rate of the overall process. In the second case, diffusion is much faster than the electrode reaction and the rate of the process is determined by the electrode kinetics. Such considerations allow significant simplifications of the equations describing the electrode processes. 


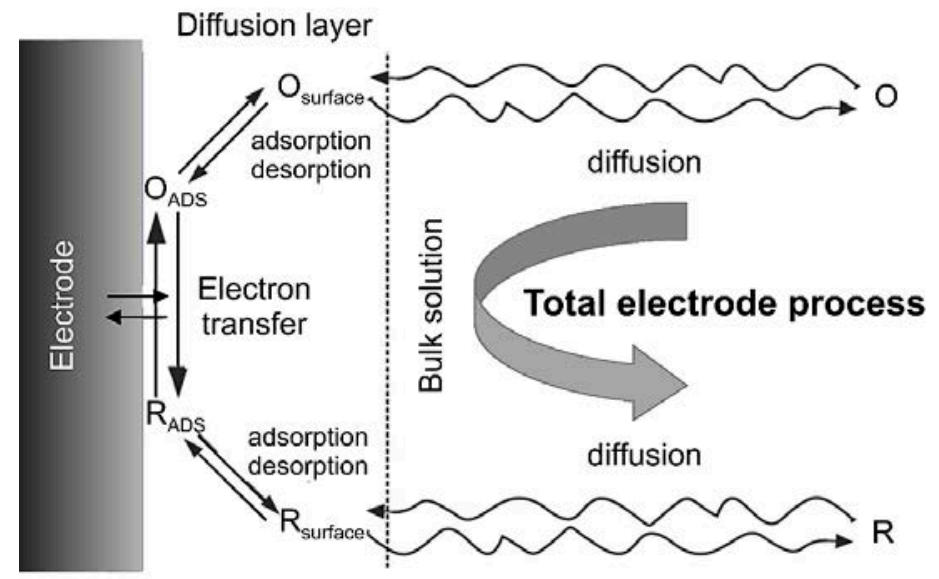

Figure 6.4. Scheme of electrode processes.

The electrode processes are often controlled by diffusion, since the electrode reaction is usually very fast compared to the diffusion. Currents that are not controlled by diffusion (steady-state currents) can be achieved with hydrodynamic electrodes (see section 6.2.6) and with microelectrodes (see section 4.2).

\subsubsection{Experimental set-up}

For all electrochemical techniques the same experimental set-up, described below, was used.

\section{Electrochemical cell}

The current is determined by the rate of an electrochemical reaction at the working electrode. According to the law of energy conservation, the same current must flow through a counter or auxiliary electrode. Thus, an electrochemical experiment requires an electrochemical cell (Fig. 6.5), a vessel with electrolyte in which two independent electrodes are placed and linked with a measuring device through the external wires to form an electrical circuit. Thus, the chemical processes occurring in the cell might be studied and controlled by the measuring device. If the redox reaction in the cell can occur spontaneously, the cell is called a galvanic cell. If the redox reaction in the cell occurs as a result of applied chemical energy, the cell is called an electrolytic cell.

In electrochemical experiments, the reaction on the auxiliary electrode is usually unknown and is not rate determining. Therefore, the dependence of the electrode potential-current on this electrode cannot be used for determination of thermodynamic parameters. Hence, classical electrochemical experiments require a third electrode, a reference electrode. Current is not normally allowed to flow through the reference electrode and the electrode is made in such way that its 
potential is constant and stable. Since the potential of the working electrode is always measured relative to the reference electrode, the electrochemical reaction on the reference electrode can theoretically be considered as a counterpart. The potential of the reference electrode is measured relative to the standard hydrogen electrode (SHE) potential, which is chosen as the zero level. ${ }^{166}$

In the simplest experiments, the cell has a two- or a three-electrode configuration. In my work, a two-electrode configuration was used for the self-powered biosensor characterisation in Paper III, as it is the standard configuration for BFCs. For all other electrochemical measurements, a three-electrode cell was used. A potentiostat was used to control the applied potential and record the current on the working electrode.

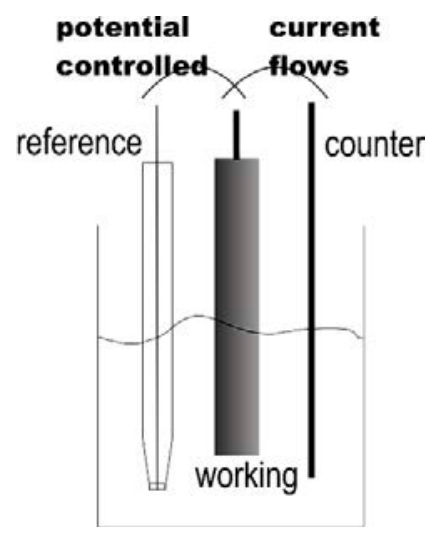

Figure 6.5. Scheme of the electrochemical cell.

\section{Working electrodes}

The working electrodes used in this work were made of carbon and gold (Fig. 6.6). Carbon is arguably the most widely used material for construction of bioelectrocatalytic systems. ${ }^{167}$. Even though carbon materials have been extensively studied in the past as electrode materials in electrochemistry, recent innovations in material science of carbons brought them to light again as materials for biosensor construction. Screen-printed carbon macrostructures (Papers I-VI), carbon microelectrodes (Paper IV-VI) and carbon electrodes with large surface area (Paper III) possess particular advantageous properties compared with the graphitic carbon electrodes used in the early 1990s and enabled development of novel bioelectrocatalytic systems. In Paper VII gold microelectrodes were used for detection of DET of individual enzyme molecules since they possess low background noise compared to carbon electrodes, due to higher surface smoothness. 
a

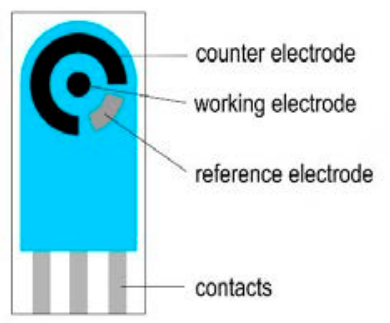

d

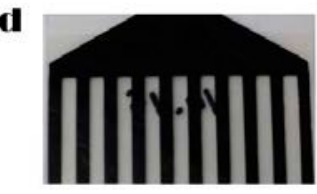

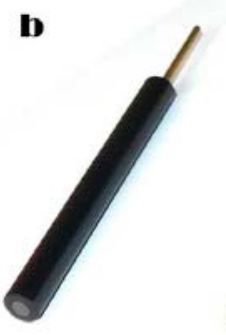

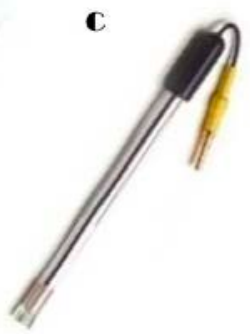

$\mathbf{e}$

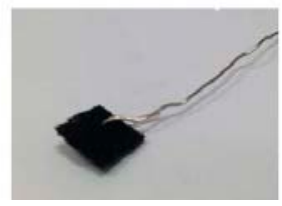

Figure 6.6. Working electrodes used in the work. a. Scheme of the screen-printed threeelectrode system. b. Photo of glassy carbon electrode. c. Photo of gold microelectrode. d. Photo of screen-printed graphite microband array. e. Photo of carbon cloth electrode.

\subsubsection{Potential sweep techniques}

Potential sweep techniques are based on scanning a chosen region of potential and measuring the resulting current due to the electrode processes.

\section{Linear-sweep voltammetry}

If we perform linear-sweep voltammetry (LSV) for investigation of the reaction (6.2) and assume that this reaction is reversible (an assumption used in the reactions investigated in this work), the potential of the working electrode should be swept from value $E_{1}$ at which $O$ cannot undergo reduction to a potential $E_{2}$, where the reaction occurs rapidly. Fig. 6.7 shows the scheme of the potential sweeping and the corresponding current response.

The current response has a peak-shaped form. The current starts to rise when the potential reaches the value at which electrode reaction can occur. Due to fast electrode reaction at potentials higher than this initial potential and slow diffusion of electroactive species, the current finally decreases as a result of depletion (diffusion limitation). ${ }^{168}$ The peak current in LSV can be described by the RandlesSevcik equation: ${ }^{168}$

$$
I_{p}=0.4663 n F A C\left(\frac{n F v D}{R T}\right)^{1 / 2}
$$

where $n$ is the number of electrons transferred, $A$ is the electrode surface area, $D$ is the diffusion coefficient of the electroactive species, $C$ is the concentration of the electroactive species in solution far from the electrode surface and $v$ is the scan rate. 

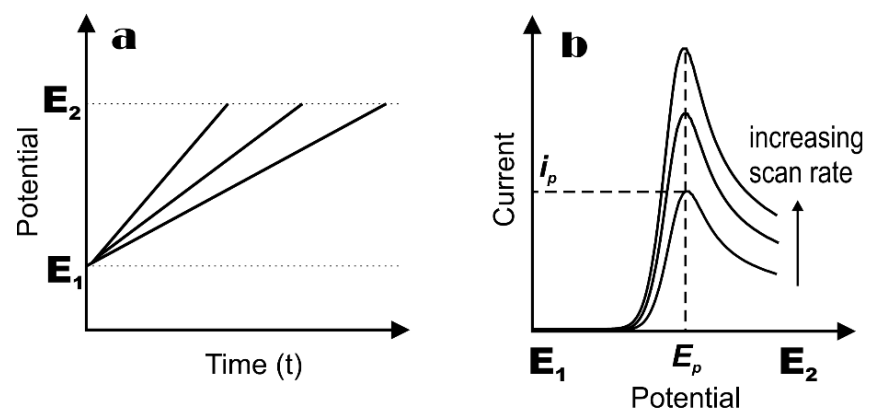

Figure 6.7. Linear sweep voltammetry. a. The potential sweep. b. Corresponding current response for the reaction (2.1).

LSV at low scan rates was applied for the determination of the OCP and the ratedetermining counterpart of the self-powered biosensor in Paper III (polarisation curve) and for qualitative characterisation of direct and mediated bioelectrocatalysis effectiveness on laccase-modified microelectrodes in comparison with commonly used carbon macrostuctures in Paper VI.

\section{Cyclic voltammetry}

Cyclic voltammetry (CV) can be described as an extension of LSV. When the potential reaches the value $E_{2}$, the direction of the sweep is reversed and the potential is scanned back to the value $E_{1}$. Fig. 6.8 illustrates the potential sweeping and the resulting cyclic voltammogram of the process.
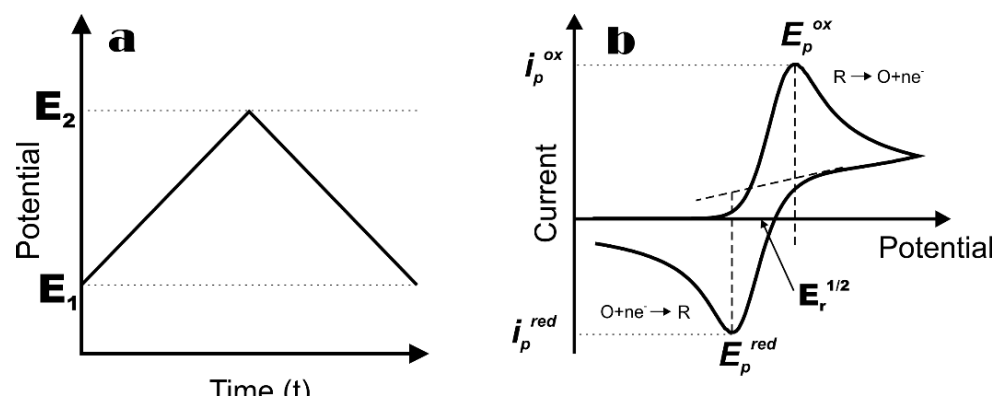

Figure 6.8. Cyclic voltammetry. a. The potential sweep. b. Corresponding cyclic voltammogram for the reaction (2.1).

For a reversible electrode reaction, the peak current in CV can be described by the Randles-Sevcik equation as for LSV, eq. (6.7). The peak currents of the forward and reverse scans have the same magnitude and the peak to peak separation is described by: ${ }^{168}$

$$
E_{p}{ }^{o x}-E_{p}^{r e d}=2.218 \frac{R T}{n F}
$$


$E_{1 / 2}^{r}$, the half-wave potential (Fig. 6.8), i.e. the potential in the middle of the peaks, is an important characteristic as it is related to the formal potential of the reaction $\mathrm{E}^{0}: 164$

$$
E_{1 / 2}^{r}=E^{0^{\prime}}+\frac{R T}{n F} \ln \left(\frac{D_{R}}{D_{O}}\right)^{s}
$$

where $D_{R}$ and $D_{O}$ are the diffusion coefficients of the reduced and oxidised forms, respectively; $s=1 / 2$ for stationary electrodes in stationary solutions, $s=1$ for microelectrodes, $s=2 / 3$ for hydrodynamic electrodes (rotating disk electrode). ${ }^{164}$

$\mathrm{E}^{\mathrm{r}}{ }_{1 / 2}$ of the $\mathrm{CV}$ can be calculated from the potentials of the peaks:

$$
E^{r}{ }_{1,2}=\frac{E_{p}^{o x}+E_{p}^{r e d}}{2}
$$

CV was used for determination of the PTZ diffusion coefficient in the siloxane gel from the Randles-Sevcik equation and for investigation of the catalytic effect in Paper I. In Paper II, the diffusion coefficient of PTZ in acetonitrile, and the catalytic constant for the enzymatic reaction, $k_{s}$, was calculated from data of $\mathrm{CV}$ measurements using the Nicholson-Shain equation: ${ }^{169}$

$$
k_{f}=k_{s}[G O x]=a\left(\frac{i_{c}}{i_{p}}\right)^{2}
$$

where $\mathrm{a}=n F v / R T, v$ is the scan rate, $n$ is the number of electrons transferred, $i_{c}$ and $i_{p}$ are the catalytic and peak currents of the mediator measured from $\mathrm{CV} b$ and a in Fig. 6.9, respectively. Plots of $\left(i_{c} / i_{p}\right)^{2}=k_{f} / a$ vs $1 / v$ for different concentrations of enzyme allows determination of $k_{f}$, a pseudo-first-order rate constant. Finally, a plot of $k_{f} v s$ concentration of the enzyme is used to calculate $k_{s}$.

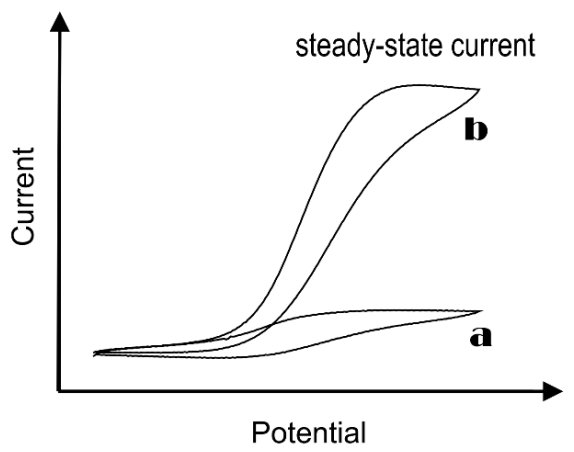

Figure 69 Typical cyclic voltammogram of a mediator. a - No enzymatic reaction occurs. $b$ - Mediator response as a result of an enzymatic reaction. 
Also in Paper II voltammetry was used to assess enzyme stability in a wateracetonitrile solution. In Paper IV-VI, CV measurements were employed for characterisation of microelectrodes, where, in Papers IV and VI, measurements under faradaic and in Paper $\mathbf{V}$, under capacitive conditions, were performed.

\subsubsection{Differential pulse voltammetry}

Differential pulse voltammetry can be considered as a derivative of linear sweep voltammetry. In DPV the potential applied to the working electrode has a form as shown in Fig. 6.10a. DPV measures the difference between the currents sampled before and at the end of a pulse. The current difference plotted against the sweeping potential yields a differential voltammogram featured with a peak-shaped response of the electrode reaction (Fig. 6.10b). The potential of the peak is related to the half-wave potential (see LSV): ${ }^{164}$

$$
E_{p}=E^{r} 1 / 2-\frac{\Delta E}{2}
$$

where $\Delta \mathrm{E}$ is the pulse amplitude. The peak current $\left(I_{p}\right)$ can be described as follows:

$$
\begin{aligned}
& I_{p}=\frac{n F A D^{1 / 2} C}{\left(\pi t_{m}\right)}\left(\frac{1-\sigma}{1+\sigma}\right) \\
& \sigma=\exp \left(\frac{n F}{R T} \frac{\Delta E}{2}\right)
\end{aligned}
$$

where $t_{m}$ is the sampling time and $C$ is the concentration of the electroactive species.
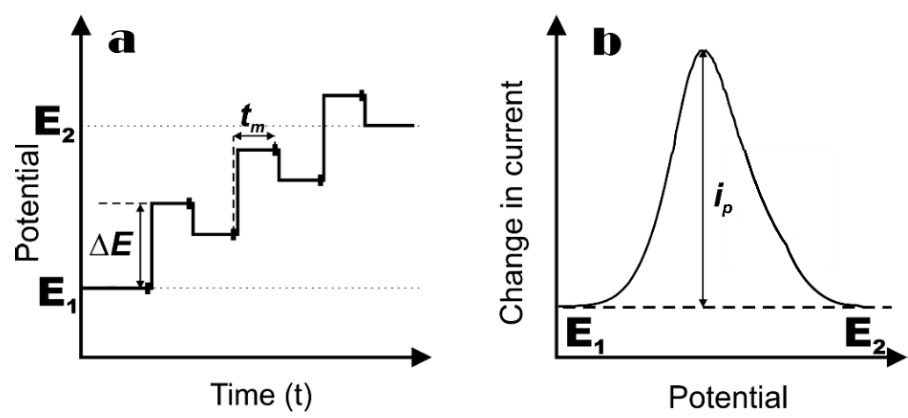

Figure 6.10. Differential pulse voltammetry. a. The variation of the applied potential. b. Current response.

The dependence of the peak current on the concentration can be used for characterisation of the analytical performance of an electrode. DPV is more sensitive than LSV and CV in terms of detection of electroactive species as it 
allows contributions of the capacitive current due to measurements of current difference to be eliminated.

DPV was used in Paper IV to demonstrate electroanalytical performances of the screen-printed microband arrays with different geometries and with ascorbic acid detection as an example. In Paper VI, DPV was applied for the detection of oxygen groups introduced during anodisation of carbon electrodes.

\subsubsection{Potential step chronoamperometry}

Being a complementery approach to potential sweeping techniques, chronoamperometry measurements, where the current is sampled while the potential of the working electrode is instantly stepped between the values $E_{1}$ and $\mathrm{E}_{2}$ for the reaction (6.2) (Fig. 6.11a), offer time-resolved voltammetric data.

Immediately after the step, a large current is detected which falls with time due to depletion of the electroactive species near the electrode surface (Fig. 6.11b). The Cottrell equation describes the dependence of the current response on time for electrodes with planar diffusion: ${ }^{168}$

$|i|=\frac{n F A D_{O}^{1 / 2}[O]}{\pi^{1 / 2} t^{1 / 2}}$

where $[O]$ is the bulk concentration of $\mathrm{O}$ (eq. (6.2)).
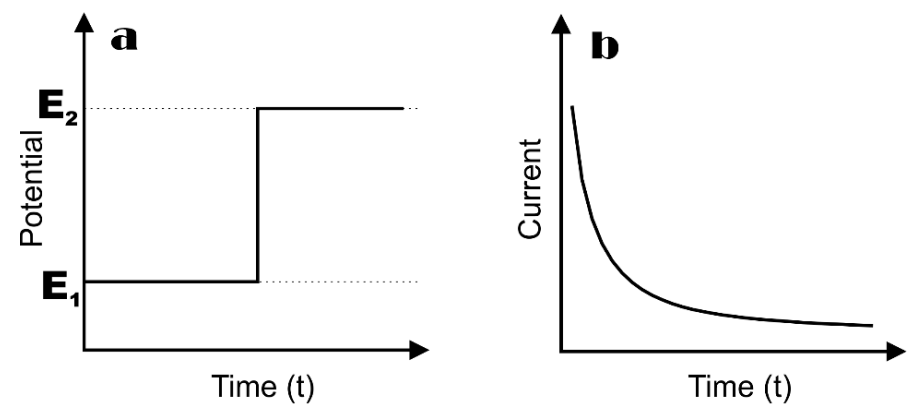

Figure 6.11. Chronoamperometry. a. The variation of the applied potential. b. Current response.

Double step chronoamperometry is a commonly used multistep technique. In this case, the working electrode is first held at an initial potential. Then it is stepped to a specific potential for a period of time. After the first step, the potential is stepped back to the initial potential.

Chronoamperometry was used in Papers II, III and VI for evaluation of the analytical performances of GOx, LOx, ChOx based biosensors, the self-powered biosensor and laccase-based biosensor, respectively. Double potential step 
chronoamperometry was employed for the investigation of the ET process between the enzyme and PTZ in Paper II. In Paper IV and V, amperometry was applied to calculate the surface area of microelectrodes. In Paper VII, chronoamperometry was used to observe DET between single enzyme globules and an electrode during collisions.

\subsubsection{Measurements on hydrodynamic electrodes}

Hydrodynamic electrodes are electrodes with the mass transport process dominated by convection. There are two common types, the rotating disk electrode and the wall-jet electrode.

\section{Rotating disk electrode}

The rotating disk electrode (RDE) used in this work is a glassy carbon disk electrode in a plastic cylinder which can rotate at various constant speeds. The Reynolds number, a parameter, which allows to judge whether the flow is turbulent or laminar, for a $\mathrm{RDE}$ is given by ${ }^{168}$

$$
\operatorname{Re}=\frac{\omega r_{c}{ }^{2}}{v}
$$

where $r_{c}$ is the radius of the cylinder, $\omega$ is the angular frequency and $v$ is the viscosity of the solution. If the Reynolds number does not exceed $10^{5}$ the flow in the solution is laminar (Fig. 6.12a). Laminar flow in the cell is a required condition for RDE electrochemical measurements.
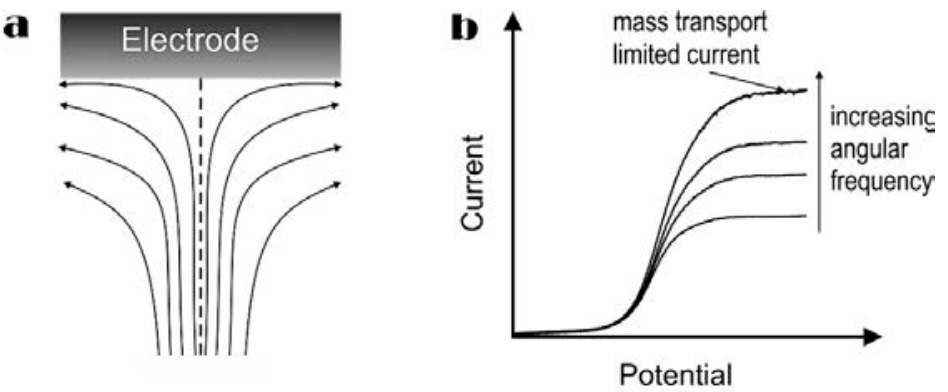

Figure 6.12. RDE measurements. a. Illustration of laminar flow. b. Current-potential curves of PTZ recorded in acetonitrile solution at different rotating rates.

Fig. 6.12b shows typical voltammograms obtained for a rotating disk electrode. In contrast to LSV or CV measurements on stationary electrodes, no peaks are observed for the RDE. The current, and therefore the reaction rate does not decrease with increasing potential as there is no depletion effect on the RDE. The current is maintained by a convective flow of electroactive species to the electrode surface and controlled by the mass transport. This mass transport-limiting current is given by Levich equation: ${ }^{170}$ 
$I_{L}=0.62 n F A C D^{2 / 3} v^{-1 / 6} \omega^{1 / 2}$

where $C$ is the concentration of electroactive species and $v$ is the viscosity of the solution.

The Levich equation was used in Paper II for the determination of the diffusion coefficient of PTZ in acetonitrile solutions.

RDE voltammetry is a convenient tool for kinetic studies of electrocatalytic reactions. The value of the ET rate constant, $k_{s}$, for eq. 4.2 can be determined using the following equation: ${ }^{171}$

$$
\frac{I_{c a t}}{I_{L}}=1.61\left(\frac{v}{D}\right)^{1 / 6}\left(\frac{k_{s} C}{\omega}\right)^{1 / 2}
$$

where $I_{c a t}$ is the limiting current measured in presence of the catalytic reaction and $I_{L}$ is the limiting current measured in absence of the catalytic reaction.

RDE voltammetry was used in Paper II for the calculation of the catalytic rate constant of the mediated process for PTZ and GOx in acetonitrile.

\section{Wall-jet electrode}

The wall-jet electrode used in this work was a screen-printed electrode placed in a flow-injection system so that a fine jet of solution ran into the centre of the electrode and spread out radially (Fig. 6.13a,b). As can be seen from Fig. 6.13a, only the solution from the incoming jet can reach the electrode surface. In flow injection systems, the analyte contacts the electrode only for a short time after injection and this leads to a peak-shaped response (Fig. 6.13c).
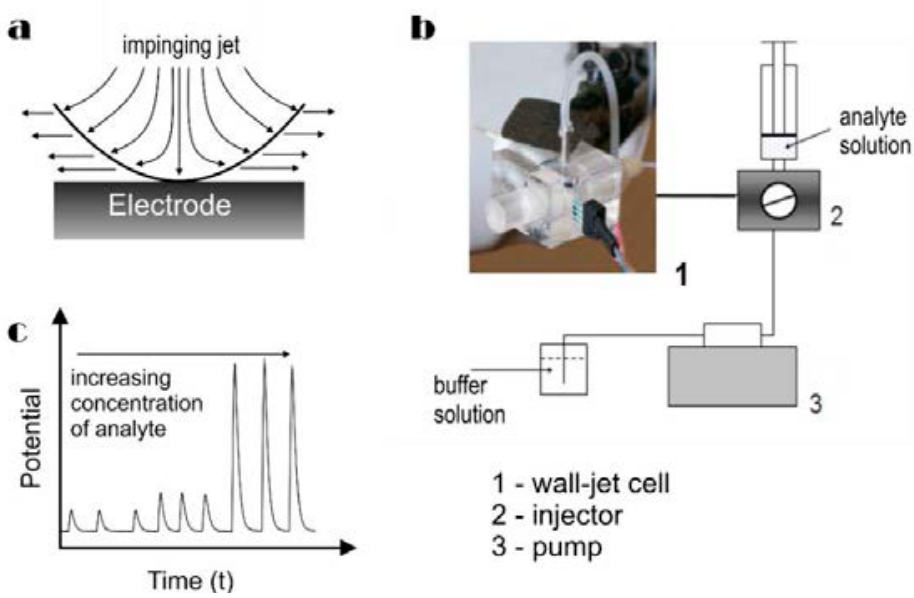

Figure. 6.13. Wall-jet electrode measurements. a. Flow pattern. b. Scheme of flowinjection system. c. Current response observed in the system. 
The flow for a wall-jet electrode is usually not completely laminar like in the case of the RDE, and this leads to a more complicated dependence between current and concentration. However, the current is proportional to the concentration of the electroactive species and the technique can therefore be used for electroanalysis.

A flow injection system was used for characterisation of the analytical performance and stability of glucose biosensors in Paper $\mathbf{I}$.

\subsubsection{Impedance spectroscopy}

Impedance spectroscopy is a powerful technique for investigation of electrical properties of electrode materials and interfaces of the electrodes. The impedance is a complex parameter of the cell when an alternating voltage is applied: ${ }^{166}$

$$
Z=\frac{U(t)}{I(t)}=|Z| e^{j \theta}=Z^{\prime}+j Z^{\prime \prime}
$$

where $U(t)=U_{m} \sin (\omega t)$ is an alternating voltage with amplitude $U_{m}$ applied to the electrode, $I(t)=I_{m} \sin (\omega t-\theta)$ is the resulting current with amplitude $I_{m}, \theta$ is the phase difference between the voltage and current, $Z^{\prime}$ and $Z^{\prime \prime}$ are the real and imaginary part of the impedance, respectively, and

$$
j=(-1)^{1 / 2}
$$

$Z^{\prime}$ is the normal resistance while $Z^{\prime \prime}$ is called the reactance. The conductance is the inverse of the resistance. In analogy, the admittance $Y$ is often used in impedance spectroscopy and it is related to the impedance by: $:^{166}$

$$
Y=\frac{1}{Z}=Y^{\prime}+j Y^{\prime \prime}
$$

The most common way to perform impedance measurements, used in Papers III and $\mathbf{V}$, is a frequency analysis. Signals with different frequencies are applied and the amplitude and phase shift, or real and imaginary parts of the response signal are measured. The impedance data are usually presented in the complex plane plots as $-Z^{\prime \prime}$ vs $Z^{\prime}$ (Nyquist diagram) (Fig. 6.14b) or $Y^{\prime \prime} v_{s} Y^{\prime}$. A plot of the frequency normalised admittance components $Y^{\prime} / \omega$ vs $Y^{\prime \prime} / \omega$ is frequently used for investigation of non-faradaic (capacitive) processes.

Electrochemical systems can be modelled by series and parallel configurations of resistors and capacitors (Fig. 6.14a shows an example). The admittance of this particular system can be expressed as:

$$
Y=\frac{1}{R_{s}}+\frac{1}{R_{p}}\left(1+j \omega C_{d l}\right)
$$

where $R_{s}$ and $R_{p}$ are the solution and polarisation resistances, respectively, $\omega$ is the angular frequency and $C_{d l}$ is the double layer capacitance. Parameters of the 
equation can be determined from the impedance data plotted in the complex plane (Fig. 6.14b).

Impedance spectroscopy was used in Paper III for the investigation of blood cell absorbance on the surface of a filament carbon cloth electrode. It was also applied in Paper $\mathbf{V}$ for characterisation of the double layer capacitance dependence on the applied potential.
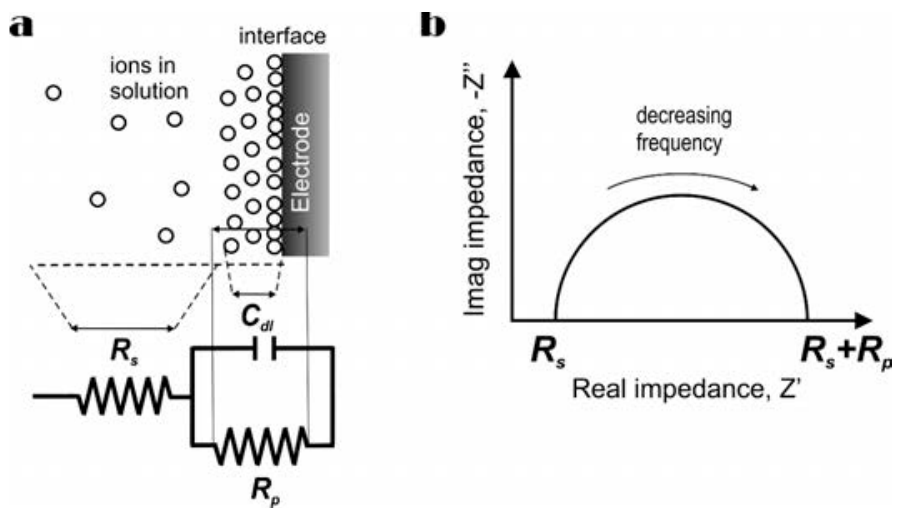

Figure. 6.14. Impedance spectroscopy. a. Simplest equivalent circuit, b. Nyquist diagram for the circuit (reproduced with modifications). ${ }^{172}$

\subsection{Spectrophotometry}

Spectrophotometry is a method of analysis based on measurements of the reflection or transmission of UV or visible light by a sample. Transmittance, $T$, is defined as the ratio of the intensity of the transmitted light, $I$, to the intensity of the incident light, $I_{0}$, according to:

$T=\frac{I}{I_{0}}$

Absorbance, $A$, is defined as:

$A=-\lg T$

The technique relies on the fundamental Bouguer-Lambert-Beer law:

$A=\varepsilon l c$

where $\varepsilon$ is the molar extinction coefficient or molar absorptivity, which is constant for a given molecule at given temperature and wavelength; $l$ is the light passage length; $c$ is the concentration of absorbing molecules. ${ }^{165}$

Spectrophotometry is a standard technique to study enzyme kinetics. ${ }^{19}$ It was applied in Papers I-III, VI and VII to determine enzyme activity. To characterise 
enzyme activity using spectrophotometry one should use some coloured compounds that are associated with the enzymatic reaction, for example, the product of the enzymatic reaction or the substrate. Spectrophotometric measurements are performed at a fixed wavelength - the maximum absorbance for this coloured compound. First, the saturation kinetics of the enzyme is examined. For this the enzymatic reaction is carried out using various concentration of the substrate at a fixed enzyme concentration to plot a Michaelis-Menton graph (see section 2.2.2). The plot can be used to determine $K_{M}$ and $V_{\max }$ values. Once the $K_{M}$ value is known, the spectrophotometric experiment with a fixed concentration of the enzyme and a concentration of the substrate well above $K_{M}$ is performed. The obtained kinetic data of absorbance changes with time are used to calculate enzyme activity in units, considering that one unit is defined as the amount of enzyme that produces one micromole of product per minute. ${ }^{19}$ 



\section{7 \\ SUMMARY OF THE PAPERS INCLUDED}

The work presented in this thesis is focused on the development of new approaches to facilitate ET in bioelectrocatalytic systems based on mediated and direct ET mechanisms.

\section{Review Paper: Bioelectrocatalytic systems for health applications}

In the review article, an overview of bioelectrocatalytic systems for in vitro health applications is presented. Some recent trends in biosensing technology, such as microelectrode- and microfluidic-based devices, paper-based point-of-care devices and wearable sensing systems with their limitations and perspectives in development are discussed. The ET mechanisms in bioelectrocatalytic systems and approaches to facilitate it, including well-known methodologies as well as the key recent findings in this area, are outlined.

\section{Papers I-III: A new hydrophobic mediator}

Papers I-III are focused on studies of a new hydrophobic mediator for oxidases unsubstituted phenothiazine. In Paper I, various hydrophobic azines were investigated as possible mediators for oxidases. A new co-immobilisation procedure to incorporate a water insoluble mediator and a hydrophilic enzyme molecule in the same membrane was developed. The mediator and glucose oxidase was immobilised in a sol-gel membrane from a water-organic mixture with a high content of organic solvent. Among the studied compounds, only the enzyme containing membrane with phenothiazine as the mediator showed catalytic response. In Paper II, the kinetic properties of the new mediator were studied using various electrochemical techniques: cyclic voltammetry, rotating disk electrode measurements and double-step chronoamperometry. The data revealed that phenothiazine functions as an efficient mediator for oxidases. Combination of the new mediator and the immobilisation procedure resulted in increased stability of the system and at the same time in the establishment of effective electron communication. The application of the developed strategy for the construction of glucose, lactate and cholesterol oxidase-based biosensors was demonstrated. The efficient bioelectrocatalytic technologies developed in Papers I and II have been utilised for the fabrication of an analytical device available for autonomous measurements, a self-powered biosensor, presented in Paper III. The anodic and cathodic counterparts of the self-powered biosensor were based on $\mathrm{ChOx}$ 
immobilisation into a sol-gel matrix on carbon cloth electrodes. Mediated biocatalytic cholesterol oxidation was used as the anodic reaction and electrocatalytic reduction of hydrogen peroxide on Prussian Blue as the cathodic reaction. Due to a synergetic effect, the characteristics of the self-powered cholesterol biosensor exceeded the combined analytical parameters of the single counterparts. The application of the biosensor for free cholesterol detection in plasma was demonstrated and results showed correlation with the standard method of colorimetric cholesterol quantification.

\section{Papers IV-VI: A microband array as a transducer}

Papers IV-VI are dedicated to the development of a simple and versatile platform for scalable fabrication of electrochemical devices with advanced characteristics, including ET, due to improved diffusion of an analyte and application of the platform for biosensing. In Paper IV, a simple approach for the production of graphite microband arrays suitable for automated electrode recovery was developed. Arrays of microband electrodes were produced by screen-printing followed by scissor cutting, which enabled the realisation of microband arrays at the cut edge. In Paper V, the effect of the surface roughness introduced by cutting, on the electrochemically active surface area of the microbands under conditions of convergent diffusion was considered. It was shown that the current response obtained under Faradaic conditions was insensitive to the roughness of the microelectrodes. The microelectrode arrays developed and characterised in Papers IV and $\mathbf{V}$ were used as a platform for the development of the substrate recycling bioelectrocatalytic system in Paper VI. An enzyme, laccase, was covalently attached via EDC/NHS chemistry to microband arrays activated by anodisation. Mediated laccase bioelectrocatalytic oxidation of phenols was studied on the fabricated microelectrode arrays and compared with macroscale graphite electrodes. The reduction of the dimensions of the transducer led to improved analytical performance of the biosensor due to nonlinear diffusion, which resulted in facilitation of ET in the system. Moreover, the utilisation of microelectrodes allowed the analysis to be performed in weakly supported media without additions of an electrolyte, and this is especially advantageous for water analysis. The microbiosensor developed in Paper VI showed fast responses towards catechol additions to tap water. This enhanced laccase-based microsensor was used for water quality monitoring and its performance for total phenol analysis of wastewater samples from different stages of the cleaning process was compared with the results of a reference method.

\section{Paper VII: Investigation of direct electron transfer from a single enzyme molecule}

Paper VII describes a new approach for the investigation of DET and factors affecting its efficiency at a single enzyme molecule level. The electrocatalytic amplification approach of collision-based electrochemistry was applied for the 
DET observation from single enzyme molecules. Laccase was used as a model enzyme. When a laccase globule collides with a gold ultramicroelectrode in the correct orientation, then the electrode will turn over the enzyme and allow catalysis of the substrate - oxygen. The observed current response in the shape of spikes due to DET between the active site of the enzyme and the electrode, allows the enzyme turnover rates for single enzyme molecules to be calculated and the factors influencing the efficiency of DET to be investigated. Influence of the applied potential and additions of inhibitor on the observed rates of DET was studied. The methodology is applicable to other redox enzymes with high catalytic activity and allows single enzyme molecules to be studied electrochemically. The suggested approach can give some insights into direct ET mechanisms and determine parameters that will facilitate DET in bioelectrocatalytic systems. 



\section{8 \\ OUTLOOK}

I hope that some of the results from this thesis may contribute to the development of inexpensive integrated biosensing systems suitable for real-life applications, such as personal diagnostics, pharmacology, food safety and environmental monitoring.

For example, the self-powered biosensor developed as a result of efficient bioelectrocatalytic technologies suggested in this work, having the double function of analytical device and a power supply, represents a promising approach for construction of fully integrated cheap platforms for point-of-care diagnostics in the format of paper-based systems or wearable biosensors. The combination of selfpowered biosensors, as an alternative or supplementary power supply, with electrochemical paper-based analytical devices towards fully integrated systems, will help to reduce the cost of such devices, thus making them attractive for applications in resource-limited conditions. Extension of power supplies for wearable biosensors to those capable of power generation directly from biological fluids on the wearer's body, such as self-powered biosensors, could bring further development of wearable sensors towards fully autonomous devices that can be integrated in body sensors and biosensor networks or "electronic skin".

Another example of work in this thesis that may be readily applied is the simple platform for scalable fabrication of electrochemical microelectrode-based bioelectrocatalytic systems. The improved performance demonstrated shows that these systems have potential for the construction of miniaturised devices for detection of low concentrations of analytes with high sensitivities, e.g. in water analysis, cell metabolism analysis or when sample volume is limited, e.g. in tears, saliva, sweat, etc. The combination of miniaturised biosensors with smartphonebased analysing platforms is a rapidly growing trend in biosensor technology. Such systems may boost the availability and accessibility of diagnostic testing, especially in developing countries.

I believe the new approach for investigation of ET processes at a single enzyme molecule will complement existing single molecule techniques, giving further insights into enzymatic ET mechanisms at the molecular level. Understanding of the ET pathways will help to design more efficient bioelectrocatalytic systems by tuning the redox potential of enzymes and their turnover rates. In addition, it will 
introduce the basis for a future generation of electrocatalysts based on enzyme mimics (i.e. artificial enzymes) that possess as high turnover rates as enzymes, but at the same time are more stable. Moreover, it has fundamental importance in providing molecular level understanding of the enzyme disorder related diseases for development of new drug design and medical devices, since a significant number of drugs work as enzyme inhibitors. In order to create effective inhibitors with a specific effect, understanding of enzymatic electron transfer mechanisms is required. 


\section{REFERENCES}

(1) Habermüller, K.; Mosbach, M.; Schuhmann, W. Fresenius' Journal of Analytical Chemistry 2000, 366, 560-568.

(2) Calabrese Barton, S.; Gallaway, J.; Atanassov, P. Chemical reviews 2004, 104, 4867-4886.

(3) Marcus, R. A.; Sutin, N. Biochimica et Biophysica Acta (BBA)-Reviews on Bioenergetics 1985, 811, 265-322.

(4) Page, C. C.; Moser, C. C.; Chen, X.; Dutton, P. L. Nature 1999, 402, 47-52.

(5) Willner, I.; Katz, E. Bioelectronics: From Theory to Applications; Wiley, 2006.

(6) Clark, L. C.; Lyons, C. Annals of the New York Academy of Sciences 1962, 102, 2945.

(7) Schläpfer, P.; Mindt, W.; Racine, P. Clinica Chimica Acta 1974, 57, 283-289.

(8) Kulys, J.; Švirmickas, G.-J. Analytica Chimica Acta 1979, 109, 55-60.

(9) Cass, A. E. G.; Davis, G.; Francis, G. D.; Hill, H. A. O.; Aston, W. J.; Higgins, I. J.; Plotkin, E. V.; Scott, L. D. L.; Turner, A. P. F. Analytical Chemistry 1984, 56, 667-671.

(10) Sekretaryova, A. N.; Eriksson, M.; Turner, A. P. F. Biotechnology Advances.

(11) Chang, R. Physical Chemistry for the Biosciences; University Science Books, 2005.

(12) Sumner, J. B. Journal of Biological Chemistry 1926, 69, 435-441.

(13) Morozova, V.; Shumakovich, G. P.; Gorbacheva, M. A.; Shleev, S. V.; Yaropolov, A. I. Biochemistry-Moscow 2007, 72, 1136-1150.

(14) Fischer, E. Berichte der deutschen chemischen Gesellschaft 1894, 27, 2985-2993.

(15) Koshland, D. E. Proceedings of the National Academy of Sciences of the United States of America 1958, 44, 98-104.

(16) Nelson, D. L.; Cox, M. M. Lehninger Principles of Biochemistry; W.H. Freeman, 2013.

(17) Michaelis, L.; Menten, M. L. Biochem. z 1913, 49, 352.

(18) Lineweaver, H.; Burk, D. Journal of the American Chemical Society 1934, 56, 658666.

(19) Cornish-Bowden, A. Fundamentals of enzyme kinetics; London : Portland Press, cop. 2004, 3. ed., 2004.

(20) Leskovac, V.; Trivic, S.; Wohlfahrt, G.; Kandrac, J.; Pericin, D. International Journal of Biochemistry \& Cell Biology 2005, 37, 731-750.

(21) Wilson, R.; Turner, A. Biosensors and Bioelectronics 1992, 7, 165-185.

(22) Bankar, S. B.; Bule, M. V.; Singhal, R. S.; Ananthanarayan, L. Biotechnology Advances 2009, 27, 489-501.

(23) Swoboda, B. E.; Massey, V. Journal of Biological Chemistry 1965, 240, 2209 2215.

(24) Lockridge, O.; Massey, V.; Sullivan, P. A. Journal of Biological Chemistry 1972, 247, 8097-8106.

(25) Maeda-Yorita, K.; Aki, K.; Sagai, H.; Misaki, H.; Massey, V. Biochimie 1995, 77, 631-642.

(26) Nikolaus, N.; Strehlitz, B. Microchimica Acta 2008, 160, 15-55.

(27) Jia, W. Z.; Bandodkar, A. J.; Valdes-Ramirez, G.; Windmiller, J. R.; Yang, Z. J.; Ramirez, J.; Chan, G.; Wang, J. Analytical Chemistry 2013, 85, 6553-6560.

(28) Shkotova, L. V.; Goriushkina, T. B.; Tran-Minh, C.; Chovelon, J. M.; Soldatkin, A. P.; Dzyadevych, S. V. Materials Science \& Engineering C-Biomimetic and Supramolecular Systems 2008, 28, 943-948. 
(29) Kriz, K.; Kraft, L.; Krook, M.; Kriz, D. Journal of Agricultural and Food Chemistry 2002, 50, 3419-3424.

(30) Iwuoha, E. I.; Rock, A.; Smyth, M. R. Electroanalysis 1999, 11, 367-373.

(31) MacLachlan, J.; Wotherspoon, A. T. L.; Ansell, R. O.; Brooks, C. J. W. Journal of Steroid Biochemistry and Molecular Biology 2000, 72, 169-195.

(32) Arya, S. K.; Datta, M.; Malhotra, B. D. Biosensors and Bioelectronics 2008, 23, 1083-1100.

(33) Vrielink, A.; Lloyd, L. F.; Blow, D. M. Journal of molecular biology 1991, 219, 533-554.

(34) Manjunatha, R.; Shivappa Suresh, G.; Savio Melo, J.; D'Souza, S. F.;

Venkatarangaiah Venkatesha, T. Talanta 2012, 99, 302-309.

(35) Yaropolov, A.; Skorobogat'Ko, O.; Vartanov, S.; Varfolomeyev, S. Applied

Biochemistry and Biotechnology 1994, 49, 257-280.

(36) Yaropolov, A.; Shleev, S.; Morozova, O.; Zaitseva, E.; Marko-Varga, G.; Emnéus, J.; Gorton, L. Journal of Analytical Chemistry 2005, 60, 553-557.

(37) Solomon, E. I.; Sundaram, U. M.; Machonkin, T. E. Chemical reviews 1996, 96, 2563-2606.

(38) Shleev, S.; Tkac, J.; Christenson, A.; Ruzgas, T.; Yaropolov, A. I.; Whittaker, J. W.; Gorton, L. Biosensors and Bioelectronics 2005, 20, 2517-2554.

(39) Schweiger, H.; Vayner, E.; Anderson, A. B. Electrochemical and Solid-State Letters 2005, 8, A585-A587.

(40) Fernandez-Fernandez, M.; Angeles Sanroman, M.; Moldes, D. Biotechnology Advances 2013, 31, 1808-1825.

(41) Betancor, L.; Johnson, G. R.; Luckarift, H. R. ChemCatChem 2013, 5, 46-60.

(42) Piontek, K.; Antorini, M.; Choinowski, T. Journal of Biological Chemistry 2002,

277, 37663-37669.

(43) Turner, A. P. F. Chemical Society Reviews 2013, 42, 3184-3196.

(44) Taylor, R. F.; Schultz, J. S. Handbook of Chemical and Biological Sensors; Taylor \& Francis, 1996.

(45) Miller, J. N.; Miller, J. C. Statistics and Chemometrics for Analytical Chemistry; Prentice Hall, 2000.

(46) McNaught, A. D., Wilkinson A., Jenkins, A.D. IUPAC compendium of chemical terminology the gold book; International Union of Pure and Applied Chemistry:

Research Triangle Park, N.C., 2006.

(47) Shrivastava, A.; Gupta, V. Chronicles of Young Scientists 2011, 2, 21-25.

(48) Harris, D. C. Quantitative Chemical Analysis, Sixth Edition; W. H. Freeman, 2003.

(49) Sabine Borgmann, A. S., Sebastian Neugebauer and Wolfgang Schuhmann.

Amperometric Biosensors; Wiley-VCH Verlag GmbH \& Co. KGaA: Weinheim, 2011.

(50) Wang, J. Chemical reviews 2008, 108, 814-825.

(51) Yahiro, A. T.; Lee, S. M.; Kimble, D. O. Biochimica et Biophysica Acta (BBA) Specialized Section on Biophysical Subjects 1964, 88, 375-383.

(52) Katz, E.; Willner, I.; Kotlyar, A. B. Journal of Electroanalytical Chemistry 1999, 479, 64-68.

(53) Leech, D.; Kavanagh, P.; Schuhmann, W. Electrochimica Acta 2012, 84, 223-234.

(54) Arechederra, R. L.; Minteer, S. D. Analytical and Bioanalytical Chemistry 2011, 400, 1605-1611.

(55) Cracknell, J. A.; Vincent, K. A.; Armstrong, F. A. Chemical Reviews 2008, 108, 2439-2461.

(56) Chaubey, A.; Malhotra, B. D. Biosensors \& Bioelectronics 2002, 17, 441-456. 
(57) Katz, E.; Shipway, A. N.; Willner, I. In Encyclopedia of Electrochemistry; WileyVCH Verlag GmbH \& Co. KGaA, 2007.

(58) Turner, A. 1987.

(59) Nicholson, R. S. Analytical Chemistry 1965, 37, 1351-1355.

(60) Davis, G. Biosensors 1985, 1, 161-178.

(61) Andrieux, C.; Saveant, J. Journal of Electroanalytical Chemistry and Interfacial Electrochemistry 1978, 93, 163-168.

(62) Laviron, E. Journal of Electroanalytical Chemistry and Interfacial Electrochemistry 1982, 131, 61-75.

(63) Tokuda, K.; Matsuda, H. Journal of electroanalytical chemistry and interfacial electrochemistry 1986, 199, 69-79.

(64) Xie, Y.; Anson, F. C. Journal of Electroanalytical Chemistry 1995, 384, 145-153.

(65) Lyons, M. E. Sensors 2002, 2, 314-330.

(66) Sekretaryova, A. N.; Vagin, M. Y.; Beni, V.; Turner, A. P. F.; Karyakin, A. A. Biosensors and Bioelectronics 2014, 53, 275-282.

(67) Cass, A. E.; Davis, G.; Francis, G. D.; Hill, H. A. O.; Aston, W. J.; Higgins, I. J.; Plotkin, E. V.; Scott, L. D.; Turner, A. P. Analytical Chemistry 1984, 56, 667-671.

(68) Dubinin, A. G.; Li, F.; Li, Y.; Yu, J. Bioelectrochemistry and Bioenergetics 1991, $25,131-135$.

(69) Jaffari, S. A.; Turner, A. P. F. Biosensors and Bioelectronics 1997, 12, 1-9.

(70) Shul'ga, A. A.; Koudelka-Hep, M.; de Rooij, N. F.; Netchiporouk, L. I. Analytical Chemistry 1994, 66, 205-210.

(71) Turner, A. P. F.; Hendry, S. P.; Cardosi, M. F. Biosensors, Instrumentation and Processing, The World Biotech Report 1(3). 1987, 125-137.

(72) Palleschi, G.; Turner, A. P. Analytica Chimica Acta 1990, 234, 459-463.

(73) Murthy, A. Biosensors and Bioelectronics 1996, 11, 191-193.

(74) Ohara, T. J.; Rajagopalan, R.; Heller, A. Analytical Chemistry 1993, 65, 35123517.

(75) Motonaka, J.; Kamizasa, M.; Faulkner, L. R. Journal of Electroanalytical Chemistry 1994, 373, 75-81.

(76) Sassolas, A.; Blum, L. J.; Leca-Bouvier, B. D. Biotechnology Advances 2012, 30 , 489-511.

(77) Gregg, B. A.; Heller, A. Analytical Chemistry 1990, 62, 258-263.

(78) Ohara, T. J.; Rajagopalan, R.; Heller, A. Analytical Chemistry 1994, 66, 24512457.

(79) Rubinstein, I.; Bard, A. J. Journal of the American Chemical Society 1980, 102, 6641-6642.

(80) Moyo, M.; Okonkwo, J. O.; Agyei, N. M. Sensors 2012, 12, 923-953.

(81) Elderfield, R. C. Heterocyclic Compounds. Edited by R.C. Elderfield; New York: Chapman \& Hall: London, 1950.

(82) Müller, D. Biochem. Z 1931, 232, 423-434.

(83) Upadhyay, A. K.; Ting, T.-W.; Chen, S.-M. Talanta 2009, 79, 38-45.

(84) Wang, Y.; Hasebe, Y. Journal of the Electrochemical Society 2012, 159, F110F118.

(85) Pereira, A. C.; Kisner, A.; Tarley, C. R. T.; Kubota, L. T. Electroanalysis 2011, 23, 1470-1477.

(86) Noorbakhsh, A.; Salimi, A.; Sharifi, E. Electroanalysis 2008, 20, 1788-1797.

(87) Liu, H.; Ying, T.; Sun, K.; Li, H.; Qi, D. Analytica Chimica Acta 1997, 344, $187-$ 199. 
(88) Ohfuji, K.; Sato, N.; Hamada-Sato, N.; Kobayashi, T.; Imada, C.; Okuma, H.; Watanabe, E. Biosensors and Bioelectronics 2004, 19, 1237-1244.

(89) Huang, Q.; An, Y.; Tang, L.; Jiang, X.; Chen, H.; Bi, W.; Wang, Z.; Zhang, W. Analytica Chimica Acta 2011, 707, 135-141.

(90) Shan, D.; Mousty, C.; Cosnier, S.; Mu, S. L. Electroanalysis 2003, 15, 1506-1512.

(91) Yao, Y.-L.; Shiu, K.-K. Electrochimica Acta 2007, 53, 278-284.

(92) Dong, S.; Wang, B.; Liu, B. Biosensors and Bioelectronics 1992, 7, 215-222.

(93) Braun, S.; Rappoport, S.; Zusman, R.; Avnir, D.; Ottolenghi, M. Materials Letters 1990, 10, 1-5.

(94) Tripathi, V. S.; Kandimalla, V. B.; Ju, H. Sensors and Actuators B: Chemical 2006, 114, 1071-1082.

(95) Collinson, M. M. Trac-Trends in Analytical Chemistry 2002, 21, 30-38.

(96) Pandey, P. C.; Upadhyay, S.; Pathak, H. C. Electroanalysis 1999, 11, 59-64.

(97) Lev, O.; Wu, Z.; Bharathi, S.; Glezer, V.; Modestov, A.; Gun, J.; Rabinovich, L.;

Sampath, S. Chemistry of Materials 1997, 9, 2354-2375.

(98) Walcarius, A. Chemistry of Materials 2001, 13, 3351-3372.

(99) Wang, B.; Zhang, J.; Dong, S. Biosensors \& Bioelectronics 2000, 15, 397-402.

(100) Liu, S. Q.; Sun, Y. M. Biosensors \& Bioelectronics 2007, 22, 905-911.

(101) Narang, U.; Prasad, P. N.; Bright, F. V.; Ramanathan, K.; Kumar, N. D.;

Malhotra, B. D.; Kamalasanan, M. N.; Chandra, S. Analytical Chemistry 1994, 66, 3139-3144.

(102) Wang, Q. L.; Lu, G. X.; Yang, B. J. Biosensors \& Bioelectronics 2004, 19, 1269 1275 .

(103) Upadhyay, A. K.; Ting, T. W.; Chen, S. M. Talanta 2009, 79, 38-45.

(104) Yashina, E. I.; Borisova, A. V.; Karyakina, E. E.; Shchegolikhina, O. I.; Vagin,

M. Y.; Sakharov, D. A.; Tonevitsky, A. G.; Karyakin, A. A. Analytical Chemistry 2010, 82, 1601-1604.

(105) Karyakin, A. A.; Karyakina, E. E.; Gorton, L.; Bobrova, O. A.; Lukachova, L. V.; Gladilin, A. K.; Levashov, A. V. Analytical Chemistry 1996, 68, 4335-4341.

(106) Karyakin, A. A.; Kotel'nikova, E. A.; Lukachova, L. V.; Karyakina, E. E.; Wang, J. Analytical Chemistry 2002, 74, 1597-1603.

(107) Zaks, A.; Klibanov, A. M. Journal of Biological Chemistry 1988, 263, 31943201 .

(108) Khmelnitsky, Y. L.; Mozhaev, V. V.; Belova, A. B.; Sergeeva, M. V.; Martinek, K. European Journal of Biochemistry 1991, 198, 31-41.

(109) Zhou, M.; Wang, J. Electroanalysis 2012, 24, 197-209.

(110) Sekretaryova, A. N.; Beni, V.; Eriksson, M.; Karyakin, A. A.; Turner, A. P. F.; Vagin, M. Y. Analytical Chemistry 2014, 86, 9540-9547.

(111) Wollenberger, U.; Lisdat, F.; Scheller, F. In Frontiers in Biosensorics II; Springer, 1997, pp 45-69.

(112) Wasa, T.; Akimoto, K.; Yao, T.; Murao, S. Nippon Kagaku Kaishi 1984, 13981403.

(113) Ferry, Y.; Leech, D. Electroanalysis 2005, 17, 113-119.

(114) Sharma, D.; Lim, Y.; Lee, Y.; Shin, H. Analytica Chimica Acta 2015, 889, 194202.

(115) Mizutani, F.; Yabuki, S.; Asai, M. Biosensors and Bioelectronics 1991, 6, 305310.

(116) Singh, A.; Park, S.; Yang, H. Analytical Chemistry 2013, 85, 4863-4868.

(117) Rose, A.; Scheller, F. W.; Wollenberger, U.; Pfeiffer, D. Fresenius' journal of analytical chemistry 2001, 369, 145-152. 
(118) Lisdat, F.; Wollenberger, U.; Makower, A.; Hörtnagl, H.; Pfeiffer, D.; Scheller, F. W. Biosensors and Bioelectronics 1997, 12, 1199-1211.

(119) Montereali, M. R.; Della Seta, L.; Vastarella, W.; Pilloton, R. Journal of

Molecular Catalysis B-Enzymatic 2010, 64, 189-194.

(120) Oliveira, T.; Barroso, M. F.; Morais, S.; de Lima-Neto, P.; Correia, A. N.;

Oliveira, M.; Delerue-Matos, C. Talanta 2013, 106, 137-143.

(121) Shervedani, R. K.; Amini, A. Bioelectrochemistry 2012, 84, 25-31.

(122) Lisdat, F.; Ho, W. O.; Wollenberger, U.; Scheller, F. W.; Richter, T.; Bilitewski, U. Electroanalysis 1998, 10, 803-807.

(123) Compton, R. G.; Wildgoose, G. G.; Rees, N. V.; Streeter, I.; Baron, R. Chemical Physics Letters 2008, 459, 1-17.

(124) Fletcher, S.; Horne, M. D. Electrochemistry Communications 1999, 1, 502-512.

(125) Taleat, Z.; Khoshroo, A.; Mazloum-Ardakani, M. Microchimica Acta 2014, 181, 865-891.

(126) Craston, D. H.; Jones, C. P.; Williams, D. E.; El Murr, N. Talanta 1991, 38, 17 26.

(127) Forster, R. J. Chemical Society Reviews 1994, 23, 289-297.

(128) Trasatti, S.; Petrii, O. Pure and applied chemistry 1991, 63, 711-734.

(129) Jarzabek, G.; Borkowska, Z. Electrochimica Acta 1997, 42, 2915-2918.

(130) Matsumoto, R.; Kano, K.; Ikeda, T. Journal of Electroanalytical Chemistry 2002, 535, 37-40.

(131) Kitazumi, Y.; Noda, T.; Shirai, O.; Yamamoto, M.; Kano, K. Physical Chemistry Chemical Physics 2014, 16, 8905-8910.

(132) Ferapontova, E.; Shleev, S.; Ruzgas, T.; Stoica, L.; Christenson, A.; Tkac, J.; Yaropolov, A.; Gorton, L.; Palacek, E.; Scheller, F. Towards Electrochemical Sensors for Genomics and Proteomics 2005, 517-598.

(133) Karyakin, A. A. Bioelectrochemistry 2012, 88, 70-75.

(134) Eddowes, M.; Hill, H.; Uosaki, K. Journal of Electroanalytical Chemistry and Interfacial Electrochemistry 1980, 116, 527-537.

(135) Krzemiński, Ł.; Cronin, S.; Ndamba, L.; Canters, G. W.; Aartsma, T. J.; Evans, S. D.; Jeuken, L. J. The Journal of Physical Chemistry B 2011, 115, 12607-12614. (136) Neto, S. A.; Hickey, D. P.; Milton, R. D.; De Andrade, A. R.; Minteer, S. D. Biosensors \& Bioelectronics 2015, 72, 247-254.

(137) Wang, Z.; Yi, J.; Yang, S. Sensors and Actuators B-Chemical 2013, 176, 211 216.

(138) Sarauli, D.; Wettstein, C.; Peters, K.; Schulz, B.; Fattakhova-Rohlfing, D.; Lisdat, F. ACS Catalysis 2015, 5, 2081-2087.

(139) Wang, X.; Latonen, R.-M.; Sjöberg-Eerola, P.; Eriksson, J.-E.; Bobacka, J.; Boer, H.; Bergelin, M. The Journal of Physical Chemistry C 2011, 115, 5919-5929.

(140) Holzinger, M.; Le Goff, A.; Cosnier, S. Frontiers in Chemistry 2014, 2.

(141) Silveira, C. M.; Baur, J.; Holzinger, M.; Moura, J. J. G.; Cosnier, S.; Almeida, M. G. Electroanalysis 2010, 22, 2973-2978.

(142) Armstrong, F. A.; Heering, H. A.; Hirst, J. Chem. Soc. Rev. 1997, 26, 169-179.

(143) Armstrong, F. A. Journal of the Chemical Society, Dalton Transactions 2002, 661-671.

(144) Hoeben, F. J. M.; Meijer, F. S.; Dekker, C.; Albracht, S. P. J.; Heering, H. A.; Lemay, S. G. ACS Nano 2008, 2, 2497-2504.

(145) Hellberg, D.; Scholz, F.; Schauer, F.; Weitschies, W. Electrochemistry communications 2002, 4, 305-309.

(146) Korshunov, A. V.; Heyrovský, M. Electroanalysis 2006, 18, 423-426. 
(147) Xiao, X.; Bard, A. J. Journal of the American Chemical Society 2007, 129, 96109612.

(148) Zhou, Y. G.; Rees, N. V.; Compton, R. G. Angewandte Chemie International Edition 2011, 50, 4219-4221.

(149) Kwon, S. J.; Zhou, H.; Fan, F.-R. F.; Vorobyev, V.; Zhang, B.; Bard, A. J. Physical Chemistry Chemical Physics 2011, 13, 5394-5402.

(150) Stuart, E.; Rees, N.; Cullen, J.; Compton, R. Nanoscale 2013, 5, 174-177.

(151) Tschulik, K.; Batchelor-McAuley, C.; Toh, H.-S.; Stuart, E. J.; Compton, R. G. Physical Chemistry Chemical Physics 2014, 16, 616-623.

(152) Cheng, W.; Compton, R. G. TrAC Trends in Analytical Chemistry 2014, 58, 7989.

(153) Kwon, S. J.; Bard, A. J. Journal of the American Chemical Society 2012, 134, 10777-10779.

(154) Kim, B.-K.; Boika, A.; Kim, J.; Dick, J. E.; Bard, A. J. Journal of the American Chemical Society 2014, 136, 4849-4852.

(155) Cheng, W.; Compton, R. G. Angewandte Chemie International Edition 2015.

(156) Silva Nunes, G.; Marty, J.-L. In Immobilization of Enzymes and Cells, Guisan, J., Ed.; Humana Press, 2006, pp 239-250.

(157) Turner, A. P. F.; Karube, I.; Wilson, G. S. Biosensors: fundamentals and applications; Oxford University Press, 1987.

(158) Deng, C. Y.; Chen, J. H.; Nie, Z.; Si, S. H. Biosensors \& Bioelectronics 2010, 26, 213-219.

(159) Dong, S.; Kuwana, T. Electroanalysis 1991, 3, 485-491.

(160) Quinto, M.; Losito, I.; Palmisano, F.; Zambonin, C. G. Analytica Chimica Acta 2000, 420, 9-17.

(161) Fu, G. L.; Yue, X. L.; Dai, Z. F. Biosensors \& Bioelectronics 2011, 26, $3973-$ 3976.

(162) Guisan, J. M. Immobilization of Enzymes and Cells; Humana Press, 2006.

(163) Mateo, C.; Palomo, J. M.; Fernandez-Lorente, G.; Guisan, J. M.; FernandezLafuente, R. Enzyme and Microbial Technology 2007, 40, 1451-1463.

(164) Brett, C. M. A.; Brett, A. M. O. Electroanalysis; Oxford Universisty Press, 1998.

(165) Золотов, Ю. А. Основы аналитической химии: В 2-х кн; Высш. шк., 1996.

(166) Scholz, F. Electroanalytical Methods: Guide to Experiments and Applications; Springer, 2009.

(167) McCreery, R. L. Chemical Reviews 2008, 108, 2646-2687.

(168) Fisher, A. C. Electrode Dynamics; Oxford University Press, 1996.

(169) Nicholson, R. S.; Shain, I. Analytical Chemistry 1964, 36, 706-723.

(170) Levich, V. G. Physicochemical hydrodynamics; Prentice-Hall: Englewood Cliffs, N.J., 1962.

(171) Andrieux, C. P.; Dumasbouchiat, J. M.; Saveant, J. M. Journal of

Electroanalytical Chemistry 1980, 113, 1-18.

(172) Wagner, M. Synthesis, characterisation and chemical sensor application of conducting polymers. academic dissertation, Abo Akademi University, Abo, Turku, Finland, 2013. 


\section{Papers}

The articles associated with this thesis have been removed for copyright reasons. For more details about these see:

http://urn.kb.se/resolve?urn=urn:nbn:se:liu:diva-125242 